\title{
Periodontal, metabolic, and cardiovascular disease: Exploring the role of inflammation and mental health
}

https://doi.org/10.1515/pteridines-2018-0013

received September 13, 2018; accepted October 10, 2018.

\begin{abstract}
Previous evidence connects periodontal disease, a modifiable condition affecting a majority of Americans, with metabolic and cardiovascular morbidity and mortality. This review focuses on the likely mediation of these associations by immune activation and their potential interactions with mental illness. Future longitudinal, and ideally interventional studies, should focus on reciprocal interactions and cascading effects, as well as points for effective preventative and therapeutic interventions across diagnostic domains to reduce morbidity, mortality and improve quality of life.
\end{abstract}

Keywords: Periodontitis; metabolic syndrome; cardiovascular disease; mental illness; inflammation.

\footnotetext{
*Corresponding author: Teodor T. Postolache: Mood and Anxiety Program, Department of Psychiatry, University of Maryland School of Medicine, Baltimore, MD 21201, USA; Rocky Mountain Mental Illness Research Education and Clinical Center (MIRECC), Veterans Integrated Service Network (VISN) 19, Military and Veteran Microbiome Consortium for Research and Education (MVM-CoRE), Denver, CO 80220, USA; Mental Illness Research, Education and Clinical Center (MIRECC), Veterans Integrated Service Network (VISN) 5, VA Capitol Health Care Network, Baltimore, MD 21201, USA, E-mail: tpostola@som.umaryland.edu

Hina Makkar, Abhishek Wadhawan, Aline Dagdag: Mood and Anxiety Program, Department of Psychiatry, University of Maryland School of Medicine, Baltimore, MD 21201, USA

Mark A. Reynolds: Department of Advanced Oral Sciences \& Therapeutics, University of Maryland School of Dentistry, Baltimore, MD 21201, USA

Abhishek Wadhawan: Saint Elizabeths Hospital, Psychiatry Residency Training Program, Washington, DC 20032, USA

Anwar T. Merchant: Department of Epidemiology and Biostatistics, Arnold School of Public Health, University of South Carolina, Columbia, SC 29208, USA

"Drs. Reynolds, Merchant and Postolache contributed equally and share senior authorship.
}

\section{List of abbreviations}

AAP: American Academy of Periodontology

AGEs: Advanced glycation end products

AgP: Aggressive periodontitis

AHA: American Heart Association

anti-CL: Anti-cardiolipin

anti-oxLDL: Anti-oxidized low-density lipoprotein

AP: Acute periodontitis

ASCVD: Atherosclerotic cardiovascular disease

C. pneumoniae: Chlamydia pneumoniae

CAL: Clinical attachment loss

CBVD: Cerebrovascular disease

CDC: Centers for Disease Control and Prevention

CIMT: Carotid-artery intima and media thickness

CHD: Coronary heart disease

$\mathrm{CI}$ : Confidence intervals

CRP: C-reactive protein

CSF: Cerebrospinal fluid

CVD: Cardiovascular disease

CVE: Cerebrovascular event

COX: Cyclooxygenase

DM: Diabetes mellitus

FPL: Federal poverty level

GCF: Gingival crevicular fluid

GOHAI: General Oral Health Assessment Index

HbA1c: Hemoglobin A1c

HDL: High-density lipoprotein

HR: Hazard ratio

HSPs: Heat-shock proteins

IDDM: Insulin-dependent diabetes mellitus

IFN-y: Interferon-gamma

Ig: Immunoglobulin

IHD: Ischemic heart disease

IL-: Interleukin

LDL: Low-density lipoprotein

LDL-C: Low-density lipoprotein cholesterol

LPS: Lipopolysaccharide

MCP-1: Monocyte chemoattractant protein-1 
MI: Myocardial infarction

MetS: Metabolic syndrome

MMPs: Matrix metalloproteinases

NHANES: National Health and Nutrition Examination

Survey

NS: Non-surgical

OHIP: Oral Health Impact Profile-14

OHQoL: Oral health-related quality of life

OR: Odds ratio

ox-LDL: Oxidized low-density lipoprotein

P. gingivalis: Porphyromonas gingivalis

PAD: Peripheral arterial disease

PAI-1: Plasminogen activator inhibitor-1

PAF: Platelet-activating factor

PAVE: Post AV Nodal Ablation Evaluation

PPD: Periodontal probing depth

RAGE: Receptor for advanced glycation end products

RANKL: Receptor activator of nuclear factor-kappa B ligand

ROS: Reactive oxygen species

RR: Relative risk

S. sanguis: Streptococcus sanguis

SG: Surgical

S+EMD: Surgical plus enamel matrix protein derivative

Th: T-helper

TNF: Tumor necrosis factor-alpha

t-PA: Tissue plasminogen activator

US: United States

vLDL: very low-density lipoprotein

vWF: von Willebrand factor

WHO: World Health Organization

The objective of this paper is to review the role of inflammation and psychiatric disorders in the wellrecognized links between periodontal disease, cardiovascular disease and metabolic diseases, such as obesity, diabetes mellitus and metabolic syndrome, and to document reasons supporting a mediating or moderating role of inflammation or mental illness.

\section{Scope of the problem}

\section{Periodontal disease}

The term periodontal disease refers to pathologic inflammatory conditions affecting the gingiva and supporting bone and connective tissue (periodontal tissues) surrounding the teeth. Periodontal disease is characteristically chronic in nature, commonly occurring in response to oral bacterial plaque and biofilm formation. The two primary periodontal diseases are gingivitis and periodontitis. Gingivitis is characterized by inflammation of the gingiva that is reversible (with proper oral hygiene) and without evidence of periodontal breakdown [1-3]. Over time, untreated gingivitis can progress to destructive periodontitis [4]. Periodontitis, in contrast, is characterized by gingival inflammation that spreads beyond the gingiva, resulting in the irreversible breakdown of the connective tissue attachment to the root, and alveolar bone resorption in a susceptible person [3]. Progressive destruction of connective tissue attachment and alveolar bone resorption results in apical migration of the gingival epithelium and pocket formation. Over time, untreated periodontitis can result in progressive destruction of the periodontium, resulting in tooth mobility, decreased masticatory function, and eventual tooth loss [5].

Over 700 different strains of bacteria have been identified in the human oral cavity, with distinct subsets often predominating in different habitats, which among others, include teeth and periodontal sulcus. Streptococcus sanguis (S. sanguis), Streptococcus oralis, Actinomyces odontolyticus and Actinomyces naeslundii typically colonize the supragingival areas of the tooth [6-8]. In contrast, Streptococcus sanguis, Streptococcus oralis, Actinomyces naeslundii, Actinomyces odontolyticus, Veillonella parvula, and Fusobacterium nucleatum frequently colonize subgingival sulcus $[8,9]$. In the presence of chronic inflammation, an increase in periodontal pocket formation is associated with a concomitant development of an anaerobic subgingival microbiota composed of anaerobes and microaerophilic gram-negative bacilli $[10,11]$. The subgingival microflora in periodontitis changes from being gram-positive predominately, to spirochetes, obligated anaerobes and gram-negative organisms, such as Tannerella forsythia, Porphyromonas gingivalis (P. gingivalis), Campylobacter rectus, Treponema denticola, Selemonas noxia, Prevotella intermedia, Aggregatibacter actinomycetecomitans [9-11]. Although periodontal diseases generally represent polymicrobial infections, certain oral bacteria, such as $P$. gingivalis, are strongly linked to periodontitis.

One of the important challenges in epidemiologic studies has been to characterize the incidence and prevalence of periodontitis, given the application of different diagnostic criteria and assessment methods [12, 13]. In order to standardize the assessment of patients with suspected periodontitis and to get more reproducible and reliable data, World Health Organization (WHO) in 1982, developed the "Community periodontal index of 
treatment needs" [14]. Case definitions have also been proposed by Centers for Disease Control and Prevention (CDC) and the American Academy of Periodontology (AAP) for performing population-based periodontitis surveillance, which are as follows: "No periodontitis" is defined as "No evidence of mild, moderate, or severe periodontitis." "Mild periodontitis" is defined as " $\geq 2$ interproximal sites with clinical attachment loss (CAL) $\geq 3$ $\mathrm{mm}$, and $\geq 2$ interproximal sites with periodontal probing depth (PPD) $\geq 4 \mathrm{~mm}$ (not on same tooth) or one site with $P P D \geq 5$ mm." "Moderate periodontitis" is defined as " $\geq 2$ interproximal sites with $\mathrm{CAL} \geq 4 \mathrm{~mm}$ (not on same tooth), or $\geq 2$ interproximal sites with $P P D \geq 5 \mathrm{~mm}$ (not on same tooth)." "Severe periodontitis" is defined as " $\geq 2$ interproximal sites with $\mathrm{CAL} \geq 6 \mathrm{~mm}$ (not on same tooth) and $\geq 1$ interproximal site with $\mathrm{PPD} \geq 5 \mathrm{~mm}$ " [15].

The prevalence of periodontitis is high among United States (US) adults, paralleling the rates of other major chronic illnesses, and constitutes a major public health concern [16]. In the most recent National Health and Nutrition Examination Survey (NHANES), 46\% of the US adult population 30 years or older, comprising nearly 65 million adults, had periodontitis, with $8.9 \%$ exhibiting severe periodontitis [17]. In the US, from 2011 to 2012, periodontitis was reported in $44.7 \%$ (SE: $\pm 2.4 \%$ ) of the adults aged $\geq 30$ years [17]. The estimation for 2011 to 2012 was consistent with the $47.2 \%$ (SE: $\pm 2.1 \%$ ), which was reported by NHANES from 2009 to 2010. The prevalence of periodontitis was $45.9 \%$, for the total combined period of 2009 to 2012 (represented by approximately 141 million adults aged $\geq 30$ years) [17]. As part of the Healthy People 2020 national health objective [18] and a major strategic objective of the Centers for Disease Control and Prevention (CDC) $[16,19]$ for the adult population in the US, efforts to reduce and monitor severe and moderate periodontitis are being done through health promotion activities and national disease surveillance.

There are two categories of the risk factors for periodontitis-namely, non-modifiable and modifiable [20]. Non-modifiable risk factors include age, ethnicity, genetic factors, and male gender [16, 21-24]. Large studies have consistently reported finding an increase in the prevalence and severity of periodontitis with age $[17,25$, 26]. In addition, the prevalence of periodontitis has been reported to be higher in males [17, 27]. In the most recent NHANES, a 50\% higher risk of periodontitis was found in males as compared to females [16]. With regard to the ethnicity, the prevalence of periodontitis has been reported to be lowest in non-Hispanic whites (40.8\%), followed by non-Hispanic Asian Americans (50.0\%), and highest in Hispanics (63.5\%) and non-Hispanic blacks (59.1\%) [17].
Moreover, the prevalence of severe periodontitis has also been reported to be more in Hispanics and non-Hispanic blacks, adults aged $\geq 50$ years, and in males [17]. On the other hand, modifiable risk factors, such as diabetes mellitus (DM), smoking, alcohol consumption, sedentary lifestyle [28], stress, osteoporosis, and viral infection, that contribute to other major chronic conditions also appear to play an important role in the pathophysiology of periodontitis $[16,23,24,29,30]$. The prevalence of periodontitis has been reported to be higher in adults, who had less than high school education level, were current smokers, and were under $100 \%$ of the federal poverty level (FPL) [17]. Moreover, the prevalence of severe periodontitis has been reported to be more in people living below $200 \%$ of FPL [17]. In fact, odds of having periodontitis in smokers are four to five times higher as compared to non-smokers [31]. Also, smoking intensity and periodontitis severity are positively related to each other [23].

Increases in the extent and severity of periodontitis can adversely impact quality of life [32]. Advanced periodontitis can result in pathologic tooth movement and loss [33]. In adults, periodontitis is the most important cause of tooth loss [34]. Abnet et al. (2005) [35] conducted a prospective cohort study in approximately 30,000 healthy participants from rural part of China over a period of 15 years, to assess the association between tooth loss and cause-specific and total mortality. They found a $13 \%$ greater incidence of mortality from any cause in the participants, who had more than the age-specific median number of teeth lost [35]. Also, in this cohort, the risks for the most common causes of death, i.e., stroke, heart disease, and upper gastrointestinal cancer, were increased by $12 \%, 28 \%$, and $35 \%$, respectively [35]. In another study from Japan, a higher risk of fatality due to cardiovascular disease (CVD) and respiratory disease was present in participants with 19 or fewer teeth, who also had difficulty eating, when compared with the participants having 20 or more teeth [36]. Multiple studies have reported that periodontal disease is associated with increased risk of death in older and younger adults from Northern Ireland and US [37, 38], in people with renal disease from Taiwan [39], in non-smokers from US [40], and in Pima Indians from US with type 2 DM [41]. Other prospective studies have also reported an association between tooth loss and increased total mortality [42-44], as well as death due to CVD [44-46], respiratory disease [47], and cancer [45, 47, 48], in geographically varied populations [41, 42, 45, 47]. Periodontal disease may impair appropriate nutritional intake, perhaps due to difficulty or pain of chewing, possibly leading to increased morbidity and mortality in these subjects [49]. 


\section{Cardiovascular diseases}

Atherosclerotic cardiovascular disease (ASCVD) constitutes a major burden of mortality worldwide. According to the WHO, approximately 17.5 million deaths in 2012 were attributed to ASCVD, constituting around $31 \%$ of the total deaths worldwide [50]. The most common forms of ASCVD are myocardial infarction (MI), cerebrovascular disease (CBVD) and peripheral arterial disease (PAD). In 2015, 366,801 deaths occurred due to coronary heart disease (CHD) [51]. Approximately 795,000 persons suffer a new or recurrent cerebrovascular event (CVE), with 185,000 being recurrent events and 610,000 being first events [51]. Moreover, in 2015, 1 in every 19 deaths in the United States were due to a stroke [51]. PAD leads to a considerable decrease in the arterial lumen of the arteries, which have their origin distal to the aortic bifurcation and usually occurs along with atherosclerosis, with intermittent claudication being its most common symptom [52, 53]. Nearly 8.5 million people aged 40 years and older are affected by PAD, and its prevalence increases with rising age from $1.6 \%$ in those aged 40 to 49 years to $22.7 \%$ in people aged 80 years or more [51]. Some studies have illustrated that PAD has been associated with increased morbidity and mortality with CVD [54-57]. The mortality due to CVD increases six times due to the presence of PAD [58].

\section{Metabolic diseases}

Metabolic syndrome (MetS) is defined as the presence of three out of the five interrelated risk factors for diabetes and cardiovascular disease, i.e., raised blood pressure, dysglycemia, obesity (particularly central adiposity), low high-density lipoprotein cholesterol levels, or elevated triglyceride levels [59]. There is a rising interest in MetS, as it is recognized as a risk factor for CVD and DM independently [59]. MetS has progressively turned up to be a predominant factor in the development of ASCVD over the last couple of decades [60]. The entire group of risk factors for CVD in MetS, including hypertension, dyslipidemia, type $2 \mathrm{DM}$, along with ASCVD, which is its main clinical outcome, contributes greatly to the morbidity and mortality worldwide [61, 62]. The MetS prevalence has increased in adolescents and has a hidden impact on the adults as well, with the rise in prevalence of obesity [63-65]. A number of studies have shown an increased prevalence of MetS in adolescents who are overweight, and also development of MetS in childhood [66-68]. The deficiency of insulin secretion or action results in a metabolic condition called DM, which has long-term complications like atherosclerosis, nerve damage, and microvascular damage [69]. Also, the occurrence of diabetes is rising worldwide in all population sections, which also includes children [70]. Data from NHANES 2011-2014 estimated that diagnosed DM was present in 23.4 million adults and undiagnosed DM was present in 7.6 million adults in the US [51]. On the other hand, DM was present in about 186,000 people that were under the age of 20 years [51]. In US adults $\geq 20$ years of age, about 1.7 million new cases of DM (type 1 or type 2) were diagnosed in 2012 [51]. DM is also associated with significant mortality. In fact in 2015, 79,535 individuals in the US, including 36,412 females and 43,123 males, had DM listed as the underlying cause of their death [51]. The estimated overall underlying-cause age-adjusted death rate attributable to DM in 2015 was 21.3 per 100,000 deaths [51].

\section{Psychiatric disorders}

Major depression, bipolar disorder, schizophrenia, anxiety disorders, and dementia constitute a major part of the burden of psychiatric illness. Nearly $17.6 \%$ of the population worldwide suffers from mental illnesses [71]. Estimates predict that psychiatric disorders will probably rank second highest on the list of causes of morbidity by 2020 [72]. It has to be taken into account that many people have very poor compliance to treatment and many go undiagnosed, due to which complete remission is not possible and it could also result in worsening of the symptoms [73, 74]. Moreover, death by suicide, an important cause of mortality associated with major psychiatric disorders, was the tenth leading cause of mortality in the US in 2014 and claimed about 45,000 deaths in the year 2016 [75, 76]. Remarkably, 54\% of the individuals who died by suicide in 2015 did not have a mental health condition, and the rates of death by suicide have shown more than 30\% increase from 1999-2016 across 25 states in US [76].

\section{Inflammation as a common denominator}

\section{Inflammation in periodontal disease}

Inflammation has a significant role in the pathogenesis of periodontal disease. Moreover, elevated pro-inflammatory mediator levels in gingival crevicular fluid (GCF) can act 
as the markers for the disease activity and severity of acute periodontitis (AP) [77, 78]. The literature shows that inflammatory mediators like IL-1 $\beta$ may act simultaneously to provoke important feedback and regulatory mechanisms which govern the harmfulness and severity of inflammatory lesions [79]. Continued tissue destruction and pathologic wounding may be a result of these cytokines, because of the persistent presence of bacterial plaque as an etiologic agent [80], and overproduction of cytokines like IL-1 $\beta$ might contribute towards this tissue destruction.

Being a marker for activated cell-mediated immunity [81], neopterin has various applications in medicine. Interaction between phagocytic cells (including macrophages, monocytes, dendritic cells and granulocytes) and T-helper (Th)1 lymphocytes results in the formation of neopterin [81-83]. The major stimulus for production of neopterin is interferon-gamma (IFN-y) [82]. However, other pro-inflammatory signals, such as TNF and lipopolysaccharide (LPS) can also elevate levels of neopterin [84]. In fact, immune-associated oxidative stress is indicated by the concentration of neopterin in the bodily fluids [85], and its concentrations correlate with reactive oxygen species (ROS) production induced by IFN-y [86]. As periodontitis involves inflammation, it is plausible that neopterin levels would be associated with severity of periodontitis as well. In a case-control study by Ozmeriç et al. (2002) [87], as compared to the systemically and periodontally healthy individuals, systemically healthy individuals with aggressive periodontitis (AgP) had significantly higher salivary neopterin levels, and there was a non-significant difference in the urinary neopterin levels within these groups of individuals. The authors of this study also reported a significantly higher total amount of neopterin in GCF of individuals with AgP, as compared to the healthy controls [87]. Similarly, in a pilot study on 29 patients having periodontitis with involvement of varying number of teeth, salivary neopterin levels increased significantly with the number of affected teeth [88]. In particular, individuals having more than 20 teeth affected with periodontitis had significantly higher salivary neopterin concentrations as compared to the individuals with lesser than 20 diseased teeth [88]. Also, there was no significant difference in the urinary neopterin levels between these two groups of individuals [88]. In yet another study, a positive correlation between GCF neopterin concentrations and CAL was reported, with the highest GCF neopterin concentrations observed in the group of individuals with moderate to severe periodontitis (mean $=51 \mathrm{nmol} / \mathrm{l})$, and the lowest concentrations in the healthy group of individuals (mean $=1.36 \mathrm{nmol} / \mathrm{l}$ ) [89].

\section{Inflammation in cardiovascular diseases}

Inflammation has been implicated in the pathogenesis of MI [90, 91], stroke [92, 93] and PAD [94, 95] as well. Atherosclerosis is the major contributing factor in most of the cases of CBVD/stroke and CVD. Deposition of cholesterol, cholesterol esters, and calcium within the vessel walls in atherosclerosis eventually leads to narrowing of the arterial lumen [96]. A variety of cell types, such as immune cells and fibroblasts, are also present in these cholesterol-rich plaques $[97,98]$. Thrombi may result from the rupture of atherosclerotic plaques, which may result in stroke or MI, after they travel distally to occlude artery/arteries. Pathogenesis of atherosclerosis involves local and/or systemic inflammatory processes, infections, and possibly autoimmune phenomenon as well [99]. A number of factors may contribute towards increased local arterial inflammation, such as immune reactions directed against the vascular wall, lipid imbalances and hemodynamic stress. These factors could together lead to initiation or progression of atherosclerotic plaques, and even complicated atherosclerotic lesions [100]. Moreover, individuals with atherosclerosis have been reported to have higher levels of serum inflammatory biomarkers, such as C-reactive protein (CRP) [101], cell adhesion molecules, various inflammatory cytokines and fibrinogen [102]. Neopterin has also emerged as a predictive and an independent marker of risk assessment for CVD [103]. In fact, importance of neopterin is not only limited to its association with systemic inflammatory response in atherogenesis, but it may also have a role in destabilization of the atherosclerotic plaque by contributing to the inflammation within the plaque [103, 104].

\section{Inflammation in metabolic diseases}

A number of studies have pointed towards links between inflammation and obesity. Obese subjects have been reported to have elevated levels of tumor necrosis factor-alpha (TNF), CRP, interleukin (IL)-6, fibrinogen and other acute-phase reactants [105-112]. Pro-inflammatory cytokines, including TNF, resistin, IL6, plasminogen activator inhibitor (PAI)-1 and monocyte chemoattractant protein (MCP)-1 may be secreted by hypertrophic adipocytes [113]. TNF has been reported to have direct effects on adipocyte insulin resistance [114, 115]. Additionally, intracellular insulin signaling has been shown to be impaired by both TNF and IL-6 [116, 117]. A close relationship exists between the plasma levels of 
CRP, TNF and IL-6, and insulin resistance and obesity $[108,118]$.

Several studies have also suggested associations of inflammatory mediators, such as CRP and IL-6, with type 2 DM, hyperglycemia and insulin resistance [119-124]. Also, localized islet inflammation has also been reported in type 2 DM [125], and it has been hypothesized that type 2 DM might involve an innate immune system pathology [126]. The coexistence of a procoagulant and a proinflammatory state has also been reported to occur in metabolic syndrome that is characterized by high fibrinogen and C-reactive protein levels [127, 128]. The data also suggests that metabolic syndrome may contribute to the greater risk for CVD and type $2 \mathrm{DM}$ via endothelial dysfunction, which might be precipitated by this chronic inflammatory state $[129,130]$. Levels of C-reactive protein rises because of the low-grade inflammation, which is associated with raised hypertension risk (one of the components of MetS) [131]. In fact, oxidative stress has also been implicated as the shared pathologic cause of various components of MetS [132].

\section{Inflammation in psychiatric disorders}

A pro-inflammatory state has also been reported to exist in major psychiatric disorders, such as schizophrenia [133-136], bipolar disorder [137-140] and depression [141144]. Moreover, neuroinflammation has been implicated in suicidal behavior [145] and in the pathophysiology of Alzheimer's disease [146] as well. Meta-analyses also point towards an evidence of immune activation in the postmortem brain samples of individuals who died by suicide, and in the blood and cerebrospinal fluid (CSF) of suicide attempters [147-149]. Moreover, mRNA transcripts of inflammatory cytokines have also been identified in suicide victims' orbitofrontal cortex [150]. It was also reported that the brains of patients who died by suicide had pronounced microgliosis [151]. Additionally, aggression, an endophenotype associated with suicidal behavior [152], can be exacerbated by the effects of individual cytokines, at least partially [153-155]. The anterior prefrontal cortex of teenagers who died by suicide has been reported to have increased levels of IL-1 1 , IL-6 and TNF at both the mRNA and protein levels [156]. Another finding that supports the role of inflammation of the central nervous system in contributing to suicidal behavior is the significantly elevated levels of IL-6 in the CSF of suicide attempters [157].

Moreover, neopterin has implications for psychiatric disorders as well, such as major depression [158], bipolar disorder [159] and schizophrenia [160, 161]. Significantly higher plasma neopterin levels have been reported in patients with depression, as compared to healthy controls [144, 162]. Urinary neopterin levels in depressed patients have also been reported to be significantly higher as compared to healthy controls [163, 164]. Similar finding was reported by a more recent study [165], which also indicated that 6-months after an acute ischemic stroke, neopterin could be an independent predictor for the development of major depression. Interestingly, serum neopterin levels were reported to be significantly higher before treatment in anti-psychotic naive schizophrenia-patients, as compared to healthy controls, which reportedly declined significantly after 3 months of treatment with anti-psychotic medications [166].

\section{Evidence connecting periodontal disease to metabolic, cardiovascular and psychiatric disorders}

\section{Cardiovascular diseases and periodontal disease}

In this section, we will discuss the studies that have looked at the possible associations between periodontal disease and various CVDs like atherosclerosis, MI, CBVD/ stroke and PAD. Strong evidence has emerged establishing an association between periodontitis and CVDs, such as ASCVD [167], PAD [168, 169], CBVD [170], and IHD [171]. However, it has been difficult to conclude a causal association between periodontitis and CVDs because both these conditions share common risk factors and exhibit multifactorial etiologies. Nevertheless, the consistency in the association between periodontitis and CVDs has been shown in systematic reviews [172, 173]. Although multiple cross-sectional, cohort, and case-control studies have also shown a significant association between periodontitis and MI [174-185], these findings have not been consistent [40, 186-191].

An observational study by Mattila et al. (1993) [167] was the foremost evidence that proposed a relationship between ASCVD and periodontitis, which reported that when compared to the healthy controls, the patients who were admitted to the hospital emergency units for acute coronary syndromes had poorer dental hygiene [192]. Subsequently, additional study depicted that bad oral hygiene resulting in periodontitis, can have a part 
to play as a CVD risk factor [26]. It has been shown by a population-based study that periodontitis was related to an elevated risk of major adverse cardiac events including the occurrence of MI [193]. Some studies have reported this association between periodontitis and MI in Iranian and Turkish populations $[194,195]$. On the other hand, the prevalence of advanced periodontitis and edentulousness was higher in the hospitalized patients with $\mathrm{MI}$ as compared to the group who did not have MI [196].

Acase-controlstudyshowed that there wasasignificant increase in risk of $\mathrm{MI}$ in patients with periodontitis even after adjusting for possible confounding factors [183]. According to the report by Bahekar and colleagues, in patients with periodontitis, the incidence of CHD is higher with a relative risk (RR) of 1.14 [95\% confidence intervals (CI): 1.074-1.213], as well as the prevalence of CHD in the periodontitis patients was higher with an odds ratio (OR) of 1.59 (95\% CI: 1.329-1.907) [197]. The association between periodontitis and recurrent MI was also reported by Renvert and group [178]. In a prospective cohort study by DeStefano et al. (1993) [198], which was based on the data from the National Health and Nutrition Epidemiologic Follow-Up Study including 9760 participants, who were followed-up for 14 years, stated that the RR for MI among individuals aged 25 to 75 years with no teeth was 1.23 (95\% CI: 1.05 to 1.44), when compared to the individuals with periodontitis or gingivitis. Furthermore, several systematic review studies and meta-analyses showing an association between CVD and periodontitis have been published [171, 173, 197, 199-204]. Humphrey and group showed an increase of around $24 \%$ to $35 \%$ in CHD risk with the varying severity of periodontitis [173]. This study demonstrated a higher CHD risk with tooth loss and periodontitis, having a RR of 1.34 (95\% CI: 1.10-1.63) and 1.24 (95\% CI: 1.01-1.51) respectively, and also a rise in the risk of CHD in patients with gingivitis was reported, which was not statistically significant [173].

Additionally, a report by Mustapha and colleagues suggested that there was an increased risk of developing CHD in those with raised systemic bacterial exposure markers such as CRP, periodontal bacterial burden and periodontitis, as compared to those without periodontal disease [203]. A study has shown an association between the presence of cardiac or valvular calcifications, which indicate subclinical atherosclerosis, and severity of periodontitis [205]. In patients with type $1 \mathrm{DM}$, a significant relationship between periodontitis duration and progression and development of coronary artery calcium has been reported [206]. However, there is a possible association between periodontal disease and coronary artery disease $[198,207]$, which is not dependent on diabetes.

Moreover, dental indices have been shown to be associated with new coronary events in individuals with diagnosed coronary artery disease [208] and with cerebral infarctions [209]. Also, increased arterial stiffness was reported in patients with periodontitis as compared to controls [210, 211]. Carotid-artery intima and media thickness (CIMT) has been reported to be associated with increased risk of having CVEs and acute MI [212]. One of the studies that showed an association between periodontal disease and increase in the CIMT was the Atherosclerosis Risk in Communities study [213], in which severity of periodontal disease was taken as a criterion to group the patients. As compared to individuals with no periodontal disease, the odds of having CIMT $\geq 1 \mathrm{~mm}$ was higher in patients having severe and moderate periodontal disease, with an OR of 2.09 (95\% CI: 1.73-2.53) and 1.40 (95\% CI: 1.17-1.67), respectively [213]. Another study demonstrated unilateral carotid calcifications visible on panoramic radiographs in $31.3 \%$ and bilateral calcifications in $7.2 \%$ of patients with periodontitis [214]. An association among systemic inflammation, atherogenesis in carotid arteries and periodontitis has been suggested as well. A study by Tapashetti and colleagues [215] depicted that elevated levels of circulating CRP were found in patients with periodontitis compared to controls, $(19.58 \pm 17.03$ vs. $5.54 \pm 1.63, p<0.004)$, and greater CIMT was reported in patients with periodontitis $(1.09 \pm 0.45$ vs. $0.57 \pm 0.06, p<$ 0.001 ). Additionally, the raised CRP had a correlation with increase in CIMT [215].

Several systematic reviews and meta-analyses assessing the relationship between CBVD and periodontitis have been published [170, 201, 216]. A metaanalysis of cohort studies reported an elevated CVE risk in patients with periodontitis and tooth loss, with RR of 1.63 (95\% CI: 1.25-2.00) and 1.39 (95\% CI: 1.13-1.65), respectively [216]. Another meta-analysis that included retrospective and prospective studies, depicted that risk of stroke was elevated by periodontitis with RR being 2.63 (95\% CI: 1.594.33) for the retrospective studies, and 1.47 (95\% CI: 1.131.92) for prospective studies [170].

PAD has also been associated with periodontitis. A cross-sectional study [217] including 1343 Korean adults aged over 40 years, who were enrolled from a community-based cohort of Yangpyeong County, reported periodontitis as a risk factor for having PAD and that the risk of having PAD in periodontitis patients is 2.03 times (95\% CI: 1.05-3.93) more, when compared to the ones without periodontitis. Calapkorur and colleagues [218] 
have illustrated in a cross-sectional study on 60 patients, that the odds ratio for developing PAD are increased by periodontitis to 5.84 (95\% CI: 1.56-21.91). Sorto-Barreras et al. (2013) [168] conducted a case-control study in Mexican population in which periodontitis was found to be associated robustly with the risk of having PAD (OR: 8.18, 95\% CI: 1.21-35.23). After adjusting for gender, age, smoking and DM, a five-fold increase in the risk of having PAD (OR: 5.45; 95\% CI: 1.57-18.89) in patients with periodontitis was shown in a case-control study by Chen et al. (2008) [169]. They assessed 25 patients with femoro-popliteal and/or aorto-iliac disease, who underwent bypass surgery [169]. The atherosclerotic specimens from the anastomotic location of the distal bypasses were assessed with the help of polymerase chain reaction in order to detect periodontopathic bacteria, and these bacteria were detected in $52 \%$ of these specimens [169]. Furthermore, the detection frequency of $P$. gingivalis was higher in patients having Fontaine grade III and grade IV level of severity of PAD, in comparison to those having grade II ( $57.1 \%$ vs. $22 \%, p=0.09$ ) [169]. These findings were consistent with those of the studies that have been done more recently [217, 219]. Mendez et al. (1998) [220] used the data from both the Dental Longitudinal Study of the US Department of Veterans Affairs and Normative Aging Study, to study the association between periodontal disease and peripheral vascular disease by using multivariate logistic regression analysis, in which 1030 subjects were followed-up for over 25 to 30 years for the development of PVD. Development of PVD was seen in 80 of those initially healthy subjects. They found a 2.27 times increased risk of developing PVD (95\% CI: 1.32-3.9, $p=0.003$ ) in the participants who had clinically significant periodontal disease in the beginning, as compared to controls [220]. In another prospective study by Hung et al. (2003) [221], 45136 eligible men from the Health Professional Follow-up Study, who did not have cardiovascular diseases in the beginning, were followed-up. The authors found that 342 of these men had developed PAD over 12-years of follow-up. They calculated a relative risk of 1.41 (95\% CI: 1.12-1.77) for developing PAD in those with a history of periodontitis, when controlled for cardiovascular risk factors, and there was no association between PAD and tooth loss in those who did not have periodontal disease (RR: 0.92; 95\% CI: 0.61-1.38) [221]. Thus, a significant association was seen between incident tooth loss and PAD, particularly in men who had periodontal disease [221]. A recent meta-analysis by Yang et al. (2018) [222] found that the risk of periodontitis has been significantly increased in patients with PAD when compared to the participants without PAD (RR:1.70,
95\% CI: 1.25-2.29, $p=0.01$ ), implying that a significant association is there between periodontitis and PAD.

Although it has been postulated that periodontal disease can alter the CVD risk [223], a causative connection has not been found. It is possible that CVD and periodontal disease are associated with each other, however, one does not result in causing the other [224]. For many decades, this has remained unclear as only a small number of studies have evaluated the consequence of periodontal treatment on CVD [225]. Uncertainty exists regarding the involvement of tooth decay, preceding periodontal disease, changes in diet following tooth loss, tooth removal procedure, or some other factors, as mediators in the association between tooth loss and CVD [226].

\section{Metabolic disease and periodontal disease}

An association between severity and frequency of periodontitis and obesity has been shown by a number of studies [227-229]. Periodontal disease has also been associated with obesity in adolescence [230]. An association between lifestyle factors and periodontitis has been investigated in a cross-sectional study involving physical activity, however, the study was unsuccessful to detect any association between them [231]. On the other hand, a cross-sectional study by Wakai et al. (1999) described a negative correlation between periodontitis and physical fitness, following adjustment for plaque, smoking, fasting plasma glucose, and age [232]. A largescale prospective study [28] looked for the association of walking, physical activity and periodontitis in 39,461 USbased health professional males, whose baseline age was 40-75 years, and reported an inverse, linear association between periodontitis and sustained physical activity and somewhat increased risk of periodontitis in men watching more television (depicts a sedentary lifestyle), which was statistically significant with a linear trend. It has been depicted that spending more time watching television has a positive correlation with obesity [233, 234], and an association between obesity and augmented risk of periodontitis has also been reported [229]. Moreover, the risk of getting obese [235] as well as diabetic [236] is lowered by exercise. Better insulin sensitivity as well as metabolism of glucose is linked to increased physical exercise, independent of obesity and diabetes [237, 238]. Additionally, diabetes is a well-known risk factor for periodontitis [239, 240], and obesity has been demonstrated to be individually related to periodontitis $[228,229]$. 
In 1997, periodontal disease was described as the sixth complication of diabetes by the American Society of Diabetes [241]. Diabetes increases the possibilities of developing periodontal disease and alters its severity [239, 242-245]. Diabetic patients are more likely to have inflammation of gingiva, dental calculus, deeper periodontal pockets and higher values for indices of plaque [246]. The individuals with diabetes tend to have more widespread dental caries [247-249], xerostomia [250] and tooth loss [251], in comparison to healthy individuals. They require periodontal treatment and prophylactic procedures more often [252]. There is sudden periodontal destruction and higher severity of periodontitis observed in diabetics with uncontrolled blood glucose level compared to the diabetics with a blood glucose level that is well-controlled [253, 254]. The severity, risk and degree of periodontitis have also been ascribed to the hyperglycemic status [255]. Moreover, the risk of periodontitis decreases with improved glycemic control in diabetics [256]. Type 2 diabetics, who have poor metabolic control, also have a greater risk of having infectious diseases like periodontitis [244, 257, 258].

It is possible that the relationship between DM and periodontitis might be a bidirectional one. A study performed in Pima Indians, depicted that the severity and prevalence of periodontitis is more in people with diabetes [244]. In diabetic patients, periodontal pockets have been illustrated to be more extensive and they develop earlier in life [259]. According to the NHANES III, the prevalence of severe periodontitis was considerably greater in patients with hemoglobin A1c (HbA1c) level of $>9 \%$ as compared to the non-diabetics [254]. Moreover, several studies report that the severity of periodontitis is related to elevations in $\mathrm{HbA1c}[260,261]$. On the other hand, the studies that looked for an association between the time duration of diabetes and periodontitis have had inconsistent results. For example, a study described that the time duration of diabetes was not related to periodontitis [262], and other studies reported that the prevalence of periodontitis increased with increase in duration of diabetes [263-265].

An increased intake of whole-grain and fiber-rich foods has been related to better insulin sensitivity [266, 267], and thus resulting in a better glycemic control. A prospective study [267], involving 34160 male health professionals with baseline age of 40-75 years, conducted by Merchant et al. (2006), found that there was a $23 \%$ less likelihood of getting periodontitis in men who were in the highest quintile of whole-grain intake, when compared to those who were in the lowest quintile (multivariate RR: 0.77; 95\% CI: 0.66-0.89; $p$ for trend
<0.001), upon adjustment for smoking, alcohol intake age, body mass index, total energy intake, and physical activity. Thus, increasing dietary intake of whole-grains without raising total caloric intake may lessen the risk of having periodontitis, as well as diabetes. Some studies have reported a relationship between periodontitis and glucose intolerance [268]. As compared to the former assumptions, periodontal disease condition is found to be more common in children suffering from diabetes [269], and also its severity increases with rising glucose levels in the blood [270].

According to a study, more plaque deposits and poor oral hygiene were found in diabetic patients as compared to non-diabetics [240]. Interestingly, diabetic individuals with well-controlled diabetes are likely to go more often to see the dentist [271], and have healthier oral hygiene habits as compared to the diabetics with poorly controlled diabetes [271, 272]. The individual attributes, which are responsible for maintaining good oral hygiene [273-275] as well as in controlling diabetes, or the influence of good dental care on HbA1c, may play an important part in this. Merchant et al. (2012) [276] reported that the majority of the children who had diabetes did not floss and brush their teeth as frequently as recommended. However, a study which was conducted in people with type 2 diabetes, was unable to find any influence of good oral hygiene on HbA1c levels [277]. Also, there are inconsistencies in results regarding the relationship between diabetes and good oral hygiene practices in children and adolescents $[278,279]$.

Some reports have stated that bad periodontal health was present in people who had MetS as compared to those who did not have it [280, 281]. A dose-response relationship was present between various components of MetS and clinical markers of periodontitis, like PPD and loss of CAL [282]. Furthermore, some reports have stated the association of periodontitis with hypertension, obesity, dyslipidemia and hyperglycemia (components of MetS) [283-288]. A study by Lee et al. (2015) [289] evaluated the links between gingivitis and MetS parameters in a Korean adolescent population generated by representative nationwide sampling. A significant association was found between gingivitis and low HDLcholesterol, as well as between gingivitis and the number of positive MetS parameters in adolescents [289]. Another study [282] reported that periodontal disease and levels of HDL cholesterol were associated with each other among female adults. As reported by Morita et al. (2009) [290], there was a significant increase in OR of the presence of periodontal pockets with the increased number of MetS 
components. Additionally, some studies have reported associations between MetS components and periodontal disease in adolescents as well [230, 291]. Hence, it has been proposed that periodontal disease should be identified as a component of MetS, as it is frequently altered in DM and a number of other systemic diseases [292].

\section{Psychiatric disorders and periodontal disease}

There has been increasing focus of attention towards the adverse physical health suffered by the people with severe psychiatric illness, specifically regarding CVD, diabetes, cancer, and chronic lung disease [293]. Oral health has not been given much attention, although it is a crucial part of our overall health [294], and is associated with a number of chronic diseases [173, 295-302]. There is an elevated risk of having dental problems in patients with psychiatric disorders. One study, from Italy, studied psychiatric inpatients, and gum disease was found in 99\% of the patients [303]. According to one Australian study, including psychiatric outpatients, 59\% of the patients were found to have moderately deep pockets [304]. Additional three studies reported that deep pockets were found in $15 \%$ to $28 \%$ of psychiatric inpatients as well [303, $305,306]$. A meta-analysis reported that the likelihood of having periodontal disease was 50 times more in patients having severe mental illness (95\% CI: 3.43-7.02) [307].

The reason behind this may be the lack of self-care, medication side-effects, poor compliance with dental treatments, negative outlook towards the physician and trouble accessing health care services [308]. Poor oral hygiene also accompanies depression and anxiety [309]. Moreover, bad oral health, particularly associated with tooth loss, could also lead to difficulty with communication, affecting other psychological and social aspects of human life [294]. Ugly, ill-fitting and painful dentition or dentures can cause issues with eating and speaking, and can contribute to social isolation, social withdrawal and low self-esteem. On the other hand, it is possible that patients with periodontitis would have social stigma from their altered appearance due to tooth loss, as well as halitosis [310], which could precipitate or worsen the negative thought patterns about themselves, thereby contributing to depression and/or anxiety [311].

Furthermore, depressed patients can have dental caries that could be attributed to dry mouth as a side effect of anti-depressants, and to bad oral hygiene as a result of self-neglect leading to poor oral hygiene and poor nutrition [312, 313]. Bipolar affective disorder patients deal with additional issues. During the manic phase, overenthusiastic flossing and tooth brushing may cause mucosal or gingival lacerations or dental abrasions [313]. Lithium as a medication for bipolar disorder, has been linked to stomatitis and xerostomia [313, 314]. Moreover, almost $50 \%$ of the dental patients have some anxiety regarding their visits to dentists, which in few cases results in a specific phobia called dental phobia [315, 316]. Dental pain perception may also be increased by anxiety or depression, irrespective of the severity of the oral condition. For instance, a somatic symptom disorder, called burning mouth disorder, occurs in people who have clinically healthy oral mucosa and is frequently related to anxiety or depression [317].

Other reasons for having a greater risk of oral health problems in individuals with psychiatric illnesses might be co-morbid substance use disorders (alcohol, tobacco, and psychostimulants), excessive consumption of sugary drinks, and financial and other difficulties in getting dental care [318-320]. Dry mouth or xerostomia is frequently associated with opportunistic gingivitis because of nutritional deficiencies caused by anorexia nervosa and psychosis [321]. In patients with bulimia, there are alterations in the secretion of saliva due to pathological changes in parotid gland [322]. Individuals suffering from severe mental illnesses like schizophrenia and dementia have more tooth decay and gum problems resulting from bacterial infection, instead of attrition, abrasion, or erosion. The explanations are similar as in other psychiatric illnesses, which include side effects of psychotropic medications like mood stabilizers, antidepressants, and antipsychotics [323]. Psychotropic medications having anticholinergic effects, can also lead to xerostomia as a side effect [314, 322, 324].

\section{Immune mediation explaining the association of periodontal disease with cardiovascular, metabolic and psychiatric disorders}

\section{Cardiovascular and periodontal disease}

How may periodontal disease lead to CVDs, including atherosclerosis, stroke/CBVD, MI and PAD? In periodontitis, which is predominantly a chronic condition, innate immune mechanisms also operate 
through certain acute-phase reactants, thereby indicating the presence of systemic inflammation in periodontitis [325, 326]. Some of the pro-inflammatory properties of the acute-phase reactants are stimulation of the regeneration and repair of a variety of tissues, activation of complement factors, and neutralizing invasive pathogens. Among these, fibrinogen, CRP and PAI-1 are the acute-phase reactants that have received most attention. Interestingly, meta-analytical studies have concluded that inflammation plays a key mediating role in the positive association between cardiovascular disease and periodontal disease [202, 203, 216, 327-329]. Modest rise in serum CRP is associated with augmented risk of cardiovascular disease in otherwise healthy persons [330, 331]. TNF has a major function in initiating the inflammatory response [332]. The association of blood TNF levels with CIMT and with risk factors for CVD is known [333]. Therefore, if these markers are also associated with periodontal disease, they might be the possible mediators in the association between CVD and periodontal disease. There is evidence that periodontal disease is related not only to CVD, but also with its risk factors. The conclusion of the results of a study [334] suggests that periodontal disease is connected to biomarkers of dyslipidemia and endothelial dysfunction, for instance, t-PA, CRP and low-density lipoprotein cholesterol (LDL-C), which are recognized risk factors for CVD.

A number of possible mechanisms linking periodontitis and CVD have been proposed in various studies, with the most important being the systemic inflammation, direct vascular injury and molecular mimicry [26]. Links between inflammatory responses that impact CVD and the inflammation due to periodontal microbial pathogens, appear in various forms.

Inflammatory markers and mediators: Periodontitis is associated with local elevations in inflammatory cytokines, as well as systemic elevations in inflammatory cytokines and acute phase proteins [335]. As compared to the periodontally healthy individuals, the patients with periodontitis have higher concentrations of a number of inflammatory markers and mediators in their systemic circulation, including CRP [336-340], fibrinogen [338, 341, 342], haptoglobin [336, 338], platelet-activating factor (PAF) [343, 344], IL-6 [345], and IL-18 (IL-18) [338]. Interestingly, the systemic levels of IL-4 and IL-10, both of which are anti-inflammatory cytokines, have been reported to be reduced in patients with chronic periodontitis [338, 346]. Hypothetically, these observations could be explained via two pathways: a) As suggested by the existing literature, periodontitis not only affects the oral cavity but possibly has systemic effects as well. An association between periodontitis and modest systemic inflammatory response has been demonstrated. Even though the mechanism leading to this association is not clear, periodontitis might act as a remote source of lowgrade inflammation systemically. This association might be a possible explanation for the observed metabolic control impairment in diabetic patients and elevated risk of CVDs in the future, as seen in individuals with periodontitis.

The indication regarding production of inflammatory cytokines and other mediators within the periodontal lesions has been supported by ample data [347]. Hypothetically, it is possible that these mediators from the periodontal lesions "spill over" into the systemic circulation and may attain concentrations that are sufficient enough to have their effects on the organs and tissues located distally from the oral cavity, provided their bioactivity is remains preserved. Eventually, other organs including the liver may be affected by these inflammatory mediators, thereby leading to induction of an acute-phase response, which could influence more organs in the body. Ultimately, development of atheromas may be initiated or accelerated due to inflammatory changes induced in the endothelium, including promotion of cytokine production and up-regulation of adhesion molecules. However, the evidence that supports such a mechanism for inflammatory mediators having access to the systemic circulation is not strong [348].

b) Microorganisms from the oral cavity have been shown to cause a number of oral infectious diseases, including periodontal disease. A large number of microbes reside in the oral cavity with different species found at different sites, including cheek, gum, teeth, palate or gingival sulcus, and they interact with their human host in the state of disease and health [349]. The oral cavity of an adult person can have approximately one billion bacteria in total. It has been well established that the oral cavity is a source of systemic infections, and in inflammatory conditions like periodontitis, the bacteria pass into the bloodstream due to disruptions in the integrity of the tissue [350, 351]. The relationship between dental procedures and bacterial endocarditis has been very well established and since then the guidelines for antimicrobial prophylaxis are valid in patients undergoing dental procedures, who have preexisting risk factors [352, 353]. In fact, patients 
with periodontitis have episodes of bacteremia even after minor trauma, including tooth-brushing [350, 354, 355]. Additionally, the prevalence of bacteremia following brushing, chewing, scaling or flossing has been associated with the periodontal status, with patients with periodontitis having higher biodiversity and higher prevalence/incidence of bacteria in the bloodstream, as well as in the periodontal tissues, as compared to the healthy individuals and patients with gingivitis [356]. Specifically, periodontal destruction and inflammation has been attributed to the presence of greater levels of a bacteria in the sub-gingival plaque, named $P$. gingivalis $[357,358]$. Moreover, oral infection with periodontal disease pathogens like $P$. gingivalis in animal models of infection has been indicated to induce promotion of inflammatory reactions in sites that are located far away from the mouth, including the atheromatous lesions [359-361]. Similarly, pathogens such as $P$. gingivalis, S. sanguis and Chlamydia pneumoniae (C. pneumoniae) have been also been reported to be found in human atherosclerotic plaques [355, 362, 363]. Within the atheromas, local as well as systemic inflammatory reactions may be stimulated by the periodontal bacteria themselves, or the proinflammatory components released from them [348]. It is possible that bacterial components/bacteriainduced alteration of serum lipids, inflammatory and endothelial cell receptor engagement, endothelial cell invasion and bacterial component/bacterial seeding of atheromas, together may further promote these inflammatory responses and play a role in the growth of atheromas [356, 364]. Initiation of an inflammatory cascade after proliferation of $P$. gingivalis in the intima of coronary arteries leads to apoptosis [365] and subsequent endothelial dysfunction [366]. P. gingivalis also mediates atherosclerosis by stimulating foam cell production in the intimal layer of the blood vessels [223]. Also, matrix metalloproteinases (MMPs) have been implicated in both rupture of atherosclerotic plaques [367], as well as periodontal destruction [368]. Additionally, oral bacteria, such as $P$. gingivalis, have been reported to induce MMPs that might also lead to rupture of atherosclerotic plaque [369]. However, limited evidence from human studies exists that implicates MMPs mediating the association between CVD and periodontitis [370, 371]. Similarly, PAF and PAF-acetyl hydrolase, have been implicated in explaining the links between CVD and periodontitis; however, the data related to this is limited [343, 344, $372,373]$.
As seen in other inflammatory processes or chronic infections, the host reacts in a similar fashion to shortlived bacteremia and systemic cytokine dumping from smoldering periodontitis lesions. For instance, in patients with periodontitis, increased levels of IL-6 have also been reported, which are known to induce hepatocytes and produce CRP, pro-coagulant mediators and other acute-phase reactant proteins [326]. CRP, which is a marker of systemic inflammation and an acute-phase reactant, is produced in response to various inflammatory cytokines within the liver [374]. Elevated levels of CRP ( $\geq 2.1 \mathrm{mg} / \mathrm{l})$ have been described as a risk-predictor for CVD and have been the focus of attention as an important marker for atherosclerosis [102, 375-380]. A higher incidence of acute thrombotic events including MI and stroke has been associated with increased levels of CRP ( $>2.1 \mathrm{mg} / 1)$ [377, 381]. Even in healthy individuals, CRP levels $>2.1 \mathrm{mg} / \mathrm{l}$ may serve as a marker for an increased long-term risk of CVD as it has been associated with a chronic pro-coagulant state $[102,378]$. However, it needs to be underscored that CRP is only a non-specific marker of the acutephase response, which implies that mild increases in CRP can be accounted for by many other known and unknown potential stimuli, including but not limited to smoking, trauma, chronic inflammatory conditions and/or infections, as well as obesity [376, 380, 382]. However, the evidence is lacking that can implicate CRP having a definitive role in the pathogenesis of atherosclerosis [383].

As described above, evidence from many studies indicates that both stroke and MI, together with underlying atherosclerosis, are all positively associated with periodontitis [200, 384-387]. In consequence of the hypothesized association of CVD with certain inflammatory and infectious diseases, the ongoing inflammatory processes in atherosclerotic lesions may also be exacerbated by the chronically elevated CRP levels in periodontitis patients, which in turn may contribute to a greater risk for CVE and CVD [96, 388-390]. Metaanalytical evidence also points towards an induction of a systemic inflammatory state in chronic periodontitis, which is marked by increased levels of CRP in patients with periodontitis as compared to controls [391]. However, as there are certain common risk factors for both periodontitis and CVD, including smoking, certain studies performed statistical correction for these variables and found that the associations between periodontitis and serum levels of CRP or/and IL-6 still remained statistically significant [328, 337, 339, 340, 345, 392-394]. Moreover, it 
has been reported that as compared to individuals with either periodontitis or CVD, the patients who have both these conditions have the highest levels of inflammatory mediators, such as CRP, alpha-antichymotrypsin and serum amyloid A, thereby suggesting an additive effect of each of these conditions on systemic inflammation [395398]. Hence, it is possible that the association between CVD and periodontitis can, at least in part, be explained by elevated levels of several inflammatory mediators that are common to both disorders. On the other hand, it is also possible that the levels of these inflammatory mediators, only reflect the intensity of systemic inflammation in CVD, which in turn may be affected moderately by inflammation in periodontitis [399].

Thrombotic and hemostatic markers: A number of thrombotic or hemostatic markers, such as fibrinogen, PAI-1, von Willebrand factor (vWF), as well as markers of platelet activation have been hypothesized to be implicated in the links between CVD and periodontitis. Greater plasma levels of fibrinogen result in higher blood viscosity and shear stress, which in turn can promote platelet aggregation and endothelial cell activation [400]. Fibrinogen has also been reported to be a risk marker for atherosclerosis and CVDs, as well as an indicator of systemic inflammation [400-403]. In fact, structural components of atheromatous lesions comprise fibrinogen and its degradation products, and within these lesions, degradation products of fibrinogen can bring about the promotion of platelet aggregation and induction of inflammatory cytokine production [404]. It is well known that tissue plasminogen activator (t-PA) plays a very important part in dissolving the blood clots [405] and plasma t-PA, which when raised might possibly be an indicator for endothelial dysfunction, has been reported to be associated with higher risk of CHD [401]. Platelets release vWF which facilitates initial hemostasis [406]. As compared to individuals having either chronic periodontitis or CVD, serum fibrinogen levels have been reported to be higher in individuals having both these disorders [407]. Platelet activation has also been reported to play a role in enhancing the development of atheromas [408]. Studies examining markers of platelet activation, have also reported increased levels and expression of these markers in periodontitis patients [409, 410]. However, data related to the levels of PAI-1, a pro-atherogenic protease inhibitor [411], in periodontitis patients appears to be conflicting [412-414] and its role in linking CVD with periodontitis is still skeptical.

Autoreactive antibodies: Under stress, such as during inflammation, heat-shock proteins (HSPs) have a protective effect on human cells, including endothelial cells, and can further interact with both the adaptive and innate immune responses to produce HSPspecific antibodies and T-cells [415]. Similarly, under stress, bacteria also express antigens that could mimic human HSPs, and thus could stimulate the production of autoreactive T-cells and antibodies to human cells [416]. Multiple studies have reported the expression of HSPs, which have been implicated in atherosclerosis, by periodontal pathogens such as $P$. gingivalis [417-419]. Also, in periodontitis patients, evidence exists regarding the presence of elevated levels of these HSPs [420], together with their ability to induce inflammatory processes that could promote atherosclerosis [421]. Moreover, a number of studies have reported the existence of cross-reactivity between human endothelial cell-HSPs and periodontal bacterial-HSPs [422-425], thereby suggesting that inflammation in atherosclerosis may be promoted by HSPinduced immune responses.

Anti-cardiolipin (anti-CL) and anti-oxidized lowdensity lipoprotein (anti-oxLDL) antibodies have also been implicated in increased risk for CVD [426-428], and also promote systemic inflammation [364]. Anti-oxLDL antibodies have also been reported to be produced in the GCF of patients with periodontitis [429]. Also, there is evidence that points towards an existence of crossreactivity of these antibodies towards components of periodontal pathogens [430, 431]. Moreover, as compared to healthy subjects, elevated levels of both these antibodies have been reported in patients with periodontitis [432-434], with a reported decrease in levels of anti-CL antibodies after periodontal therapy $[435,436]$, pointing towards a periodontal source of these auto-reactive antibodies.

Thus, pathogenic inflammatory responses in atherosclerosis may beimpacted by a number of antibodies. Moreover, elevated systemic antibody responses to several periodontal microorganisms are known to exist in patients with periodontitis. "Molecular mimicry" could operate, resulting in periodontal pathogen-induced formation of cross-reactive antibodies that may eventually lead to recognition of antigens in the host. Under certain circumstances, the risk for atherosclerosis may be augmented or atherosclerosis may be accelerated by these antibodies via promoting lipid entry into the macrophages, blocking anti-atherogenic effects of protective molecules, or by increasing inflammation of the endothelial lining [364].

Lipids: Elevated serum LDL-C is a well-known risk factor for CVD [331, 437]. A number of studies have implicated serum lipids in patients with periodontitis, as 
potentially playing a role in its association with CVD via inflammatory pathways. As compared to healthy controls, patients with chronic periodontitis have been reported to have higher serum levels of total cholesterol [438-440], LDL [438-440], oxidized low-density lipoprotein (ox-LDL) [434], small dense LDL [420, 435, 441] and triglycerides [434], all of which are known to be pro-atherogenic [442]. Also, lower levels of high-density lipoprotein (HDL), an anti-atherogenic lipid sub-type, have been reported in patients with chronic periodontitis, as compared to healthy controls [434, 435, 438]. Moreover, following periodontal therapy in patients with chronic periodontitis, improvement in serum lipid profiles has been reported [412, 435, 443, 444]. Most of the complications of DM have been linked to hyperglycemia, but there also occurs a disruption in the metabolism of fatty acids leading to hyperlipidemia [445]. A study showed an elevated serum triglyceride levels in patients with adult periodontitis [283]. This study also speculated the hypothesis that triglycerides may be a common link between coronary artery disease, adult periodontitis, and DM, owing to an increased reaction to cell agonists including bacterial [283].

It has also been demonstrated that $P$. gingivalis raises the levels of LDL and total cholesterol in blood by upregulating the protein, which affects the blood levels of LDL cholesterol in mice [447]. The inflammatory response in the atheromas may be enhanced by the adaptive immune responses and thereby exacerbate the baseline inflammation. In response to the bacteria within the intimal plaques in atherosclerosis, antibodies produced may either cross-react with modified LDL leading to inflammatory cells incorporating more lipids within the walls of the vessels, or may cross-react with endothelial cells, or could be pro-inflammatory. Th1 responses in the atheromas may be triggered by some of these antibodies, or by inflammatory cytokines, thereby furthering macrophage activation and promoting inflammation [356]. Moreover, it has been postulated that periodontal microbes affect glycogenesis in liver [448], insulin action [449], and can result in change of gut flora resulting in metabolic alterations and systemic inflammation [450]. Hence, in periodontitis patients, serum levels of lipids are elevated, which tend to be potentially inflammatory, including triglycerides, very low-density lipoproteins (vLDLs) and LDLs. Sub-forms of these lipids are more likely to be encompassed in the atheromas, as they may have greater susceptibility to being altered and may enter the blood vessel wall with greater ease. These processes could quicken the growth of localized atheromatous lesions, and may thus, advance their maturation.
Genetic markers: Individual variations in the inflammatory response in both atherosclerosis and periodontal infection may be explained by certain genetic markers. For example, evidence from genomewide association studies have consistently implicated the ANRIL locus and its variants, as being associated with CVDs [451-458] and type 2 DM [459-461]. Interestingly, variants at this locus have been consistently found to be associated with AgP as well [462-464]. Even though, it has not yet been determined that a causal role exists for ANRIL variants in both CVD and periodontitis, however, it is possible that it has a role in the common inflammatory pathways for both these disorders. Also, additive effects of some or all of the above mechanisms may together operate in individual patients, thereby affecting inflammation in their cardiovascular system.

\section{Metabolic diseases and periodontal disease}

A number of conditions, such as hyperlipidemia [465], periodontitis [466, 467] and insulin-dependent diabetes mellitus (IDDM) [468], have been linked to the excessive production of cytokines like IL-1. Production of IL-1 in gingival tissues in periodontitis may result in pathologic injury and continuous tissue destruction, when local bacterial infections like $P$. gingivalis infection are persistently present [469]. Moreover, macrophage function abnormalities triggered by a rise in serum lipid levels, might possibly change the secretion of cytokines required for the process of natural healing [470]. A trend was observed for raised IL-1 levels in GCF [471] in patients with type 2 diabetes having hyperlipidemia as well. Thus, a vicious cycle could emerge, with periodontitis leading to inflammation and metabolic disease that could further augment inflammation, which in turn might further worsen periodontitis and metabolic disease. Also, there is a vicious circle between inflammation furthering hyperglycemia and insulin resistance, both of which also worsen inflammation [223, 326, 391, 449], thereby adversely affecting metabolic control and potentially leading to the development of complications related to DM [472]. Furthermore, in terms of TNF, a cytokine that has been well-known to induce insulin resistance [115, 473-477], its levels in the plasma of adult patients with type 2 DM have been reported to be related to the severity of periodontitis in a dose-response fashion [478].

Diabetes mellitus may itself contribute to the development of periodontitis. In order to explain the pathogenesis for an accelerated periodontal destruction in diabetic patients, a 'two-hit' model has been proposed 
[472]. Several animal [479-482] and human [483-485] studies have reported the presence of a hyperinflammatory phenotype in DM, which has been associated with neutrophil priming mediated by increased protein kinase C activity and levels [486]. Some studies have illustrated raised production of IL-1 $\beta$ in GCF of IDDM patients who had periodontitis [446], and elevated IL-1 $\beta$, TNF, and prostaglandin E2 production by monocytes of IDDM patients [487]. Hence, the hyperinflammatory state could potentially magnify the local, as well as the systemic inflammatory response to pathogens. This alteration of host response to bacterial challenge has been hypothesized to be mediated by cytokine dysregulation due to prolonged TNF expression [481, 488]. Also, evidence from human and animal studies has indicated that collagen degradation is increased and its synthesis is reduced in DM [489-491], which could further contribute to progression and development of periodontitis [492, 493]. Similarly, evidence from multiple animal and human studies indicates that in DM, enhanced alveolar bone destruction may occur secondary to hyperglycemiamediated modulation of receptor activator of nuclear factor-kappa B ligand (RANKL) to osteoprotegerin ratio in periodontal tissues [494-496], and the process of osseous repair following resorption of bone could be impaired due to increased apoptosis of bone-lining cells and fibroblasts [497-499]. Hence, all these factors could together contribute to uncoupling of bone destruction and repair in diabetics with periodontitis.

Moreover, interaction between receptor for advanced glycation end products (RAGE) that is a member of the immunoglobulin superfamily of cell-surface molecules and is a multiligand signaling receptor, and its ligands called advanced glycation end products (AGEs), has also been hypothesized to mediate periodontal disease in DM. Several findings from a number of studies support this hypothesis, including increased expression of markers for oxidative stress and of AGEs in gingival tissues of patients with diabetes and periodontitis [500], increased gingival tissue RAGE expression in diabetics who also had periodontitis [501], increasing serum levels of AGEs being associated with increasing severity of periodontitis associated with diabetes [502], and suppression of collagen production by fibroblasts in the periodontal and gingival ligament that was mediated by AGEs $[503,504]$. Similarly, findings from in vitro and animal studies have also supported this hypothesis [505-510].

Thus, according to the 'two-hit' model, in an environment of enhanced RAGE expression, bacterial challenge could precipitate impaired repair and exaggerated inflammation of the periodontal tissue in diabetics, thereby resulting in severe and accelerated periodontal tissue damage [472]. Also, increased blood glucose levels result in the formation of AGEs, which also bind to RAGE present in the periodontium resulting in an inflammatory reaction [511]. A study by Lalla et al. (2000) demonstrated that blockade of RAGE receptor in mice with diabetes lessened the inflammatory reaction and resulting destruction of alveolar bone [508].

Also, metabolic syndrome and periodontitis may be linked through common pathophysiological pathways as both of these disorders have been associated with systemic inflammation. Insulin resistance that has been reported in individuals with periodontitis, may be precipitated by a complex interplay of the host inflammatory response to alterations of lipid levels, adiposity and periodontal infections [512]. Decreased levels of leptin, an anti-obesity adipocytokine [513], in the gingival tissue and the GCF have been related to worsened periodontal status [514516]. Interestingly, on the other hand, serum leptin levels tend to increase with greater periodontal destruction [516]. This could be explained by either possibly higher rate of leptin removal from gingiva after gingival inflammationmediated vasodilation, or probable rise in the serum leptin levels as a means to offset inflammation in periodontitis $[515,516]$. Adiponectin is an adipocytokine whose lower levels have been associated with diabetes, obesity and insulin resistance [517]. Even though an in-vitro study has reported that adiponectin may have an anti-osteoclastic effect in periodontitis [518], limited and conflicting data exists regarding its potential role in the inflammatory links between periodontitis and MetS [519-521]. Resistin is also an adipocytokine, which has a pro-inflammatory action [522], and has been implicated in insulin resistance [523]. Moreover, a positive association between bleeding on probing and serum resistin levels, as well as the presence of higher serum levels of resistin have been reported in periodontitis patients, as compared to healthy controls [520, 521].

Additionally, in mice, it has been reported that $P$. gingivalis induced up-regulation of a protein known to play a critical role in regulating circulating LDL cholesterol levels resulted in increased circulating levels of total and LDL-cholesterol levels after an intraperitoneal infection with this organism [447]. Also, an alteration of the gut microbiota has been reported in mice after oral administration of $P$. gingivalis, which coincided with increased systemic inflammation and insulin resistance [450]. 


\section{Oxidative stress in mediating links between periodontal disease and metabolic and cardi- ovascular diseases}

Oxidative stress due to raised reactive oxygen species (ROS) levels has been involved in the pathological mechanism of developing a number of diseases, such as DM and CVDs [524-526]. Additionally, MetS has various component disorders that share a common pathologic phenomenon, i.e., oxidative stress [132]. A decline in response of periodontal tissue against bacterial plaque may occur because the antioxidant defense mechanism in periodontal tissue can be altered in MetS [132, 527]. Individuals with periodontitis tend to have a decreased anti-oxidant capacity and an increased pro-oxidative state, which could together promote reduction in insulin sensitivity that could be further worsened by consumption of diet rich in fat by these individuals [528]. However, oxidative stress may itself contribute to periodontal disease pathogenesis [529, 530]. Periodontal disease itself increases the activity of neutrophils by enhancing oxidative stress markers and chronic inflammation [530]. A study by Marchetti et al. (2012) [287] proposed that there might be a raised production of ROS in obese patients and that they also require additional insulin for the maintenance of blood glucose levels, which can lead to the development of type 2 diabetes. AGEs are also produced as a result of oxidative stress [531] and hyperglycemia, which as described above, may also contribute to the destruction of the periodontal tissue.

\section{Psychiatric disorders and periodontal disease}

Psychosocial stress, a common risk factor for various psychiatric disorders [532], and also markedly increased during exacerbations of mental illness, induces a number of interactions between cells of the immune systems and sympathetic nervous system, sensoric peptidergic nervous system and the neuro-endocrine system, including hypothalamic, pituitary, adrenal-derived and other hormones, which in turn could influence periodontitis [533, 534]. In particular, overactivation of HPA axis has been implicated in major depression [535], which is associated with heightened release of glucocorticoids from the adrenal cortex and of corticotropin-releasing hormone from the hypothalamus [536]. A number of immunosuppressive actions of glucocorticoids, such as inhibition of antibody secretion [immunoglobulin (Ig) IgA and IgG] [536], inhibition of production of cytokines [537], reduced accumulation of macrophages, eosinophils, and neutrophils at sites of inflammation and decreased number of circulating lymphocytes, monocytes, and eosinophils [538, 539], together may increase the susceptibility to acquire periodontal infection and also exacerbate the periodontal disease. In fact, as compared to healthy controls, levels of IL-6 and cortisol in the GCF have been found to be elevated in women with depression [540, 541]. Moreover, in a rat-model of ligature-induced periodontal disease, administration of an antidepressant fluoxetine was reported to protect against periodontal bone resorption and destruction of collagen fibers by suppressing the proinflammatory responses [reduction of IL-1 $1 \beta$ and cyclooxygenase (COX)-2 mRNA expression], as well as the proteolytic enzyme activity (MMP-9) [542]. Periodontal destruction may also be enhanced by release of prostaglandin and proteases, which in turn is mediated by stress-induced secretion of catecholamines from the autonomic nervous system under stress [543, 544]. Moreover, altered nutrition associated with periodontal disease [545] may affect the gut microbiota [546], which may further have an influence on the psychiatric symptoms [547] through the gut-brain connection, as evidenced by a number of animal [548-554], clinical [555] and imaging studies [556]. Furthermore, gut-microbiota have immuno-modulatory effects on the brain [557-559], and oral pathogens of periodontitis in turn may alter the gut-microbiota $[450,560,561]$, thereby affecting psychiatric symptomatology. Since, inflammation and psychiatric disorders are predictively connected, thus increased inflammation in periodontal disease may causally contribute to psychiatric disorders as well.

\section{Effects of periodontal treatment}

\section{Effect of periodontal treatment on cardiovas- cular diseases}

Certain studies have reported an association between periodontal treatment and a decrease in the risk of cardiovascular events. Lee et al. (2015) performed a retrospective cohort study on more than 700,000 patients with/without periodontal disease and reported that as compared to the subjects without periodontal disease, the risk of acute myocardial infarction was highest in patients with periodontal disease who received no treatment for it (hazard ratio [HR] $=1.23$, [95\% CI: $1.13-$ 
1.35]), followed by the patients with periodontal disease who received intensive treatment $(\mathrm{HR}=1.09$ [95\% CI: 1.03-1.15]), and was the least in patients with periodontal disease who received only dental prophylaxis $(\mathrm{HR}=0.90$, [95\% CI: 0.86-0.95]) [562]. Thus, even though intensive periodontal treatment slightly raised the risk for acute myocardial infarction, it was still less than that related to no periodontal treatment at all. In another retrospective cohort study on more than 15,000 patients with diabetes, Peng et al. (2016) [563] reported that as compared to the patients that had received non-advanced periodontal treatment, the patients receiving advanced periodontal treatment (including sub-gingival curettage and flap operations) had significantly lower rates of heart failure ( $\mathrm{HR}=0.60$ [95\% CI: 0.45-0.80]) and myocardial infarction ( $\mathrm{HR}=0.92$ [95\% CI: 0.85-0.99]). However, the difference in the rate of stroke was not significant between these two groups ( $\mathrm{HR}=0.95$ [95\% CI: 0.85-1.06]) [563]. Moreover, as compared to the subjects who respond well to periodontal treatment, poor responders have been reported to have a significantly higher incidence rate ratio for CVD (1.28 [95\% CI: 1.07-1.53; $p=0.007]$ ), which increased further in subjects with the most remaining teeth up to 1.39 (95\% CI: 1.13-1.73; $p=0.002$ ) [564]. Thus, progression of CVD might be influenced by successful periodontal treatment.

Moreover, measures/markers of CVD risk are also affected by periodontal treatment. Evidence from randomized controlled trials has demonstrated that as early as one to two months after periodontal treatment, a reduction occurs in the systemic levels of CRP, E-selectin, and IL-6 [565-568], as well as in the number of pathogenic microorganisms in dental plaque [569]. Also, endothelial function tends to improve by 2 months after periodontal treatment [568]. In a meta-analysis, Orlandi et al. (2014) [570] arrived at a conclusion that improvement of endothelial function and reduction in systemic inflammation occurred with periodontal treatment, with one study reporting that these effects significantly lasted for 3-12 months post-treatment [571]. Also, following periodontal treatment in patients with periodontitis and/ or CVD, including full-mouth extraction, a decline in the serum fibrinogen levels has been reported [572-574]. In studies examining measures of cardiovascular outcomes post-treatment for periodontitis, even though a transient increase in brachial artery flow-mediated dilation (FMD), a marker of endothelial dysfunction [575], has been reported within 24 hours of periodontal treatment [568], other studies have reported an improvement in measures of cardiovascular pathology, including the measures for endothelial dysfunction, Framingham
Risk Score and systolic blood pressure, as early as 1-2 months post-periodontal treatment [131, 576-578]. Teeuw and colleagues performed a meta-analysis on 25 studies and reported that the interventions to treat periodontitis resulted in the improvement of endothelial function and a reduction in atherosclerotic disease biomarkers profile of atherosclerosis [210]. Vidal and colleagues [579] conducted an interventional prospective cohort pilot study consisting of 26 patients ( $53.6 \pm 8.0$ years old), who had generalized chronic periodontitis and refractory hypertension. There was a significant reduction in all the assessed cardiovascular risk markers with periodontal treatment. Left ventricular mass was decreased by $12.9 \mathrm{~g}$, pulse wave velocity was decreased by $0.9 \mathrm{~m} / \mathrm{s}(p<0.01)$, median values of diastolic blood pressure and systolic blood pressure were decreased by $10.0 \mathrm{mmHg}$ and 12.5 $\mathrm{mmHg}$, respectively, and levels of IL-6, fibrinogen, and CRP were reduced by $1.4 \mathrm{pg} / \mathrm{dl}, 37.5 \mathrm{mg} / \mathrm{dl}(p<0.01)$ and $0.5 \mathrm{mg} / \mathrm{dl}$, respectively, after 6 months of periodontal treatment [579]. Thus, in refractory hypertensive patients, there was a significant reduction in the levels of IL-6, CRP, fibrinogen, arterial stiffness, blood pressure, and left ventricular mass, with periodontal treatment, thereby possibly reducing the risk for CVD [579]. However, the data which illustrates that periodontal treatment affects ASCVD risk is inadequate; although the randomized controlled trial demonstrating the effect of periodontal treatment on endothelial dysfunction [568] indicates that the evidence for these effects is reasonable, as ASCVD could be predicted by endothelial dysfunction [580]. Hence, even if there is a very small positive impact of periodontal treatment on risk of CVD, this could be a major advancement in community health for the prevention of CVD. Additionally, a study by Blum et al. (2007) [581] demonstrated that periodontal treatment improved the vascular endothelial function effectively, and may be helpful in the prevention of PAD by protecting the vascular injury. Moreover, studies on periodontal therapy employing conservative approaches, such as scaling, root planing and antibiotic treatment, have reported a post-treatment reduction in the systemic levels of certain acute-phase reactants, as well as inflammatory mediators, including CRP, IL-6, TNF, fibrinogen, PAI-1, and WBC counts [131, 412, 572-574, 576-578, 582-584]. However, some studies have suggested otherwise, with no changes observed in the serum levels of acute-phase reactants and inflammatory mediators after conservative treatment for periodontitis $[585,586]$. Similarly, results from metaanalyses examining the effect of periodontal treatment on the serum levels of CRP have been mixed [391, 587]. 
On the other hand, periodontal treatment in itself may present as a moderate stimulus for temporarily inducing an increase in inflammation [588], and it has been associated with endothelial dysfunction 24 hours post-treatment [568] and a transient rise in systemic prothrombotic/inflammatory mediators lasting for at least one week [588]. The trauma and bacteremia following periodontal treatment may explain these findings [356]. However, this increase in inflammation is temporary and is outweighed by the reduction in inflammation that is lasting and prolonged. In a self-controlled case series study, Minassian et al. (2010) [589] reported a significantly greater incidence rate ratio (1.50 [95\% CI: 1.09-2.06]) in the first 4 weeks after invasive dental treatment, even after exclusion of subjects with prescriptions for antiplatelet or salicylate drugs before treatment, and individuals with coronary artery disease, diabetes or hypertension. Moreover, the increased rate of vascular events normalized to baseline values within 6 months of receiving treatment [589].

\section{Effect of periodontal treatment on metabolic diseases}

Merchant et al. (2016) performed a prospective cohort study on individuals receiving care at Veterans Health Administration medical facilities, in order to evaluate the effects of long-term periodontal care (with mean followup period of 1.7 years) on HbA1c in type 2 diabetics, who also had periodontal disease [590]. In this study, marginal structural models were applied to account for potential selection bias and confounding [590]. HbA1c was reported to decrease by $-0.02 \%$ and $-0.074 \%$, after periodontal treatment at baseline and follow-up, respectively [590]. Moreover, individuals with higher baseline HbA1c values had greater reduction in HbA1c $(\triangle \mathrm{HbA} 1 \mathrm{c}=-0.25 \%)$ after receiving periodontal treatment [590]. It is possible that among individuals with diabetes, periodontal treatment may lead to improved glycemic control and insulin sensitivity, by reducing circulating inflammatory mediators, including TNF [591-594], CRP [591, 592, 594, 595], fibrinogen [593] and IL-6 [592, 596], and by increasing the levels of adiponectin [592, 597]. Even among individuals without DM, systemic inflammation may be reduced by periodontal treatment [223, 391]. With periodontal treatment, a reduction in HbA1c was found in people with diabetes [598]. Also, outcomes from the Post AV Nodal Ablation Evaluation (PAVE) study indicated that in overweight people, the treatment of periodontitis might be less impactful [599]. Additionally, periodontal treatment, be it non-surgical periodontal treatment or supragingival therapy, when performed in diabetic patients who have well-controlled blood glucose level, did improve periodontal problems with no harmful effects on diabetes when the patients were tested after 4 months after receiving periodontal treatment [246]. Few studies have stated that there occurs an improvement in periodontal health in individuals with diabetes with the non-surgical periodontal therapy and/or subgingival scaling [600-603], and a different study emphasized that periodontal treatment with subgingival curettage, root planing, and extractions as a treatment, if required, led to improvement in glycemic control in diabetics [604].

\section{Effect of periodontal treatment on psychiatric disorders}

To our knowledge, there are no studies that directly report the effects of periodontal treatment on psychiatric disorders or outcomes. However, one study by Ozcelik et al. (2007) [605] had assessed the effects of one-week long surgical (SG), surgical plus enamel matrix protein derivative (S+EMD), and non-surgical (NS) periodontal treatment modalities on Oral health-related quality of life (OHQoL). Two questionnaires, Oral Health Impact Profile-14 (OHIP) and General Oral Health Assessment Index (GOHAI) were used in this study to evaluate OHQoL, and these questionnaires also included measures of a number of psychological (self-consciousness, worry, anxiety, etc.) and behavioral impacts (irritability, limiting social contact, dietary changes, etc.) [605]. The authors reported that starting from the first post-treatment day until the $7^{\text {th }}$ post-treatment day, the individuals in the SG group had significantly ( $p=0.001)$ worst OHQoL scores (including more psychological and behavioral impacts) than the NS and S+EMD groups [605]. Interestingly, in the SG group, after initial worsening of the psychological and behavioral impact sub-scores of OHQoL for the first $1-2$ days post-treatment, these scores returned to the baseline values only after 6-7 days [605]. On the other hand, the sub-scores for psychological and behavioral impact domains of OHQoL in the NS and S+EMD groups, started to improve from baseline values on day 1 post-treatment, and continued to decline till day 7 after treatment [605]. These observations can be possibly explained by the fact that surgical periodontal intervention could lead to a much more severe and prolonged pro-inflammatory response, thereby releasing inflammatory mediators, 
which as described in earlier sections, may contribute to psychiatric symptoms. Moreover, improved outcomes on OHQoL scores in the S+EMD group as compared to the SG could be attributed to the periodontal tissue regenerative properties of the enamel matrix protein derivative [606], which might attenuate the duration and severity of the pro-inflammatory response following the surgical intervention for periodontitis.

\section{Effect of periodontal treatment on neopterin}

After periodontal treatment in individuals with moderate to severe periodontitis, a drastic decrease (from $51 \mathrm{nmol} / 1$ to $1.77 \mathrm{nmol} / \mathrm{l}$ ) in the level of GCF neopterin concentrations was observed [89]. Similar results have also been reported in other studies on patients with periodontitis $[607,608]$, as well as in patients with a combination of periodontitis and/or DM [609]. On the other hand, a study by Bodur et al. (2003) [610] reported no significant differences in both pre- and post-periodontal treatment-GCF neopterin levels between the group of patients with $\mathrm{AgP}$ and periodontally healthy controls. However, mean salivary neopterin concentrations were significantly higher in patients as compared to the controls, but there was no significant difference between the pre- and post-periodontal treatment levels of salivary neopterin concentrations among the AgP group [610]. Moreover, after periodontal treatment, urinary neopterin levels were significantly higher in the AgP group, when compared with pre-treatment urinary neopterin levels and with the urinary neopterin levels of the control subjects [610].

\section{Implications, conclusions and future directions}

Periodontal disease, CVD, metabolic diseases and psychiatric disorders pose a major global health-burden. They share multiple risk factors and have a multifactorial bi-directional, as well as, multi-directional etiology. As described above, robust evidence depicts an association between these disorders, which points towards inflammation being one of the major links between them.

Periodontal disease has been associated with significant worsening of quality of life [32, 611-615], and periodontal treatment has been reported to improve the quality of life of patients [615-617]. Additionally, as described in greater detail above, periodontal treatment

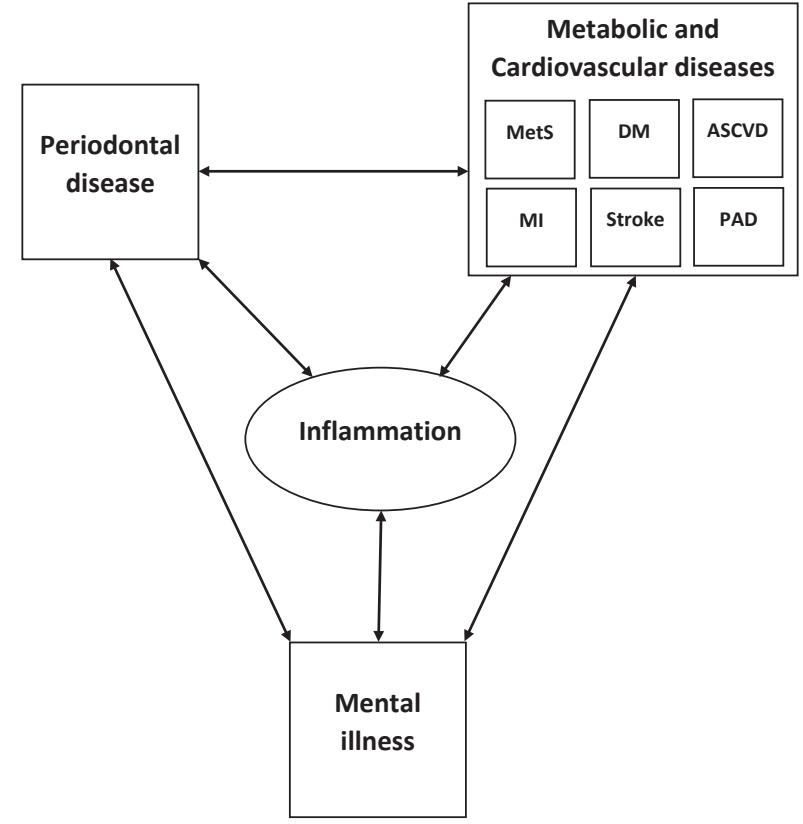

Figure 1: A graphical representation depicting the links between periodontal disease, metabolic diseases, cardiovascular diseases, and mental illness, with inflammation as a common mediator between these disorders. (MetS: Metabolic syndrome; DM: Diabetes mellitus; ASCVD: Atherosclerotic cardiovascular disease; MI: Myocardial infarction; PAD: Peripheral arterial disease).

reduces the morbidity associated with co-morbid systemic diseases, such as CVD and diabetes, in patients with periodontitis [590]. Hence, it becomes essential to prevent and manage periodontal disease to reduce its burden of morbidity and mortality in various populations.

From the viewpoint of public health, the prevention and treatment of periodontitis are possible; therefore, improvement in oral health is possible by effectively implementing the treatment measures and prevention programs. The underlying principle behind the diagnosis, treatment and prevention of periodontitis is evading the detrimental effects of periodontitis, like alveolar bone loss and resulting tooth loss, and preserving the dentition of a person. Periodontitis can be managed with treatment, but there is very little knowledge on how to prevent it [30]. Few studies have demonstrated that toothbrushing, specifically with fluoride containing toothpaste, decreases dental caries [618]. On the other hand, daily procedures like use of chewing gum or tooth-brushing, can also result in episodes of bacteremia in patients with periodontitis, and it can occur multiple times daily [619-622], which, as described above, could also contribute to CVD. It is likely that the benefits of oral hygiene possibly outweigh the risks associated with it due to bacteremic episodes. 
However, benefits of maintaining good oral hygiene in periodontitis have not been reported in other studies [623625]. It is also likely that in addition to oral hygiene, other factors like genetic predisposition, may have a greater part to play in the etiology of periodontitis than was formerly speculated [21, 22]. However, in children, timely detection of oral conditions as well as a good oral hygiene, are very crucial in the treatment and prevention of periodontal disease [626, 627]. As gingival bleeding is more frequent in children with diabetes, oral hygiene is specifically necessary in them [240, 628].

It is essential that dentists and general practitioners (including cardiologists, endocrinologists, and perhaps, psychiatrists) co-operate for the promotion of oral and general health by increasing access to periodontal treatment, coordinating referrals between them, and increasing awareness about the links between these disorders. Dentists should be watchful for the presence of risk factors for periodontitis, CVD and MetS in their patients, which can be modified via lifestyle changes. Once identified, such risk factors should be addressed in a comprehensive periodontal treatment setting by the dentists by advising their patients on lifestyle changes, such as physical exercise, consumption of whole grain or high-fiber diet and smoking cessation. Mental health professionals should include oral health considerations in the comprehensive assessment and treatment of individuals with severe mental illness. There is an availability of standard checklists for assessing oral health [305, 629-631], which can be utilized by all health professionals, and thereby facilitate the screening for co-morbid periodontal disease in their patients. Similarly, interventions including iatrogenic dry mouth management, early dental referral, and help in maintaining good oral hygiene, can be employed by all physicians. American Heart Association (AHA) guidelines should be followed to reduce the risks associated with comorbid periodontitis in patients with a history of CVD. The patients of periodontitis in whom additional risk factors for ASCVD are present, such as overweight/ obesity, smoking, hypertension and who have not visited a doctor in the past year, should be referred for a routine physical examination. This forward leaning stance is critical, as periodontal disease is often under-treated [25] because it does not present with any pain in early stages of the disease and progresses slowly [632].

In brief, psychiatric illnesses may represent an important link between periodontal disease, metabolic diseases and CVDs. As described above, inflammation is a critical pivot between all these conditions. However, this relationship has an element of complexity. Early on, after periodontal therapy, an increase in the serum levels of the markers of CVD risk during the period of first 24 hours [568] to 4 weeks [589, 633], points towards an increased risk for inflammation-mediated adverse outcomes during this time period. Hence, it becomes essential to individually personalize the timing of monitoring and treating psychiatric, metabolic and cardiovascular co-morbidities for each patient relative to individual time points, (e.g., according to the interval of time elapsed since they had an intervention for periodontal disease). Also, expansion needs to happen in terms of the clinical settings, where recommendations for maintaining a good oral hygiene and referrals to a dentist's office for treating dental health issues are made, including the cardiology, endocrinology, primary care and mental health clinics. Similarly, it becomes important to screen patients' psychiatric, cardiovascular and metabolic health issues in a dentist's office.

As described above in various sections, there are gaps in the scientific data that are short of causal links between periodontal disease and CVD, metabolic diseases, and psychiatric disorders. Even though, it has been established that well-designed randomized controlled trials should be preferred to determine a causal inference from an exposure towards an outcome [634], there could be certain scenarios, e.g., in studies evaluating the effects of periodontal treatment to an outcome [590], where randomization cannot be feasible, thereby making an RCT prone to confounding. Also, standard methods for controlling confounding (e.g., regression analyses) can be rendered inappropriate when a time-varying confounder is affected by prior treatment, as the covariate could play the role of both a mediator as well as a confounder of the effect of treatment on outcome over-time [635, 636]. Interestingly, a new class of causal models called marginal structural models, can utilize observational data to estimate the causal effect of a time-dependent exposure, while taking into account the occurrence of time-dependent covariates that could also function concurrently as intermediate variables and confounders [636, 637]. These models are designed to control for the effects of confounding variables that are affected by previous treatment or that change over time, by utilizing a multi-step estimation procedure [636]. These models create an artificial population by using inverse-probability (of exposure) weights, and in this population, causal effects can be estimated after removing imbalances among co-variates [590, 636, 638]. Thus, using marginal structural models on large epidemiological data can uncover potential causal links between periodontal disease and CVD, metabolic diseases, and psychiatric disorders. 
Futurestudiesshouldfocuson:1)redoing previouswork connecting periodontitis and metabolic/cardiovascular health with measurement of indicators of the presence and severity of mental illness, with adjustment and stratification, 2) studying periodontal disease in pregnancy and the effect of treating it on metabolic factors (e.g., diabetes), and mental health in mothers and development in the offspring, with measurement of mediators of inflammation, 3) investigating the effect of psychiatric treatment, in those with untreated mental illness, on periodontal health, 4) exploring how periodontal disease could also contribute to mental illness, rather than only on how psychiatric disorders could affect periodontal disease, 5) analyzing dental health in individuals with vs. without suicide attempts, 6) performing neuroimaging analyses, functional and structural, and glial imaging in individuals with vs. without periodontitis (before and after), 7) identifying the group of individuals most at risk for psychiatric exacerbation due to periodontitis or its treatment, 8) analyzing in large registries the effect of periodontal treatment on mental health and metabolic disease and use marginal structural modeling to account for bias, 9) investigating inflammatory markers for predicting severity and timing of possible interventions, and monitoring of these patients, 10) identifying interventions that would have the greatest overall impact across domains, and the groups of individuals, who would benefit most from periodontal disease prevention and treatment, 11) comparing medications for similar indications in a randomized fashion to determine the best agent to use in individuals with or at risk for periodontitis, 12) increasing adherence to preventative and treatment strategies for periodontal disease in individuals with mental illness, and 13) exploring genetic, epigenetic and environmental factors in large population studies that put individuals at shared risk for periodontal disease, mental illness, metabolic and cardiovascular disease.

Acknowledgments: This work was supported by the MidAtlantic Nutrition Obesity Research Center Pilot NORC grant (Postolache, PI), a subaward of the parent grant P30 DK072488 (Mitchell, PI). Additional support for the writing of this manuscript was provided by the Rocky Mountain MIRECC, Denver Colorado and Military and Veteran Microbiome Consortium for Research and Education (MVM-CoRE), Denver, CO. The authors thank Alexandra Dagdag for her help in proofreading this manuscript. We thank the staff of the Amish Research Clinic of the University of Maryland for their overall support and the trainees of the Mood and Anxiety Program for their help with references, mailings and data management. The views, opinions and findings contained in this article belong to the authors and should not be construed as an official position of the $\mathrm{NIH}$, or the US Department of Veterans Affairs.

Conflict of interest: All authors of this paper declare no conflict of interest.

\section{References}

1. Page R.C., Schroeder H.E., Periodontitis in man and other animals. A comparative review. S. Karger. Basel, Switzerland; 1982.

2. Lang N.P., Lindhe J, Clinical Periodontology and Implant Dentistry, 2 Volume Set. 6th edition. Wiley-Blackwell. Chicester, United Kingdom; 2015.

3. Armitage GC. Development of a classification system for periodontal diseases and conditions. Ann Periodontol. 1999;4(1):1-6.

4. Mariotti A. Dental plaque-induced gingival diseases. Ann Periodontol. 1999;4(1):7-19.

5. Oliver RC, Brown LJ, Loe H. Periodontal diseases in the United States population. J Periodontol. 1998;69(2):269-78.

6. Socransky S, Manganiello A, Propas D, Oram V, Van Houte J. Bacteriological studies of developing supragingival dental plaque. J Periodontal Res. 1977;12(2):90-106.

7. Guggenheim B, Giertsen E, Schüpbach P, Shapiro S. Validation of an in vitro biofilm model of supragingival plaque. J Dent Res 2001;80(1):363-70.

8. Ximénez-Fyvie LA, Haffajee AD, Socransky SS. Microbial composition of supra-and subgingival plaque in subjects with adult periodontitis. J Clin Periodontol. 2000;27(10):722-32.

9. Paster BJ, Boches SK, Galvin JL, Ericson RE, Lau CN, Levanos VA, et al. Bacterial diversity in human subgingival plaque. J Bacteriol. 2001;183(12):3770-83.

10. Tanner A, Maiden M, Macuch P, Murray L, Kent Jr R. Microbiota of health, gingivitis, and initial periodontitis. J Clin Periodontol. 1998;25(2):85-98.

11. Moore W. Microbiology of periodontal disease. J Periodontal Res. 1987;22(5):335-41.

12. Kingman A, Albandar JM. Methodological aspects of epidemiological studies of periodontal diseases. Periodontol 2000. 2002;29(1):11-30.

13. Dye BA. Global periodontal disease epidemiology. Periodontol 2000. 2012;58(1):10-25.

14. Ainamo J, Barmes D, Beagrie G, Cutress T, Martin J, SardoInfirri J. Development of the World Health Organization (WHO) community periodontal index of treatment needs (CPITN). Int Dent J. 1982;32(3):281-91.

15. Eke PI, Page RC, Wei L, Thornton-Evans G, Genco RJ. Update of the case definitions for population-based surveillance of periodontitis. J Periodontol. 2012;83(12):1449-54. 
16. Eke PI, Dye BA, Wei L, Thornton-Evans GO, Genco RJ. Prevalence of periodontitis in adults in the United States: 2009 and 2010. J Dent Res. 2012;91(10):914-20.

17. Eke PI, Dye BA, Wei L, Slade GD, Thornton-Evans GO, Borgnakke WS, et al. Update on Prevalence of Periodontitis in Adults in the United States: NHANES 2009 to 2012. J Periodontol. 2015;86(5):611-22.

18. National Center for Health Statistics. Healthy People 2010. 2015 [updated November 6, 2015]. Available from: https://www.cdc. gov/nchs/healthy_people/hp2010.htm.

19. Eke PI, Genco RJ. CDC Periodontal Disease Surveillance Project: background, objectives, and progress report. J Periodontol. 2007;78(7S):1366-71.

20. Reynolds MA. Modifiable risk factors in periodontitis: at the intersection of aging and disease. Periodontol 2000. 2014;64(1):7-19.

21. Armitage GC, Wu Y, Wang HY, Sorrell J, di Giovine FS, Duff GW. Low prevalence of a periodontitis-associated interleukin-1 composite genotype in individuals of Chinese heritage. J Periodontol. 2000;71(2):164-71.

22. Michalowicz BS, DiehI SR, Gunsolley JC, Sparks BS, Brooks CN, Koertge TE, et al. Evidence of a substantial genetic basis for risk of adult periodontitis. J Periodontol. 2000;71(11):1699-707.

23. Grossi SG, Zambon JJ, Ho AW, Koch G, Dunford RG, Machtei $\mathrm{EE}$, et al. Assessment of risk for periodontal disease. I. Risk indicators for attachment loss. J Periodontol. 1994;65(3):260-7.

24. Genco RJ, Borgnakke WS. Risk factors for periodontal disease. Periodontol 2000. 2013;62(1):59-94.

25. Dye BA, Vargas CM. The use of a modified CPITN approach to estimate periodontal treatment needs among adults aged 20-79 years by socio-demographic characteristics in the United States, 1988-94. Community Dent Health. 2002;19(4):215-23.

26. Lockhart PB, Bolger AF, Papapanou PN, Osinbowale O, Trevisan $M$, Levison ME, et al. Periodontal disease and atherosclerotic vascular disease: does the evidence support an independent association?: a scientific statement from the American Heart Association. Circulation. 2012;125(20):2520-44.

27. Shiau HJ, Reynolds MA. Sex differences in destructive periodontal disease: a systematic review. J Periodontol. 2010;81(10):1379-89.

28. Merchant AT, Pitiphat W, Rimm EB, Joshipura K. Increased physical activity decreases periodontitis risk in men. Eur J Epidemiol. 2003;18(9):891-8.

29. Genco RJ. Current view of risk factors for periodontal diseases. J Periodontol. 1996;67(10 Suppl):1041-9.

30. Burt B; Research, Science and Therapy Committee of the American Academy of Periodontology. Position paper: epidemiology of periodontal diseases. J Periodontol. 1996;67(9):935-45.

31. Grossi SG, Genco RJ, Machtei EE, Ho AW, Koch G, Dunford $\mathrm{R}$, et al. Assessment of risk for periodontal disease. II. Risk indicators for alveolar bone loss. J Periodontol. 1995;66(1):239.

32. Meusel DR, Ramacciato JC, Motta RH, Júnior RBB, Flório FM. Impact of the severity of chronic periodontal disease on quality of life. J Oral Sci. 2015;57(2):87-94.

33. Hyde S, Dupuis V, Mariri BP, Dartevelle S. Prevention of tooth loss and dental pain for reducing the global burden of oral diseases. Int Dent J. 2017;67 Suppl 2:19-25.
34. Thornton-Evans G, Eke P, Wei L, Palmer A, Moeti R, Hutchins $S$, et al. Periodontitis among adults aged $>/=30$ years - United States, 2009-2010. MMWR Suppl. 2013;62(3):129-35.

35. Abnet CC, Qiao Y-L, Dawsey SM, Dong Z-W, Taylor PR, Mark SD. Tooth loss is associated with increased risk of total death and death from upper gastrointestinal cancer, heart disease, and stroke in a Chinese population-based cohort. Int J Epidemiol. 2005;34(2):467-74.

36. Aida J, Kondo K, Yamamoto T, Hirai H, Nakade M, Osaka K, et al. Oral health and cancer, cardiovascular, and respiratory mortality of Japanese. J Dent Res. 2011;90(9):1129-35.

37. Linden GJ, Linden K, Yarnell J, Evans A, Kee F, Patterson CC. All-cause mortality and periodontitis in 60-70-year-old men: a prospective cohort study. J Clin Periodontol. 2012;39(10):9406.

38. Xu F, Lu B. Prospective association of periodontal disease with cardiovascular and all-cause mortality: NHANES III follow-up study. Atherosclerosis. 2011;218(2):536-42.

39. Chen LP, Chiang CK, Peng YS, Hsu SP, Lin CY, Lai CF, et al. Relationship between periodontal disease and mortality in patients treated with maintenance hemodialysis. Am J Kidney Dis. 2011;57(2):276-82.

40. Dorn JM, Genco RJ, Grossi SG, Falkner KL, Hovey KM, Iacoviello $L$, et al. Periodontal disease and recurrent cardiovascular events in survivors of myocardial infarction (MI): the Western New York Acute MI Study. J Periodontol. 2010;81(4):502-11.

41. Saremi A, Nelson RG, Tulloch-Reid M, Hanson RL, Sievers ML, Taylor GW, et al. Periodontal disease and mortality in type 2 diabetes. Diabetes Care. 2005;28(1):27-32.

42. Abnet CC, Qiao YL, Dawsey SM, Dong ZW, Taylor PR, Mark SD. Tooth loss is associated with increased risk of total death and death from upper gastrointestinal cancer, heart disease, and stroke in a Chinese population-based cohort. Int J Epidemiol. 2005;34(2):467-74.

43. Garcia RI, Krall EA, Vokonas PS. Periodontal disease and mortality from all causes in the VA Dental Longitudinal Study. Ann Periodontol. 1998;3(1):339-49.

44. Schwahn C, Polzer I, Haring R, Dorr M, Wallaschofski H, Kocher $\mathrm{T}$, et al. Missing, unreplaced teeth and risk of all-cause and cardiovascular mortality. Int J Cardiol. 2013;167(4):1430-7.

45. Heitmann BL, Gamborg M. Remaining teeth, cardiovascular morbidity and death among adult Danes. Prev Med. 2008;47(2):156-60.

46. Holmlund A, Holm G, Lind L. Number of teeth as a predictor of cardiovascular mortality in a cohort of 7,674 subjects followed for 12 years. J Periodontol. 2010;81(6):870-6.

47. Aida J, Kondo K, Yamamoto T, Hirai H, Nakade M, Osaka K, et al. Oral health and cancer, cardiovascular, and respiratory mortality of Japanese. J Dent Res. 2011;90(9):1129-35.

48. Ansai T, Takata Y, Yoshida A, Soh I, Awano S, Hamasaki T, et al. Association between tooth loss and orodigestive cancer mortality in an 80-year-old community-dwelling Japanese population: a 12-year prospective study. BMC Public Health. 2013;13:814.

49. Ritchie CS, Joshipura K, Hung HC, Douglass CW. Nutrition as a mediator in the relation between oral and systemic disease: associations between specific measures of adult oral health and nutrition outcomes. Crit Rev Oral Biol Med. 2002;13(3):291300 . 
50. World Health Organization. Global status report on noncommunicable diseases 2014. 2014 [updated 2014]. Available from: http://apps.who.int/iris/bitstream/handle/106 65/148114/9789241564854_eng.pdf;jsessionid=EE939D743C3 73AEC938F528B292B7684? sequence $=1$.

51. Benjamin EJ, Virani SS, Callaway CW, Chamberlain AM, Chang AR, Cheng S, et al. Heart disease and stroke statistics-2018 update: a report from the American Heart Association. Circulation. 2018;137(12):e67-e492.

52. Ouma GO, Jonas RA, Usman MH, Mohler ER, 3rd. Targets and delivery methods for therapeutic angiogenesis in peripheral artery disease. Vasc Med. 2012;17(3):174-92.

53. Kullo IJ, Rooke TW. CLINICAL PRACTICE. Peripheral Artery Disease. N Engl J Med. 2016;374(9):861-71.

54. Howell MA, Colgan MP, Seeger RW, Ramsey DE, Sumner DS. Relationship of severity of lower limb peripheral vascular disease to mortality and morbidity: a six-year follow-up study. J Vasc Surg. 1989;9(5):691-6; discussion 6-7.

55. McKenna M, Wolfson S, Kuller L. The ratio of ankle and arm arterial pressure as an independent predictor of mortality. Atherosclerosis. 1991;87(2-3):119-28.

56. Leng GC, Fowkes FG, Lee AJ, Dunbar J, Housley E, Ruckley CV. Use of ankle brachial pressure index to predict cardiovascular events and death: a cohort study. BMJ. 1996;313(7070):1440-4.

57. Leng GC, Lee AJ, Fowkes FG, Whiteman M, Dunbar J, Housley E, et al. Incidence, natural history and cardiovascular events in symptomatic and asymptomatic peripheral arterial disease in the general population. Int J Epidemiol. 1996;25(6):1172-81.

58. Hirsch AT, Criqui MH, Treat-Jacobson D, Regensteiner JG, Creager MA, Olin JW, et al. Peripheral arterial disease detection, awareness, and treatment in primary care. JAMA. 2001;286(11):1317-24.

59. Alberti K, Eckel RH, Grundy SM, Zimmet PZ, Cleeman JI, Donato KA, et al. Harmonizing the metabolic syndrome: a joint interim statement of the international diabetes federation task force on epidemiology and prevention; national heart, lung, and blood institute; American heart association; world heart federation; international atherosclerosis society; and international association for the study of obesity. Circulation. 2009;120(16):1640-5.

60. Third Report of the National Cholesterol Education Program (NCEP). Third Report of the National Cholesterol Education Program (NCEP) Expert Panel on Detection, Evaluation, and Treatment of High Blood Cholesterol in Adults (Adult Treatment Panel III) final report. Circulation. 2002;106(25):3143-421.

61. Grundy SM, Brewer HB, Jr., Cleeman JI, Smith SC, Jr., Lenfant C. Definition of metabolic syndrome: Report of the National Heart, Lung, and Blood Institute/American Heart Association conference on scientific issues related to definition. Circulation. 2004;109(3):433-8.

62. Yusuf S, Reddy S, Ounpuu S, Anand S. Global burden of cardiovascular diseases: part I: general considerations, the epidemiologic transition, risk factors, and impact of urbanization. Circulation. 2001;104(22):2746-53.

63. Crespo PS, Prieto Perera JA, Lodeiro FA, Azuara LA. Metabolic syndrome in childhood. Public Health Nutr. 2007;10(10a):11215.

64. Huang TT, Ball GD, Franks PW. Metabolic syndrome in youth: current issues and challenges. Appl Physiol Nutr Metab. 2007;32(1):13-22.
65. Pergher RN, Melo ME, Halpern A, Mancini MC. Is a diagnosis of metabolic syndrome applicable to children? J Pediatr (Rio J). 2010;86(2):101-8.

66. Cook S, Weitzman M, Auinger P, Nguyen M, Dietz WH. Prevalence of a metabolic syndrome phenotype in adolescents: findings from the third National Health and Nutrition Examination Survey, 1988-1994. Arch Pediatr Adolesc Med. 2003;157(8):821-7.

67. Cruz ML, Weigensberg MJ, Huang TT, Ball G, Shaibi GQ, Goran MI. The metabolic syndrome in overweight Hispanic youth and the role of insulin sensitivity. J Clin Endocrinol Metab. 2004;89(1):108-13.

68. Weiss R, Dziura J, Burgert TS, Tamborlane WV, Taksali SE, Yeckel $\mathrm{CW}$, et al. Obesity and the metabolic syndrome in children and adolescents. N Engl J Med. 2004;350(23):2362-74.

69. Association AD. Standards of medical care in diabetes--2011. Diabetes Care. 2011;34 Suppl 1:S11-61.

70. Dabelea D, Bell RA, D’Agostino RB, Jr., Imperatore G, Johansen $J M$, Linder $B$, et al. Incidence of diabetes in youth in the United States. JAMA. 2007;297(24):2716-24.

71. Steel Z, Marnane C, Iranpour C, Chey T, Jackson JW, Patel V, et al. The global prevalence of common mental disorders: a systematic review and meta-analysis 1980-2013. Int J Epidemiol. 2014;43(2):476-93.

72. World Health Organization. The Global Burden of Disease 2004 update. 2008 [updated 2008]. Available from: http:// www.who.int/healthinfo/global_burden_disease/GBD_ report_2004update_full.pdf.

73. Kauppi K, Hatonen H, Adams CE, Valimaki M. Perceptions of treatment adherence among people with mental health problems and health care professionals. J Adv Nurs. 2015;71(4):777-88.

74. National Institute of Mental Health. Statistics. 2018 [updated January, 2018]. Available from: https://www.nimh.nih.gov/ health/statistics/index.shtml.

75. Centers for Disease Control and Prevention. National Center for Injury Prevention and Control. Web-based injury statistics query and reporting system (WISQARS) 2017 [updated July 19, 2016]. Available from: https://www.cdc. gov/injury/images/lc-charts/leading_causes_of_death_age_ group_2014_1050w760h.gif.

76. Stone DM, Simon TR, Fowler KA, Kegler SR, Yuan K, Holland KM, et al. Vital Signs: Trends in State Suicide Rates - United States, 1999-2016 and Circumstances Contributing to Suicide - 27 States, 2015. MMWR Morb Mortal Wkly Rep 2018;67:617-624.

77. Offenbacher S. Periodontal diseases: pathogenesis. Ann Periodontol. 1996;1(1):821-78.

78. Masada MP, Persson R, Kenney JS, Lee SW, Page RC, Allison AC. Measurement of interleukin- $1 \alpha$ and- $1 \beta$ in gingival crevicular fluid: Implications for the pathogenesis of periodontal disease. J Periodontal Res. 1990;25(3):156-63.

79. Page RC. The role of inflammatory mediators in the pathogenesis of periodontal disease. J Periodontal Res. 1991;26(3):230-42.

80. Manouchehr-Pour M, Spagnuolo P, Rodman H, Bissada N. Comparison of neutrophil chemotactic response in diabetic patients with mild and severe periodontal disease. J Periodontol. 1981;52(8):410-5.

81. Fuchs D, Hausen A, Reibnegger G, Werner ER, Dierich MP, Wachter H. Neopterin as a marker for activated cell-mediated 
immunity: application in HIV infection. Immunol Today. 1988;9(5):150-5.

82. Huber C, Batchelor JR, Fuchs D, Hausen A, Lang A, Niederwieser $D$, et al. Immune response-associated production of neopterin. Release from macrophages primarily under control of interferon-gamma. J Exp Med. 1984;160(1):310-6.

83. Wirleitner B, Reider D, Ebner S, Böck G, Widner B, Jaeger M, et al. Monocyte-derived dendritic cells release neopterin. J Leukoc Biol. 2002;72(6):1148-53.

84. Werner-Felmayer G, Werner ER, Fuchs D, Hausen A, Reibnegger G, Wachter H. Tumour necrosis factor-alpha and lipopolysaccharide enhance interferon-induced tryptophan degradation and pteridine synthesis in human cells. Biol Chem Hoppe Seyler. 1989;370(9):1063-9.

85. Murr C, Widner B, Wirleitner B, Fuchs D. Neopterin as a marker for immune system activation. Curr Drug Metab. 2002;3(2):17587.

86. Nathan C. Peroxide and pteridine: a hypothesis on the regulation of macrophage antimicrobial activity by interferon gamma. Interferon. 1986;7:125-43.

87. Ozmeriç N, Baydar T, Bodur A, Engin AB, Uraz A, Eren K, et al. Level of neopterin, a marker of immune cell activation in gingival crevicular fluid, saliva, and urine in patients with aggressive periodontitis. J Periodontol. 2002;73(7):720-5.

88. Vrecko K, Staedtler P, Mischak I, Maresch L, Reibnegger G. Periodontitis and concentrations of the cellular immune activation marker neopterin in saliva and urine. Clin Chim Acta. 1997;268(1-2):31-40.

89. Pradeep A, Kumar MS, Ramachandraprasad M, Shikha C. Gingival crevicular fluid levels of neopterin in healthy subjects and in patients with different periodontal diseases. J Periodontol. 2007;78(10):1962-7.

90. Neumann F-J, Ott I, Gawaz M, Richardt G, Holzapfel H, Jochum $M$, et al. Cardiac release of cytokines and inflammatory responses in acute myocardial infarction. Circulation. 1995;92(4):748-55.

91. Frangogiannis NG, Smith CW, Entman ML. The inflammatory response in myocardial infarction. Cardiovascular research. 2002;53(1):31-47.

92. Del Zoppo G, Ginis I, Hallenbeck JM, ladecola C, Wang X, Feuerstein GZ. Inflammation and stroke: putative role for cytokines, adhesion molecules and iNOS in brain response to ischemia. Brain Pathol. 2000;10(1):95-112.

93. Chamorro Á. Role of inflammation in stroke and atherothrombosis. Cerebrovasc Dis. 2004;17(Suppl. 3):1-5.

94. Tzoulaki I, Murray GD, Lee AJ, Rumley A, Lowe GD, Fowkes FGR. Inflammatory, haemostatic, and rheological markers for incident peripheral arterial disease: Edinburgh Artery Study. Eur Heart J. 2007;28(3):354-62.

95. Ridker PM, Stampfer MJ, Rifai N. Novel risk factors for systemic atherosclerosis: a comparison of $\mathrm{C}$-reactive protein, fibrinogen, homocysteine, lipoprotein (a), and standard cholesterol screening as predictors of peripheral arterial disease. JAMA. 2001;285(19):2481-5.

96. Lusis AJ. Atherosclerosis. Nature. 2000;407(6801):233-41.

97. Ross R. Cell biology of atherosclerosis. Annu Rev Physiol. 1995;57:791-804.

98. Libby P, Ridker PM, Hansson GK, Leducq Transatlantic Network on Atherothrombosis. Inflammation in Atherosclerosis:
From Pathophysiology to Practice. J Am Coll Cardiol. 2009;54(23):2129-38.

99. Ross R. Atherosclerosis-an inflammatory disease. N Engl J Med. 1999;340(2):115-26.

100. Ludewig B, Zinkernagel RM, Hengartner H. Arterial inflammation and atherosclerosis. Trends Cardiovasc Med. 2002;12(4):154-9.

101. Shah SH, Newby LK. C-reactive protein: a novel marker of cardiovascular risk. Cardiol Rev. 2003;11(4):169-79.

102. Blake GJ, Ridker PM. Inflammatory bio-markers and cardiovascular risk prediction. J Intern Med. 2002;252(4):28394.

103. Fuchs D, Avanzas P, Arroyo-Espliguero R, Jenny M, ConsuegraSanchez L, Kaski J. The role of neopterin in atherogenesis and cardiovascular risk assessment. Curr Med Chem. 2009;16(35):4644-53.

104. Adachi T, Naruko T, Itoh A, Komatsu R, Abe Y, Shirai N, et al. Neopterin is associated with plaque inflammation and destabilization in human coronary atherosclerotic lesions. Heart. 2007.

105. Pradhan AD, Manson JE, Rifai N, Buring JE, Ridker PM. C-reactive protein, interleukin 6 , and risk of developing type 2 diabetes mellitus. JAMA. 2001;286(3):327-34.

106. Vozarova B, Weyer C, Hanson K, Tataranni PA, Bogardus C, Pratley RE. Circulating interleukin- 6 in relation to adiposity, insulin action, and insulin secretion. Obes Res. 2001;9(7):4147.

107. Dandona P, Weinstock R, Thusu K, Abdel-Rahman E, Aljada A, Wadden T. Tumor necrosis factor- $\alpha$ in sera of obese patients: fall with weight loss. J Clin Endocrinol Metab. 1998;83(8):290710.

108. Kern PA, Ranganathan S, Li C, Wood L, Ranganathan G. Adipose tissue tumor necrosis factor and interleukin-6 expression in human obesity and insulin resistance. Am J Physiol Endocrinol Metab. 2001;280(5):E745-E51.

109. Dandona P, Aljada A, Bandyopadhyay A. Inflammation: the link between insulin resistance, obesity and diabetes. Trends Immunol. 2004;25(1):4-7.

110. Grace C, Goldrick R. Fibrinolysis and body build: interrelationships between blood fibrinolysis, body composition and parameters of lipid and carbohydrate metabolism. J Atheroscler Res. 1968;8(4):705-19.

111. Fearnley G, Vincent C, Chakrabarti R. Reduction of blood fibrinolytic activity in diabetes mellitus by insulin. Lancet. 1959;274(7111):1067.

112. Ogston D, McAndrew G. Fibrinolysis in obesity. Lancet. 1964;2:1205-7.

113. Shoelson SE, Herrero L, Naaz A. Obesity, inflammation, and insulin resistance. Gastroenterology. 2007;132(6):2169-80.

114. Feinstein R, Kanety H, Papa M, Lunenfeld B, Karasik A. Tumor necrosis factor-alpha suppresses insulin-induced tyrosine phosphorylation of insulin receptor and its substrates. J Biol Chem. 1993;268(35):26055-8.

115. Hotamisligil GS, Shargill NS, Spiegelman BM. Adipose expression of tumor necrosis factor-alpha: direct role in obesity-linked insulin resistance. Science. 1993;259(5091):8791.

116. Rotter V, Nagaev I, Smith U. Interleukin-6 (IL-6) induces insulin resistance in 3T3-L1 adipocytes and is, like IL-8 and tumor necrosis factor- $\alpha$, overexpressed in human fat cells from 
insulin-resistant subjects. J Biol Chem. 2003;278(46):4577784.

117. Hotamisligil G. Molecular mechanisms of insulin resistance and the role of the adipocyte. Int J Obes Relat Metab Disord. 2000;24(S4):S23.

118. Hotamisligil G. The role of TNF $\alpha$ and TNF receptors in obesity and insulin resistance. J Intern Med. 1999;245(6):621-5.

119. Ford ES. Body mass index, diabetes, and C-reactive protein among US adults. Diabetes care. 1999;22(12):1971-7.

120. Pickup J, Mattock M, Chusney G, Burt D. NIDDM as a disease of the innate immune system: association of acute-phase reactants and interleukin- 6 with metabolic syndrome X. Diabetologia. 1997;40(11):1286.

121. Tsigos C, Papanicolaou DA, Kyrou I, Defensor R, Mitsiadis CS, Chrousos GP. Dose-dependent effects of recombinant human interleukin-6 on glucose regulation. J Clin Endocrinol Metab. 1997;82(12):4167-70.

122. Festa A, D’Agostino Jr R, Howard G, Mykkanen L, Tracy RP, Haffner SM. Chronic subclinical inflammation as part of the insulin resistance syndrome: the Insulin Resistance Atherosclerosis Study (IRAS). Circulation. 2000;102(1):42-7.

123. Sandler S, Bendtzen K, Eizirik DL, Welsh M. Interleukin-6 affects insulin secretion and glucose metabolism of rat pancreatic islets in vitro. Endocrinology. 1990;126(2):1288-94.

124. Grau AJ, Buggle F, Becher H, Werle E, Hacke W. The association of leukocyte count, fibrinogen and C-reactive protein with vascular risk factors and ischemic vascular diseases. Thromb Res. 1996;82(3):245-55.

125. Donath MY. Targeting inflammation in the treatment of type 2 diabetes: time to start. Nat Rev Drug Discov. 2014;13(6):46576.

126. Pickup J, Crook M. Is type II diabetes mellitus a disease of the innate immune system? Diabetologia. 1998;41(10):1241-8.

127. Wannamethee SG, Lowe GD, Shaper AG, Rumley A, Lennon L, Whincup $\mathrm{PH}$. The metabolic syndrome and insulin resistance: relationship to haemostatic and inflammatory markers in older non-diabetic men. Atherosclerosis. 2005;181(1):101-8.

128. Ford ES. The metabolic syndrome and C-reactive protein, fibrinogen, and leukocyte count: findings from the Third National Health and Nutrition Examination Survey. Atherosclerosis. 2003;168(2):351-8.

129. Grundy SM. Metabolic syndrome: a multiplex cardiovascular risk factor. J Clin Endocrinol Metab. 2007;92(2):399-404.

130. Sjöholm Å, Nyström T. Endothelial inflammation in insulin resistance. Lancet. 2005;365(9459):610-2.

131. Higashi Y, Goto C, Jitsuiki D, Umemura T, Nishioka K, Hidaka $\mathrm{T}$, et al. Periodontal infection is associated with endothelial dysfunction in healthy subjects and hypertensive patients. Hypertension. 2008;51(2):446-53.

132. Bullon P, Morillo JM, Ramirez-Tortosa MC, Quiles JL, Newman HN, Battino M. Metabolic syndrome and periodontitis: is oxidative stress a common link? J Dent Res. 2009;88(6):503-18.

133. Kim Y-K, Myint A-M, Lee B-H, Han C-S, Lee H-J, Kim D-J, et al. Th1, Th2 and Th3 cytokine alteration in schizophrenia. Prog Neuropsychopharmacol Biol Psychiatry. 2004;28(7):1129-34.

134. Rapaport MH, McAllister CG, Pickar D, Nelson DL, Paul SM. Elevated levels of soluble interleukin 2 receptors in schizophrenia. Arch Gen Psychiatry. 1989;46(3):291-2.
135. Cazzullo C, Sacchetti E, Galluzzo A, Panariello A, Colombo F, Zagliani A, et al. Cytokine profiles in drug-naive schizophrenic patients. Schizophr Res. 2001;47(2-3):293-8.

136. Moises HW, Schindler L, Leroux M, Kirchner H. Decreased production of interferon alpha and interferon gamma in leucocyte cultures of schizophrenic patients. Acta Psychiatr Scand. 1985;72(1):45-50.

137. Stertz L, Magalhães PV, Kapczinski F. Is bipolar disorder an inflammatory condition? The relevance of microglial activation. Current opinion in psychiatry. 2013;26(1):19-26.

138. Goldstein BI, Kemp DE, Soczynska JK, McIntyre RS. Inflammation and the phenomenology, pathophysiology, comorbidity, and treatment of bipolar disorder: a systematic review of the literature. Journal of Clinical Psychiatry. 2009;70(8):1078.

139. Berk M, Kapczinski F, Andreazza A, Dean O, Giorlando F, Maes $M$, et al. Pathways underlying neuroprogression in bipolar disorder: focus on inflammation, oxidative stress and neurotrophic factors. Neuroscience $\&$ biobehavioral reviews. 2011;35(3):804-17.

140. Brietzke E, Stertz L, Fernandes BS, Kauer-Sant'Anna M, Mascarenhas M, Vargas AE, et al. Comparison of cytokine levels in depressed, manic and euthymic patients with bipolar disorder. Journal of affective disorders. 2009;116(3):214-7.

141. Myint A-M, Leonard BE, Steinbusch HW, Kim Y-K. Th1, Th2, and Th3 cytokine alterations in major depression. Journal of affective disorders. 2005;88(2):167-73.

142. Kaestner F, Hettich M, Peters M, Sibrowski W, Hetzel G, Ponath $G$, et al. Different activation patterns of proinflammatory cytokines in melancholic and non-melancholic major depression are associated with HPA axis activity. Journal of affective disorders. 2005;87(2-3):305-11.

143. Schiepers OJ, Wichers MC, Maes M. Cytokines and major depression. Prog Neuropsychopharmacol Biol Psychiatry. 2005;29(2):201-17.

144. Maes M. Cytokines in major depression. 1994.

145. Brundin L, Erhardt S, Bryleva E, Achtyes ED, Postolache T. The role of inflammation in suicidal behaviour. Acta Psychiatr Scand. 2015;132(3):192-203.

146. Wyss-Coray T. Inflammation in Alzheimer disease: driving force, bystander or beneficial response? Nat Med. 2006;12(9):1005.

147. Black C, Miller BJ. Meta-analysis of cytokines and chemokines in suicidality: distinguishing suicidal versus nonsuicidal patients. Biol Psychiatry. 2015;78(1):28-37.

148. Ducasse D, Olié E, Guillaume S, Artéro S, Courtet P. A metaanalysis of cytokines in suicidal behavior. Brain Behav Immun. 2015;46:203-11.

149. Serafini G, Pompili M, Seretti ME, Stefani H, Palermo M, Coryell W, et al. The role of inflammatory cytokines in suicidal behavior: a systematic review. Eur Neuropsychopharmacol. 2013;23(12):1672-86.

150. Tonelli LH, Stiller J, Rujescu D, Giegling I, Schneider B, Maurer $\mathrm{K}$, et al. Elevated cytokine expression in the orbitofrontal cortex of victims of suicide. Acta Psychiatr Scand. 2008;117(3):198206.

151. Steiner J, Bielau H, Brisch R, Danos P, Ullrich O, Mawrin C, et al. Immunological aspects in the neurobiology of suicide: elevated microglial density in schizophrenia and depression is associated with suicide. J Psychiatr Res. 2008;42(2):151-7. 
152. Mann JJ, Arango VA, Avenevoli S, Brent DA, Champagne FA, Clayton P, et al. Candidate endophenotypes for genetic studies of suicidal behavior. Biol Psychiatry. 2009;65(7):556-63.

153. Hassanain M, Bhatt S, Zalcman S, Siegel A. Potentiating role of interleukin-1beta (IL-1beta) and IL-1beta type 1 receptors in the medial hypothalamus in defensive rage behavior in the cat. Brain Res. 2005;1048(1-2):1-11.

154. Bhatt S, Bhatt R, Zalcman SS, Siegel A. Role of IL-1 beta and $5-\mathrm{HT} 2$ receptors in midbrain periaqueductal gray (PAG) in potentiating defensive rage behavior in cat. Brain Behav Immun. 2008;22(2):224-33.

155. Dunn AJ. Effects of cytokines and infections on brain neurochemistry. Clin Neurosci Res. 2006;6(1-2):52-68.

156. Pandey GN, Rizavi HS, Ren X, Fareed J, Hoppensteadt DA, Roberts RC, et al. Proinflammatory cytokines in the prefrontal cortex of teenage suicide victims. J Psychiatr Res. 2012;46(1):57-63.

157. Lindqvist D, Janelidze S, Hagell P, Erhardt S, Samuelsson M, Minthon L, et al. Interleukin- 6 is elevated in the cerebrospinal fluid of suicide attempters and related to symptom severity. Biol Psychiatry. 2009;66(3):287-92.

158. Celik C, Erdem M, Cayci T, Ozdemir B, Ozgur Akgul E, Kurt YG, et al. The association between serum levels of neopterin and number of depressive episodes of major depression. Prog Neuropsychopharmacol Biol Psychiatry. 2010;34(2):372-5.

159. Hoekstra R, Fekkes D, Pepplinkhuizen L, Loonen A, Tuinier S, Verhoeven W. Nitric oxide and neopterin in bipolar affective disorder. Neuropsychobiology. 2006;54(1):75-81.

160. Korte S, Arolt V, Peters M, Weitzsch C, Rothermundt M, Kirchner $\mathrm{H}$. Increased serum neopterin levels in acutely ill and recovered schizophrenic patients. Schizophr Res. 1998;32(1):63-7.

161. Sperner-Unterweger B, Barnas C, Fleischhacker WW, Fuchs D, Meise U, Reibnegger G, et al. Is schizophrenia linked to alteration in cellular immunity? Schizophr Res. 1989;2(4):41721.

162. Dunbar P, Hill J, Neale T, Mellsop G. Neopterin measurement provides evidence of altered cell-mediated immunity in patients with depression, but not with schizophrenia. Psychol Med. 1992;22(4):1051-7.

163. Taymur I, Ozdel K, Ozen NE, Gungor BB, Atmaca M. Urinary neopterine levels in patients with major depressive disorder: alterations after treatment with paroxetine and comparison with healthy controls. Psychiatr Danub. 2015;27(1):25-30.

164. Abou-Saleh MT, Anderson DN, Collins J, Hughes K, Cattell RJ, Hamon CG, et al. The role of pterins in depression and the effects of antidepressive therapy. Biol Psychiatry. 1995;38(7):458-63.

165. Tang CZ, Zhang YL, Wang WS, Li WG, Shi JP. Elevated Serum Levels of Neopterin at Admission Predicts Depression After Acute Ischemic Stroke: a 6-Month Follow-Up Study. Mol Neurobiol. 2016;53(5):3194-204.

166. Chittiprol S, Venkatasubramanian G, Neelakantachar N, Babu SS, Reddy NA, Shetty KT, et al. Oxidative stress and neopterin abnormalities in schizophrenia: a longitudinal study. J Psychiatr Res. 2010;44(5):310-3.

167. Mattila KJ, Valle MS, Nieminen MS, Valtonen VV, Hietaniemi KL. Dental infections and coronary atherosclerosis. Atherosclerosis. 1993;103(2):205-11.

168. Soto-Barreras U, Olvera-Rubio JO, Loyola-Rodriguez JP, Reyes-Macias JF, Martinez-Martinez RE, Patino-Marin N, et al. Peripheral arterial disease associated with caries and periodontal disease. J Periodontol. 2013;84(4):486-94.

169. Chen YW, Umeda M, Nagasawa T, Takeuchi Y, Huang Y, Inoue Y, et al. Periodontitis may increase the risk of peripheral arterial disease. Eur J Vasc Endovasc Surg. 2008;35(2):153-8.

170. Sfyroeras GS, Roussas N, Saleptsis VG, Argyriou C, Giannoukas AD. Association between periodontal disease and stroke. J Vasc Surg. 2012;55(4):1178-84.

171. Leng WD, Zeng XT, Kwong JS, Hua XP. Periodontal disease and risk of coronary heart disease: An updated meta-analysis of prospective cohort studies. Int J Cardiol. 2015;201:469-72.

172. Lockhart PB, Bolger AF, Papapanou PN, Osinbowale O, Trevisan $M$, Levison ME, et al. Periodontal disease and atherosclerotic vascular disease: does the evidence support an independent association? A scientific statement from the American Heart Association. Circulation. 2012;125(20):2520-44.

173. Humphrey LL, Fu R, Buckley DI, Freeman M, Helfand M. Periodontal disease and coronary heart disease incidence: a systematic review and meta-analysis. J Gen Intern Med. 2008;23(12):2079-86.

174. Rutger Persson G, Ohlsson O, Pettersson T, Renvert S. Chronic periodontitis, a significant relationship with acute myocardial infarction. Eur Heart J. 2003;24(23):2108-15.

175. Cueto A, Mesa F, Bravo M, Ocaña-Riola R. Periodontitis as risk factor for acute myocardial infarction. A case control study of Spanish adults. J Periodontal Res. 2005;40(1):36-42.

176. Andriankaja OM, Genco RJ, Dorn J, Dmochowski J, Hovey $\mathrm{K}$, Falkner KL, et al. The use of different measurements and definitions of periodontal disease in the study of the association between periodontal disease and risk of myocardial infarction. J Periodontol. 2006;77(6):1067-73.

177. Andriankaja OM, Genco RJ, Dorn J, Dmochowski J, Hovey K, Falkner KL, et al. Periodontal disease and risk of myocardial infarction: the role of gender and smoking. Eur J Epidemiol. 2007;22(10):699-705.

178. Renvert S, Ohlsson O, Pettersson T, Persson GR. Periodontitis: a future risk of acute coronary syndrome? A follow-up study over 3 years. J Periodontol. 2010;81(7):992-1000.

179. Holmlund A, Hedin M, Pussinen PJ, Lerner UH, Lind L. Porphyromonas gingivalis $(\mathrm{Pg})$ a possible link between impaired oral health and acute myocardial infarction. Int J Cardiol. 2011;148(2):148-53.

180. Samani MK, Jalali F, Ahadi SMS, Hoseini SR, Sattari FD. The relationship between acute myocardial infarction and periodontitis. Caspian J Intern Med. 2013;4(2):667.

181. Li P, He L, Sha Y, Luan Q. Periodontal status of patients with post-acute myocardial infarction. Beijing Da Xue Xue Bao Yi Xue Ban. 2013;45(1):22-6.

182. Kodovazenitis G, Pitsavos C, Papadimitriou L, Vrotsos I, Stefanadis C, Madianos P. Association between periodontitis and acute myocardial infarction: a case-control study of a nondiabetic population. J Periodontal Res. 2014;49(2):246-52.

183. Rydén L, Buhlin K, Ekstrand E, de Faire U, Gustafsson A, Holmer J, et al. Periodontitis increases the risk of a first myocardial infarction: a report from the PAROKRANK study. Circulation. 2016:CIRCULATIONAHA. 115.020324.

184. Yu YH, Chasman DI, Buring JE, Rose L, Ridker PM. Cardiovascular risks associated with incident and prevalent periodontal disease. J Clin Periodontol. 2015;42(1):21-8. 
185. Holmlund A, Holm G, Lind L. Severity of periodontal disease and number of remaining teeth are related to the prevalence of myocardial infarction and hypertension in a study based on 4,254 subjects. J Periodontol. 2006;77(7):1173-8.

186. Bazile A, Bissada NF, Nair R, Siegel BP. Periodontal assessment of patients undergoing angioplasty for treatment of coronary artery disease. J Periodontol. 2002;73(6):631-6.

187. Buhlin K, Gustafsson A, Hakansson J, Klinge B. Oral health and cardiovascular disease in Sweden. J Clin Periodontol. 2002;29(3):254-9.

188. Parkar SM, Modi GN, Jani J. Periodontitis as risk factor for acute myocardial infarction: A case control study. Heart Views. 2013;14(1):5-11.

189. Joshipura KJ, Rimm EB, Douglass CW, Trichopoulos D, Ascherio A, Willett WC. Poor oral health and coronary heart disease. I Dent Res. 1996;75(9):1631-6.

190. Howell TH, Ridker PM, Ajani UA, Hennekens CH, Christen WG. Periodontal disease and risk of subsequent cardiovascular disease in U.S. male physicians. J Am Coll Cardiol. 2001;37(2):445-50.

191. Willershausen I, Weyer V, Peter M, Weichert C, Kasaj A, Munze $\mathrm{T}$, et al. Association between chronic periodontal and apical inflammation and acute myocardial infarction. Odontology. 2014;102(2):297-302.

192. Mattila KJ, Nieminen MS, Valtonen VV, Rasi VP, Kesaniemi YA, Syrjala SL, et al. Association between dental health and acute myocardial infarction. BMJ. 1989;298(6676):779-81.

193. Chou SH, Tung YC, Lin YS, Wu LS, Lin CP, Liou EJ, et al. Major Adverse Cardiovascular Events in Treated Periodontitis: A Population-Based Follow-Up Study from Taiwan. PLoS One. 2015;10(6):e0130807.

194. Emingil G, Buduneli E, Aliyev A, Akilli A, Atilla G. Association between periodontal disease and acute myocardial infarction. J Periodontol. 2000;71(12):1882-6.

195. Amoian B, Maboudi A, Abbasi V. A periodontal health assessment of hospitalized patients with myocardial infarction. Caspian J Intern Med. 2011;2(2):234-9.

196. Wozakowska-Kaplon B, Wlosowicz M, Gorczyca-Michta I, Gorska R. Oral health status and the occurrence and clinical course of myocardial infarction in hospital phase: a casecontrol study. Cardiol J. 2013;20(4):370-7.

197. Bahekar AA, Singh S, Saha S, Molnar J, Arora R. The prevalence and incidence of coronary heart disease is significantly increased in periodontitis: a meta-analysis. Am Heart J. 2007;154(5):830-7

198. DeStefano F, Anda RF, Kahn HS, Williamson DF, Russell CM. Dental disease and risk of coronary heart disease and mortality. BMJ. 1993;306(6879):688-91.

199. Madianos PN, Bobetsis GA, Kinane DF. Is periodontitis associated with an increased risk of coronary heart disease and preterm and/or low birth weight births? J Clin Periodontol. 2002;29 Suppl 3:22-36; discussion 7-8.

200. Janket SJ, Baird AE, Chuang SK, Jones JA. Meta-analysis of periodontal disease and risk of coronary heart disease and stroke. Oral Surg Oral Med Oral Pathol Oral Radiol Endod. 2003;95(5):559-69.

201. Scannapieco FA, Bush RB, Paju S. Associations between periodontal disease and risk for atherosclerosis, cardiovascular disease, and stroke. A systematic review. Ann Periodontol. 2003;8(1):38-53.
202. Khader YS, Albashaireh ZS, Alomari MA. Periodontal diseases and the risk of coronary heart and cerebrovascular diseases: a meta-analysis. J Periodontol. 2004;75(8):1046-53.

203. Mustapha IZ, Debrey S, Oladubu M, Ugarte R. Markers of systemic bacterial exposure in periodontal disease and cardiovascular disease risk: a systematic review and metaanalysis. J Periodontol. 2007;78(12):2289-302.

204. Blaizot A, Vergnes JN, Nuwwareh S, Amar J, Sixou M. Periodontal diseases and cardiovascular events: meta-analysis of observational studies. Int Dent J. 2009;59(4):197-209.

205. Pressman GS, Qasim A, Verma N, Miyamae M, Arishiro K, Notohara Y, et al. Periodontal disease is an independent predictor of intracardiac calcification. Biomed Res Int. 2013;2013:854340.

206. Groves DW, Krantz MJ, Hokanson JE, Johnson LR, Eckel RH, Kinney GL, et al. Comparison of Frequency and Duration of Periodontal Disease With Progression of Coronary Artery Calcium in Patients With and Without Type 1 Diabetes Mellitus. Am J Cardiol. 2015;116(6):833-7.

207. Beck JD, Offenbacher S, Williams R, Gibbs P, Garcia R. Periodontitis: a risk factor for coronary heart disease? Ann Periodontol. 1998;3(1):127-41.

208. Mattila K, Valtonen V, Nieminen M, Huttunen JK. Dental infection and the risk of new coronary events: prospective study of patients with documented coronary artery disease. Clin Infect Dis. 1995;20(3):588-92.

209. Syrjänen J, Peltola J, Valtonen V, livanainen M, Kaste $M$, Huttunen J. Dental infections in association with cerebral infarction in young and middle-aged men. J Intern Med. 1989;225(3):179-84.

210. Teeuw WJ, Slot DE, Susanto H, Gerdes VE, Abbas F, D'Aiuto F, et al. Treatment of periodontitis improves the atherosclerotic profile: a systematic review and meta-analysis. J Clin Periodontol. 2014;41(1):70-9.

211. Schmitt A, Carra MC, Boutouyrie P, Bouchard P. Periodontitis and arterial stiffness: a systematic review and meta-analysis. J Clin Periodontol. 2015;42(11):977-87.

212. O'Leary DH, Polak JF, Kronmal RA, Manolio TA, Burke GL, Wolfson SK, Jr. Carotid-artery intima and media thickness as a risk factor for myocardial infarction and stroke in older adults. Cardiovascular Health Study Collaborative Research Group. N Engl J Med. 1999;340(1):14-22.

213. Beck JD, Elter JR, Heiss G, Couper D, Mauriello SM, Offenbacher S. Relationship of periodontal disease to carotid artery intimamedia wall thickness: the atherosclerosis risk in communities (ARIC) study. Arterioscler Thromb Vasc Biol. 2001;21(11):181622.

214. Ravon NA, Hollender LG, McDonald V, Persson GR. Signs of carotid calcification from dental panoramic radiographs are in agreement with Doppler sonography results. J Clin Periodontol. 2003;30(12):1084-90.

215. Tapashetti RP, Guvva S, Patil SR, Sharma S, Pushpalatha HM. C-reactive Protein as Predict of Increased Carotid Intima Media Thickness in Patients with Chronic Periodontitis. J Int Oral Health. 2014;6(4):47-52.

216. Lafon A, Pereira B, Dufour T, Rigouby V, Giroud M, Bejot Y, et al. Periodontal disease and stroke: a meta-analysis of cohort studies. Eur J Neurol. 2014;21(9):1155-61, e66-7.

217. Ahn YB, Shin MS, Han DH, Sukhbaatar M, Kim MS, Shin HS, et al. Periodontitis is associated with the risk of subclinical 
atherosclerosis and peripheral arterial disease in Korean adults. Atherosclerosis. 2016;251:311-8.

218. Calapkorur MU, Alkan BA, Tasdemir Z, Akcali Y, Saatci E. Association of peripheral arterial disease with periodontal disease: analysis of inflammatory cytokines and an acute phase protein in gingival crevicular fluid and serum. J Periodontal Res. 2017;52(3):532-9.

219. Aoyama N, Suzuki JI, Kobayashi N, Hanatani T, Ashigaki N, Yoshida A, et al. Periodontitis deteriorates peripheral arterial disease in Japanese population via enhanced systemic inflammation. Heart Vessels. 2017;32(11):1314-9.

220. Mendez MV, Scott T, LaMorte W, Vokonas P, Menzoian JO, Garcia R. An association between periodontal disease and peripheral vascular disease. Am J Surg. 1998;176(2):153-7.

221. Hung HC, Willett W, Merchant A, Rosner BA, Ascherio A, Joshipura KJ. Oral health and peripheral arterial disease. Circulation. 2003;107(8):1152-7.

222. Yang S, Zhao LS, Cai C, Shi Q, Wen N, Xu J. Association between periodontitis and peripheral artery disease: a systematic review and meta-analysis. BMC Cardiovasc Disord. 2018;18(1):141

223. Kebschull M, Demmer RT, Papapanou PN. "Gum bug, leave my heart alone!"--epidemiologic and mechanistic evidence linking periodontal infections and atherosclerosis. J Dent Res. 2010;89(9):879-902.

224. Joshipura K, Ritchie C, Douglass C. Strength of evidence linking oral conditions and systemic disease. Compend Contin Educ Dent Suppl. 2000(30):12-23; quiz 65.

225. Li C, Lv Z, Shi Z, Zhu Y, Wu Y, Li L, et al. Periodontal therapy for the management of cardiovascular disease in patients with chronic periodontitis. Cochrane Database Syst Rev. 2014(8):Cd009197.

226. Joshipura KJ, Douglass CW, Willett WC. Possible explanations for the tooth loss and cardiovascular disease relationship. Ann Periodontol. 1998;3(1):175-83.

227. Suvan J, D’Aiuto F, Moles DR, Petrie A, Donos N. Association between overweight/obesity and periodontitis in adults. A systematic review. Obes Rev. 2011;12(5):e381-404.

228. Saito T, Shimazaki Y, Sakamoto M. Obesity and periodontitis. N Engl J Med. 1998;339(7):482-3.

229. Saito T, Shimazaki Y, Koga T, Tsuzuki M, Ohshima A. Relationship between upper body obesity and periodontitis. J Dent Res. 2001;80(7):1631-6.

230. Modéer T, Blomberg C, Wondimu B, Lindberg TY, Marcus C. Association between obesity and periodontal risk indicators in adolescents. Int J Pediatr Obes. 2011;6(2-2):e264-70.

231. Sakki TK, Knuuttila ML, Vimpari SS, Hartikainen MS. Association of lifestyle with periodontal health. Community Dent Oral Epidemiol. 1995;23(3):155-8.

232. Wakai K, Kawamura T, Umemura O, Hara Y, Machida J, Anno T, et al. Associations of medical status and physical fitness with periodontal disease. J Clin Periodontol. 1999;26(10):664-72.

233. Gortmaker SL, Dietz WH, Jr., Cheung LW. Inactivity, diet, and the fattening of America. J Am Diet Assoc. 1990;90(9):1247-52, 55.

234. Ching PL, Willett WC, Rimm EB, Colditz GA, Gortmaker SL, Stampfer MJ. Activity level and risk of overweight in male health professionals. Am J Public Health. 1996;86(1):25-30.

235. Coakley EH, Rimm EB, Colditz G, Kawachi I, Willett W. Predictors of weight change in men: results from the Health Professionals
Follow-up Study. Int J Obes Relat Metab Disord. 1998;22(2):8996.

236. Hu FB, Sigal RJ, Rich-Edwards JW, Colditz GA, Solomon CG, Willett WC, et al. Walking compared with vigorous physical activity and risk of type 2 diabetes in women: a prospective study. JAMA. 1999;282(15):1433-9.

237. Goodyear LJ, Kahn BB. Exercise, glucose transport, and insulin sensitivity. Annu Rev Med. 1998;49:235-61.

238. Borghouts LB, Keizer HA. Exercise and insulin sensitivity: a review. Int J Sports Med. 2000;21(1):1-12.

239. Chavarry NG, Vettore MV, Sansone C, Sheiham A. The relationship between diabetes mellitus and destructive periodontal disease: a meta-analysis. Oral Health Prev Dent. 2009;7(2):107-27.

240. Khader YS, Dauod AS, El-Qaderi SS, Alkafajei A, Batayha WQ. Periodontal status of diabetics compared with nondiabetics: a meta-analysis. J Diabetes Complications. 2006;20(1):59-68.

241. Mealey BL, Oates TW. Diabetes mellitus and periodontal diseases. J Periodontol. 2006;77(8):1289-303.

242. Marigo L, Cerreto R, Giuliani M, Somma F, Lajolo C, Cordaro M. Diabetes mellitus: biochemical, histological and microbiological aspects in periodontal disease. Eur Rev Med Pharmacol Sci. 2011;15(7):751-8.

243. Taylor GW, Borgnakke WS. Periodontal disease: associations with diabetes, glycemic control and complications. Oral Dis. 2008;14(3):191-203.

244. Emrich LJ, Shlossman M, Genco RJ. Periodontal disease in non-insulin-dependent diabetes mellitus. J Periodontol. 1991;62(2):123-31.

245. Sandler HC, Stahl SS. Prevalence of periodontal disease in a hospitalized population. J Dent Res. 1960;39:439-49.

246. Christgau M, Palitzsch KD, Schmalz G, Kreiner U, Frenzel $S$. Healing response to non-surgical periodontal therapy in patients with diabetes mellitus: clinical, microbiological, and immunologic results. J Clin Periodontol. 1998;25(2):112-24.

247. Seppala B, Seppala M, Ainamo J. A longitudinal study on insulin-dependent diabetes mellitus and periodontal disease. J Clin Periodontol. 1993;20(3):161-5.

248. Hintao J, Teanpaisan R, Chongsuvivatwong V, Ratarasan C, Dahlen G. The microbiological profiles of saliva, supragingival and subgingival plaque and dental caries in adults with and without type 2 diabetes mellitus. Oral Microbiol Immunol. 2007;22(3):175-81.

249. Taylor GW, Manz MC, Borgnakke WS. Diabetes, periodontal diseases, dental caries, and tooth loss: a review of the literature. Compend Contin Educ Dent Suppl. 2004;25(3):17984, 86-8, 90; quiz 92.

250. Dodds MW, Yeh CK, Johnson DA. Salivary alterations in type 2 (non-insulin-dependent) diabetes mellitus and hypertension. Community Dent Oral Epidemiol. 2000;28(5):373-81.

251. Rees TD. Periodontal management of the patient with diabetes mellitus. Periodontol 2000. 2000;23:63-72.

252. Sandberg GE, Sundberg HE, Wikblad KF. A controlled study of oral self-care and self-perceived oral health in type 2 diabetic patients. Acta Odontol Scand. 2001;59(1):28-33.

253. Ainamo J, Lahtinen A, Uitto VJ. Rapid periodontal destruction in adult humans with poorly controlled diabetes. A report of 2 cases. J Clin Periodontol. 1990;17(1):22-8. 
254. Tsai C, Hayes C, Taylor GW. Glycemic control of type 2 diabetes and severe periodontal disease in the US adult population. Community Dent Oral Epidemiol. 2002;30(3):182-92.

255. Taylor GW, Burt BA, Becker MP, Genco RJ, Shlossman M. Glycemic control and alveolar bone loss progression in type 2 diabetes. Ann Periodontol. 1998;3(1):30-9.

256. Taylor GW. Periodontal treatment and its effects on glycemic control: A review of the evidence. Oral Surg Oral Med Oral Pathol Oral Radiol Endod. 1999;87(3):311-6.

257. Katz PP, Wirthlin MR, Jr., Szpunar SM, Selby JV, Sepe SJ, Showstack JA. Epidemiology and prevention of periodontal disease in individuals with diabetes. Diabetes Care. 1991;14(5):375-85.

258. Shlossman M, Knowler WC, Pettitt DJ, Genco RJ. Type 2 diabetes mellitus and periodontal disease. J Am Dent Assoc. (1939). 1990;121(4):532-6.

259. Tervonen T, Oliver RC. Long-term control of diabetes mellitus and periodontitis. J Clin Periodontol. 1993;20(6):431-5.

260. Soskolne WA. Epidemiological and clinical aspects of periodontal diseases in diabetics. Ann Periodontol. 1998;3(1):3-12.

261. Almas K, Al-Qahtani M, Al-Yami M, Khan N. The relationship between periodontal disease and blood glucose level among type II diabetic patients. J Contemp Dent Pract. 2001;2(4):1825.

262. Sandberg GE, Sundberg HE, Fjellstrom CA, Wikblad KF. Type 2 diabetes and oral health: a comparison between diabetic and non-diabetic subjects. Diabetes Res Clin Pract. 2000;50(1):27 34.

263. Rajhans NS, Kohad RM, Chaudhari VG, Mhaske NH. A clinical study of the relationship between diabetes mellitus and periodontal disease. J Indian Soc Periodontol. 2011;15(4):388 92.

264. Khader YS, Albashaireh ZS, Hammad MM. Periodontal status of type 2 diabetics compared with nondiabetics in north Jordan. East Mediterr Health J. 2008;14(3):654-61.

265. Pathak A, Shakya V, Chandra A, Goel K. Association between diabetes mellitus and periodontal status in north Indian adults. European J Gen Dent. 2013;2(1):58-61.

266. Jenkins DJ, Axelsen M, Kendall CW, Augustin LS, Vuksan V, Smith U. Dietary fibre, lente carbohydrates and the insulinresistant diseases. Br J Nutr. 2000;83(S1):S157-S63.

267. Merchant AT, Pitiphat W, Franz M, Joshipura KJ. Whole-grain and fiber intakes and periodontitis risk in men. Am J Clin Nutr. 2006;83(6):1395-400

268. Zadik Y, Bechor R, Galor S, Levin L. Periodontal disease might be associated even with impaired fasting glucose. Br Dent J. 2010;208(10):E20.

269. Lalla E, Cheng B, Lal S, Tucker S, Greenberg E, Goland R, et al. Periodontal changes in children and adolescents with diabetes: a case-control study. Diabetes Care. 2006;29(2):2959.

270. Lalla E, Cheng B, Lal S, Kaplan S, Softness B, Greenberg E, et al. Diabetes-related parameters and periodontal conditions in children. J Periodontal Res. 2007;42(4):345-9.

271. Bakhshandeh S, Murtomaa H, Vehkalahti MM, Mofid R, Suomalainen K. Oral self-care and use of dental services among adults with diabetes mellitus. Oral Health Prev Dent. 2008;6(4):279-86.
272. Kneckt MC, Syrjala AM, Knuuttila ML. Attributions to dental and diabetes health outcomes. J Clin Periodontol. 2000;27(3):20511.

273. Kneckt MC, Keinanen-Kiukaanniemi SM, Knuuttila ML, Syrjala AM. Self-esteem as a characteristic of adherence to diabetes and dental self-care regimens. J Clin Periodontol. 2001;28(2):175-80.

274. Syrjala AM, Kneckt MC, Knuuttila ML. Dental self-efficacy as a determinant to oral health behaviour, oral hygiene and HbA1c level among diabetic patients. J Clin Periodontol. 1999;26(9):616-21.

275. Syrjala AM, Niskanen MC, Knuuttila ML. The theory of reasoned action in describing tooth brushing, dental caries and diabetes adherence among diabetic patients. J Clin Periodontol. 2002;29(5):427-32.

276. Merchant AT, Oranbandid S, Jethwani M, Choi YH, Morrato EH, Pitiphat W, et al. Oral care practices and A1c among youth with type 1 and type 2 diabetes. J Periodontol. 2012;83(7):856-63.

277. Lee HK, Choi SH, Won KC, Merchant AT, Song KB, Jeong SH, et al. The effect of intensive oral hygiene care on gingivitis and periodontal destruction in type 2 diabetic patients. Yonsei Med J. 2009;50(4):529-36.

278. Orlando VA, Johnson LR, Wilson AR, Maahs DM, Wadwa RP, Bishop FK, et al. Oral Health Knowledge and Behaviors among Adolescents with Type 1 Diabetes. Int J Dent. 2010;2010:942124.

279. Siudikiene J, Maciulskiene V, Dobrovolskiene R, Nedzelskiene I. Oral hygiene in children with type I diabetes mellitus. Stomatologija. 2005;7(1):24-7.

280. D’Aiuto F, Sabbah W, Netuveli G, Donos N, Hingorani AD, Deanfield J, et al. Association of the metabolic syndrome with severe periodontitis in a large U.S. population-based survey. J Clin Endocrinol Metab. 2008;93(10):3989-94.

281. Khader Y, Khassawneh B, Obeidat B, Hammad M, El-Salem K, Bawadi $\mathrm{H}$, et al. Periodontal status of patients with metabolic syndrome compared to those without metabolic syndrome. J Periodontol. 2008;79(11):2048-53.

282. Shimazaki Y, Saito T, Yonemoto K, Kiyohara Y, lida M, Yamashita Y. Relationship of metabolic syndrome to periodontal disease in Japanese women: the Hisayama Study. J Dent Res. 2007;86(3):271-5.

283. Cutler CW, Shinedling EA, Nunn M, Jotwani R, Kim BO, Nares S, et al. Association between periodontitis and hyperlipidemia: cause or effect? J Periodontol. 1999;70(12):1429-34.

284. Nishimura F, Murayama Y. Periodontal inflammation and insulin resistance--lessons from obesity. J Dent Res. 2001;80(8):16904.

285. Al-Zahrani MS, Borawski EA, Bissada NF. Periodontitis and three health-enhancing behaviors: maintaining normal weight, engaging in recommended level of exercise, and consuming a high-quality diet. J Periodontol. 2005;76(8):1362-6.

286. Chaffee BW, Weston SJ. Association between chronic periodontal disease and obesity: a systematic review and meta-analysis. J Periodontol. 2010;81(12):1708-24.

287. Marchetti E, Monaco A, Procaccini L, Mummolo S, Gatto R, Tete $S$, et al. Periodontal disease: the influence of metabolic syndrome. Nutr Metab (Lond). 2012;9(1):88.

288. Desvarieux M, Demmer RT, Jacobs DR, Jr., Rundek T, Boden-Albala B, Sacco RL, et al. Periodontal bacteria and 
hypertension: the oral infections and vascular disease epidemiology study (INVEST). J Hypertens. 2010;28(7):1413-21.

289. Lee KS, Lee SG, Kim EK, Jin HJ, Im SU, Lee HK, et al. Metabolic syndrome parameters in adolescents may be determinants for the future periodontal diseases. J Clin Periodontol. 2015;42(2):105-12.

290. Morita T, Ogawa Y, Takada K, Nishinoue N, Sasaki Y, Motohashi $\mathrm{M}$, et al. Association between periodontal disease and metabolic syndrome. J Public Health Dent. 2009;69(4):248-53.

291. Franchini R, Petri A, Migliario M, Rimondini L. Poor oral hygiene and gingivitis are associated with obesity and overweight status in paediatric subjects. J Clin Periodontol. 2011;38(11):1021-8.

292. Nishimura F, Iwamoto Y, Mineshiba J, Shimizu A, Soga Y, Murayama Y. Periodontal disease and diabetes mellitus: the role of tumor necrosis factor-alpha in a 2-way relationship. J Periodontol. 2003;74(1):97-102.

293. Lawrence D, Jablensky AV, Holman CD, Pinder TJ. Mortality in Western Australian psychiatric patients. Soc Psychiatry Psychiatr Epidemiol. 2000;35(8):341-7.

294. Mirza I, Day R, Phelan M, Wulff-Cochrane V. Oral health of psychiatric in-patients: a point prevalence survey of an innercity hospital. Psychiatric Bulletin. 2001;25(4):143-5.

295. Cullinan MP, Ford PJ, Seymour GJ. Periodontal disease and systemic health: current status. Aust Dent J. 2009;54 Suppl 1:S62-9.

296. Chapple IL. The impact of oral disease upon systemic healthSymposium overview. J Dent. 2009;37(8):S568-71.

297. Haumschild MS, Haumschild RJ. The importance of oral health in long-term care. J Am Med Dir Assoc. 2009;10(9):667-71.

298. Williams RC, Barnett AH, Claffey N, Davis M, Gadsby R, Kellett $M$, et al. The potential impact of periodontal disease on general health: a consensus view. Curr Med Res Opin. 2008;24(6):1635-43.

299. Desvarieux M, Demmer RT, Rundek T, Boden-Albala B, Jacobs DR, Jr., Papapanou PN, et al. Relationship between periodontal disease, tooth loss, and carotid artery plaque: the Oral Infections and Vascular Disease Epidemiology Study (INVEST). Stroke. 2003;34(9):2120-5.

300. Shultis WA, Weil EJ, Looker HC, Curtis JM, Shlossman M, Genco RJ, et al. Effect of periodontitis on overt nephropathy and end-stage renal disease in type 2 diabetes. Diabetes Care. 2007;30(2):306-11.

301. Azarpazhooh A, Leake JL. Systematic review of the association between respiratory diseases and oral health. J Periodontol. 2006;77(9):1465-82.

302. Scannapieco FA. Systemic effects of periodontal diseases. Dent Clin North Am. 2005;49(3):533-50, vi.

303. Angelillo IF, Nobile CG, Pavia M, De Fazio P, Puca M, Amati A. Dental health and treatment needs in institutionalized psychiatric patients in Italy. Community Dent Oral Epidemiol. 1995;23(6):360-4.

304. Burchell A, Fernbacher S, Lewis R, Neil A. “Dental as Anything” Inner South Community Health Service Dental Outreach to People with a Mental Illness. Aust J Prim Health. 2006;12(2):7582.

305. Rekha R, Hiremath SS. Oral health status and treatment requirments of confectionery workers in Bangalore city. A comparative study. Indian J Dent Res. 2002;13(3-4):161-5.
306. Tang WK, Sun FC, Ungvari GS, O'Donnell D. Oral health of psychiatric in-patients in Hong Kong. Int J Soc Psychiatry. 2004;50(2):186-91.

307. Kisely S, Baghaie H, Lalloo R, Siskind D, Johnson NW. A systematic review and meta-analysis of the association between poor oral health and severe mental illness. Psychosom Med. 2015;77(1):83-92.

308. Warren KR, Postolache TT, Groer ME, Pinjari O, Kelly DL, Reynolds MA. Role of chronic stress and depression in periodontal diseases. Periodontol 2000. 2014;64(1):127-38.

309. Alkan A, Cakmak O, Yilmaz S, Cebi T, Gurgan C. Relationship Between Psychological Factors and Oral Health Status and Behaviours. Oral Health Prev Dent. 2015;13(4):331-9.

310. O’Dowd LK, Durham J, McCracken GI, Preshaw PM. Patients' experiences of the impact of periodontal disease. J Clin Periodontol. 2010;37(4):334-9.

311. Beck AT. Cognitive therapy. A 30-year retrospective. Am Psychol. 1991;46(4):368-75.

312. Little JW. Dental implications of mood disorders. Gen Dent. 2004;52(5):442-50; quiz 51.

313. Clark DB. Dental care for the patient with bipolar disorder. J Can Dent Assoc. 2003;69(1):20-4.

314. Page MM. Psychotropic drugs and dentistry. Aust Prescr. 2007;30(4):98-101.

315. Cormac I, Jenkins P. Understanding the importance of oral health in psychiatric patients. Adv Psychiatr Treat. 1999;5(1):53-60.

316. American Psychiatric Association. Diagnostic and Statistical Manual of Mental Disorders 5th Edition. Washington, DC; 2013.

317. Coculescu EC, Radu A, Coculescu BI. Burning mouth syndrome: a review on diagnosis and treatment. J Med Life. 2014;7(4):5125.

318. Bardow A, Nyvad B, Nauntofte B. Relationships between medication intake, complaints of dry mouth, salivary flow rate and composition, and the rate of tooth demineralization in situ. Arch Oral Biol. 2001;46(5):413-23.

319. Lewis S, Jagger RG, Treasure E. The oral health of psychiatric in-patients in South Wales. Spec Care Dentist. 2001;21(5):1826.

320. Ramon T, Grinshpoon A, Zusman SP, Weizman A. Oral health and treatment needs of institutionalized chronic psychiatric patients in Israel. Eur Psychiatry. 2003;18(3):101-5.

321. Lo Russo L, Campisi G, Di Fede O, Di Liberto C, Panzarella V, Lo Muzio L. Oral manifestations of eating disorders: a critical review. Oral Dis. 2008;14(6):479-84.

322. Milosevic A. Eating disorders and the dentist. Br Dent J. 1999;186(3):109-13.

323. Lalloo R, Kisely S, Amarasinghe H, Perera R, Johnson N. Oral health of patients on psychotropic medications: a study of outpatients in Queensland. Australas Psychiatry. 2013;21(4):338-42.

324. Bretz WA. Oral profiles of bulimic women: Diagnosis and management. What is the evidence? J Evid Based Dent Pract. 2002;2(4):267-72.

325. Ebersole JL, Cappelli D. Acute-phase reactants in infections and inflammatory diseases. Periodontol 2000. 2000;23:19-49.

326. Loos BG. Systemic markers of inflammation in periodontitis. J Periodontol. 2005;76(11 Suppl):2106-15. 
327. Kweider M, Lowe GD, Murray GD, Kinane DF, McGowan DA. Dental disease, fibrinogen and white cell count; links with myocardial infarction? Scott Med J. 1993;38(3):73-4.

328. Slade GD, Offenbacher S, Beck JD, Heiss G, Pankow JS. Acutephase inflammatory response to periodontal disease in the US population. J Dent Res. 2000;79(1):49-57.

329. Wu T, Trevisan M, Genco RJ, Falkner KL, Dorn JP, Sempos CT. Examination of the relation between periodontal health status and cardiovascular risk factors: serum total and high density lipoprotein cholesterol, C-reactive protein, and plasma fibrinogen. Am J Epidemiol. 2000;151(3):273-82.

330. Ridker PM, Buring JE, Shih J, Matias M, Hennekens CH. Prospective study of $\mathrm{C}$-reactive protein and the risk of future cardiovascular events among apparently healthy women. Circulation. 1998;98(8):731-3.

331. Ridker PM, Hennekens CH, Buring JE, Rifai N. C-reactive protein and other markers of inflammation in the prediction of cardiovascular disease in women. N Engl J Med. 2000;342(12):836-43.

332. Bazzoni F, Beutler B. The tumor necrosis factor ligand and receptor families. N Engl J Med. 1996;334(26):1717-25.

333. Skoog T, Dichtl W, Boquist S, Skoglund-Andersson C, Karpe F, Tang $R$, et al. Plasma tumour necrosis factor-alpha and early carotid atherosclerosis in healthy middle-aged men. Eur Heart J. 2002;23(5):376-83.

334. Joshipura KJ, Wand HC, Merchant AT, Rimm EB. Periodontal disease and biomarkers related to cardiovascular disease. J Dent Res. 2004;83(2):151-5.

335. Moutsopoulos NM, Madianos PN. Low-grade inflammation in chronic infectious diseases: paradigm of periodontal infections. Ann N Y Acad Sci. 2006;1088:251-64.

336. Ebersole JL, Machen RL, Steffen MJ, Willmann DE. Systemic acute-phase reactants, C-reactive protein and haptoglobin, in adult periodontitis. Clin Exp Immunol. 1997;107(2):347-52.

337. Noack B, Genco RJ, Trevisan M, Grossi S, Zambon JJ, De Nardin E. Periodontal infections contribute to elevated systemic C-reactive protein level. J Periodontol. 2001;72(9):1221-7.

338. Buhlin K, Hultin M, Norderyd O, Persson L, Pockley AG, Rabe $P$, et al. Risk factors for atherosclerosis in cases with severe periodontitis. J Clin Periodontol. 2009;36(7):541-9.

339. Gomes-Filho IS, Freitas Coelho JM, da Cruz SS, Passos JS, Teixeira de Freitas CO, Aragao Farias NS, et al. Chronic periodontitis and C-reactive protein levels. J Periodontol. 2011;82(7):969-78.

340. Pejcic A, Kesic LJ, Milasin J. C-reactive protein as a systemic marker of inflammation in periodontitis. Eur J Clin Microbiol Infect Dis. 2011;30(3):407-14.

341. Schwahn C, Völzke H, Robinson DM, Luedemann J, Bernhardt $\mathrm{O}$, Gesch D, et al. Periodontal disease, but not edentulism, is independently associated with increased plasma fibrinogen levels. Thromb Haemost. 2004;92(02):244-52.

342. Kweider M, Lowe G, Murray G, Kinane D, McGowan D. Dental disease, fibrinogen and white cell count; links with myocardial infarction? Scott Med J. 1993;38(3):73-4.

343. Zheng P, Chen H, Shi S, Jepsen S, Eberhard J. Periodontal parameters and platelet-activating factor levels in serum and gingival crevicular fluid in a Chinese population. J Clin Periodontol. 2006;33(11):797-802.

344. Chen H, Zheng P, Zhu H, Zhu J, Zhao L, El Mokhtari NE, et al. Platelet-activating factor levels of serum and gingival crevicular fluid in nonsmoking patients with periodontitis and/or coronary heart disease. Clin Oral Investig. 2010;14(6):629-36.

345. Loos BG, Craandijk J, Hoek FJ, Wertheim-van Dillen PM, van der Velden U. Elevation of systemic markers related to cardiovascular diseases in the peripheral blood of periodontitis patients. J Periodontol. 2000;71(10):1528-34.

346. Passoja A, Puijola I, Knuuttila M, Niemelä O, Karttunen R, Raunio T, et al. Serum levels of interleukin-10 and tumour necrosis factor- $\alpha$ in chronic periodontitis. J Clin Periodontol. 2010;37(10):881-7.

347. Preshaw PM, Taylor JJ. How has research into cytokine interactions and their role in driving immune responses impacted our understanding of periodontitis? J Clin Periodontol. 2011;38 Suppl 11:60-84.

348. Teles R, Wang CY. Mechanisms involved in the association between periodontal diseases and cardiovascular disease. Oral Dis. 2011;17(5):450-61.

349. Dewhirst FE, Chen T, Izard J, Paster BJ, Tanner AC, Yu W-H, et al. The human oral microbiome. J Bacteriol. 2010;192(19):5002-17.

350. Sconyers JR, Crawford J, Moriarty J. Relationship of bacteremia to toothbrushing in patients with periodontitis. J Am Dent Assoc. 1973;87(3):616-22.

351. Forner L, Larsen T, Kilian M, Holmstrup P. Incidence of bacteremia after chewing, tooth brushing and scaling in individuals with periodontal inflammation. J Clin Periodontol. 2006;33(6):401-7.

352. Cahill TJ, Harrison JL, Jewell P, Onakpoya I, Chambers JB, Dayer $M$, et al. Antibiotic prophylaxis for infective endocarditis: a systematic review and meta-analysis. Heart. 2017;103(12):93744.

353. Nishimura RA, Otto CM, Bonow RO, Carabello BA, Erwin JP, Fleisher LA, et al. 2017 AHA/ACC focused update of the 2014 AHA/ACC guideline for the management of patients with valvular heart disease: a report of the American College of Cardiology/American Heart Association Task Force on Clinical Practice Guidelines. Leducq Transatlantic Network on Atherothrombosis. 2017;70(2):252-89.

354. Lazansky JP, Robinson L, Rodofsky L. Factors influencing the incidence of bacteremias following surgical procedures in the oral cavity. J Dent Res. 1949;28(6):533-43.

355. Tomás I, Diz P, Tobías A, Scully C, Donos N. Periodontal health status and bacteraemia from daily oral activities: systematic review/meta-analysis. J Clin Periodontol. 2012;39(3):213-28.

356. Tonetti MS, Van Dyke TE. Periodontitis and atherosclerotic cardiovascular disease: consensus report of the Joint EFP/ AAP Workshop on Periodontitis and Systemic Diseases. J Clin Periodontol. 2013;40 Suppl 14:S24-9.

357. Socransky SS, Haffajee AD. Periodontal microbial ecology. Periodontol 2000. 2005;38(1):135-87.

358. Moutsopoulos NM, Madianos PN. Low-grade inflammation in chronic infectious diseases. Ann N Y Acad Sci. 2006;1088(1):251-64.

359. Hayashi C, Gudino CV, Gibson FC, 3rd, Genco CA. Review: Pathogen-induced inflammation at sites distant from oral infection: bacterial persistence and induction of cell-specific innate immune inflammatory pathways. Mol Oral Microbiol. 2010;25(5):305-16.

360. Gibson FC, 3rd, Yumoto H, Takahashi Y, Chou HH, Genco CA. Innate immune signaling and Porphyromonas gingivalisaccelerated atherosclerosis. J Dent Res. 2006;85(2):106-21. 
361. Gibson FC, 3rd, Genco CA. Porphyromonas gingivalis mediated periodontal disease and atherosclerosis: disparate diseases with commonalities in pathogenesis through TLRs. Curr Pharm Des. 2007;13(36):3665-75.

362. Chiu B. Multiple infections in carotid atherosclerotic plaques. Am Heart J. 1999;138(5 Pt 2):S534-6.

363. Kozarov EV, Dorn BR, Shelburne CE, Dunn Jr WA, ProgulskeFox A. Human atherosclerotic plaque contains viable invasive Actinobacillus actinomycetemcomitans and Porphyromonas gingivalis. Arterioscler Thromb Vasc Biol. 2005;25(3):e17-e8.

364. Schenkein HA, Loos BG. Inflammatory Mechanisms Linking Periodontal Diseases to Cardiovascular Diseases. J Clin Periodontol. 2013;40(0 14):S51-S69.

365. Roth GA, Ankersmit HJ, Brown VB, Papapanou PN, Schmidt AM, Lalla E. Porphyromonas gingivalis infection and cell death in human aortic endothelial cells. FEMS Microbiol Lett. 2007;272(1):106-13.

366. Pober JS, Min W, Bradley JR. Mechanisms of endothelial dysfunction, injury, and death. Annu Rev Pathol. 2009;4:71-95.

367. Galis ZS, Khatri JJ. Matrix metalloproteinases in vascular remodeling and atherogenesis: the good, the bad, and the ugly. Circ Res. 2002;90(3):251-62.

368. Page RC. The pathobiology of periodontal diseases may affect systemic diseases: inversion of a paradigm. Ann Periodontol. 1998;3(1):108-20.

369. Hajishengallis G, Sharma A, Russell MW, Genco RJ. Interactions of oral pathogens with toll-like receptors: possible role in atherosclerosis. Ann Periodontol. 2002;7(1):72-8.

370. Söder PÖ, Meurman J, Jogestrand T, Nowak J, Söder B. Matrix metalloproteinase-9 and tissue inhibitor of matrix metalloproteinase-1 in blood as markers for early atherosclerosis in subjects with chronic periodontitis. J Periodontal Res. 2009;44(4):452-8.

371. Behle JH, Sedaghatfar MH, Demmer RT, Wolf DL, Celenti R, Kebschull M, et al. Heterogeneity of systemic inflammatory responses to periodontal therapy. J Clin Periodontol. 2009;36(4):287-94.

372. Schenkein HA, Barbour SE, Berry C, Kipps B, Tew JG. Invasion of human vascular endothelial cells by Actinobacillus actinomycetemcomitans via the receptor for platelet-activating factor. Infect Immun. 2000;68(9):5416-9.

373. Lösche W, Marshal G, Krause S, Kocher T, Kinane D. Lipoprotein-associated phospholipase A2 and plasma lipids in patients with destructive periodontal disease. J Clin Periodontol. 2005;32(6):640-4.

374. Black S, Kushner I, Samols D. C-reactive protein. J Biol Chem. 2004;279(47):48487-90.

375. Ridker PM, Brown NJ, Vaughan DE, Harrison DG, Mehta JL. Established and emerging plasma biomarkers in the prediction of first atherothrombotic events. Circulation. 2004;109(25 Suppl 1):Iv6-19.

376. Blake GJ, Ridker PM. High sensitivity C-reactive protein for predicting cardiovascular disease: an inflammatory hypothesis. Eur Heart J. 2001;22(5):349-52.

377. Ridker PM, Cushman M, Stampfer MJ, Tracy RP, Hennekens CH. Inflammation, aspirin, and the risk of cardiovascular disease in apparently healthy men. N Engl J Med. 1997;336(14):973-9.

378. Blake GJ, Ridker PM. C-reactive protein: a surrogate risk marker or mediator of atherothrombosis? Am J Physiol Regul Integr Comp Physiol. 2003;285(5):R1250-2.
379. Danesh J, Collins R, Appleby P, Peto R. Association of fibrinogen, $C$-reactive protein, albumin, or leukocyte count with coronary heart disease: meta-analyses of prospective studies. JAMA. 1998;279(18):1477-82.

380. Blake GJ, Rifai N, Buring JE, Ridker PM. Blood pressure, C-reactive protein, and risk of future cardiovascular events. Circulation. 2003;108(24):2993-9.

381. Ridker PM, Rifai N, Rose L, Buring JE, Cook NR. Comparison of $\mathrm{C}$-reactive protein and low-density lipoprotein cholesterol levels in the prediction of first cardiovascular events. N Engl J Med. 2002;347(20):1557-65.

382. Florez H, Castillo-Florez S, Mendez A, Casanova-Romero P, Larreal-Urdaneta C, Lee $D$, et al. C-reactive protein is elevated in obese patients with the metabolic syndrome. Diabetes Res Clin Pract. 2006;71(1):92-100.

383. Ridker PM. C-reactive protein: eighty years from discovery to emergence as a major risk marker for cardiovascular disease. Clin Chem. 2009;55(2):209-15.

384. Soder PO, Soder B, Nowak J, Jogestrand T. Early carotid atherosclerosis in subjects with periodontal diseases. Stroke. 2005;36(6):1195-200.

385. Leivadaros E, van der Velden U, Bizzarro S, ten Heggeler JM, Gerdes VE, Hoek FJ, et al. A pilot study into measurements of markers of atherosclerosis in periodontitis. J Periodontol. 2005;76(1):121-8.

386. Meurman JH, Sanz M, Janket SJ. Oral health, atherosclerosis, and cardiovascular disease. Crit Rev Oral Biol Med. 2004;15(6):403-13.

387. Desvarieux M, Demmer RT, Rundek T, Boden-Albala B, Jacobs DR, Jr., Sacco RL, et al. Periodontal microbiota and carotid intima-media thickness: the Oral Infections and Vascular Disease Epidemiology Study (INVEST). Circulation. 2005;111(5):576-82.

388. Haynes WG, Stanford C. Periodontal disease and atherosclerosis: from dental to arterial plaque. Arterioscler Thromb Vasc Biol. 2003;23(8):1309-11.

389. Tousoulis D, Davies G, Stefanadis C, Toutouzas P, Ambrose JA. Inflammatory and thrombotic mechanisms in coronary atherosclerosis. Heart. 2003;89(9):993-7.

390. Libby P, Ridker PM, Maseri A. Inflammation and atherosclerosis. Circulation. 2002;105(9):1135-43.

391. Paraskevas S, Huizinga JD, Loos BG. A systematic review and meta-analyses on C-reactive protein in relation to periodontitis. J Clin Periodontol. 2008;35(4):277-90.

392. Buhlin K, Gustafsson A, Pockley AG, Frostegard J, Klinge B. Risk factors for cardiovascular disease in patients with periodontitis. Eur Heart J. 2003;24(23):2099-107.

393. Slade GD, Ghezzi EM, Heiss G, Beck JD, Riche E, Offenbacher S. Relationship between periodontal disease and C-reactive protein among adults in the Atherosclerosis Risk in Communities study. Arch Intern Med. 2003;163(10):1172-9.

394. Beck JD, Offenbacher S. Relationships among clinical measures of periodontal disease and their associations with systemic markers. Ann Periodontol. 2002;7(1):79-89.

395. Glurich I, Grossi S, Albini B, Ho A, Shah R, Zeid M, et al. Systemic inflammation in cardiovascular and periodontal disease: comparative study. Clin Diagn Lab Immunol. 2002;9(2):425-32.

396. Liu J, Wu Y, Ding Y, Meng S, Ge S, Deng H. Evaluation of serum levels of $\mathrm{C}$-reactive protein and lipid profiles in patients with 
chronic periodontitis and/or coronary heart disease in an ethnic Han population. Quintessence Int. 2010;41(3):239-47.

397. Malali E, Basar I, Emekli-Alturfan E, Elemek E, Oktay S, Ayan F, et al. Levels of $\mathrm{C}$-reactive protein and protein $\mathrm{C}$ in periodontitis patients with and without cardiovascular disease. Pathophysiol Haemost Thromb. 2010;37(1):49-54.

398. Persson GR, Pettersson T, Ohlsson O, Renvert S. Highsensitivity serum C-reactive protein levels in subjects with or without myocardial infarction or periodontitis. J Clin Periodontol. 2005;32(3):219-24.

399. Anand SS, Yusuf S. C-reactive protein is a bystander of cardiovascular disease. Eur Heart J. 2010;31(17):2092-6.

400. Ernst $E$. The role of fibrinogen as a cardiovascular risk factor. Atherosclerosis. 1993;100(1):1-12.

401. Thompson S, Kienast J, Pyke S, Haverkate F, Van de loo J. Hemostatic factors and the risk of myocardial infarction or sudden death in patients with angina pectoris. N Engl J Med. 1995;332(10):635-41.

402. Fibrinogen Studies Collaboration, Danesh J, Lewington S, Thompson SG, Lowe G, Collins R, Kostis J, et al. Plasma fibrinogen level and the risk of major cardiovascular diseases and nonvascular mortality: an individual participant metaanalysis. JAMA. 2005;0ct 12;294(14):1799-809.

403. Pearson TA, Mensah GA, Alexander RW, Anderson JL, Cannon III RO, Criqui M, et al. Markers of inflammation and cardiovascular disease: application to clinical and public health practice: a statement for healthcare professionals from the Centers for Disease Control and Prevention and the American Heart Association. Circulation. 2003;107(3):499-511.

404. Davalos D, Akassoglou K, editors. Fibrinogen as a key regulator of inflammation in disease. Semin Immunopathol. 2012;Jan;34(1):43-62.

405. Loscalzo J, Braunwald E. Tissue plasminogen activator. N Engl J Med. 1988;319(14):925-31.

406. Mattila K, Rasi V, Nieminen M, Valtonen V, Kesaniemi A, Syrjala $S$, et al. von Willebrand factor antigen and dental infections. Thromb Res. 1989;56(2):325-9.

407. Amabile N, Susini G, Pettenati-Soubayroux I, Bonello L, Gil JM, Arques S, et al. Severity of periodontal disease correlates to inflammatory systemic status and independently predicts the presence and angiographic extent of stable coronary artery disease. J Intern Med. 2008;263(6):644-52.

408. Davì G, Patrono C. Platelet activation and atherothrombosis. N Engl J Med. 2007;357(24):2482-94.

409. Papapanagiotou D, Nicu EA, Bizzarro S, Gerdes VE, Meijers JC, Nieuwland R, et al. Periodontitis is associated with platelet activation. Atherosclerosis. 2009;202(2):605-11.

410. Fredman G, Oh SF, Ayilavarapu S, Hasturk H, Serhan $\mathrm{CN}$, Van Dyke TE. Impaired phagocytosis in localized aggressive periodontitis: rescue by Resolvin E1. PLoS One. 2011;6(9):e24422.

411. Lupu F, Bergonzelli GE, Heim DA, Cousin E, Genton CY, Bachmann F, et al. Localization and production of plasminogen activator inhibitor-1 in human healthy and atherosclerotic arteries. Arterioscler Thromb. 1993;13(7):1090-100.

412. Montebugnoli L, Servidio D, Miaton RA, Prati C, Tricoci $\mathrm{P}$, Melloni $\mathrm{C}$, et al. Periodontal health improves systemic inflammatory and haemostatic status in subjects with coronary heart disease. J Clin Periodontol. 2005;32(2):188-92.
413. Bretz WA, Weyant RJ, Corby PM, Ren D, Weissfeld L, Kritchevsky $\mathrm{SB}$, et al. Systemic inflammatory markers, periodontal diseases, and periodontal infections in an elderly population. J Am Geriatr Soc. 2005;53(9):1532-7.

414. Bizzarro S, Van Der Velden U, Ten Heggeler JM, Leivadaros E, Hoek FJ, Gerdes VE, et al. Periodontitis is characterized by elevated PAl-1 activity. J Clin Periodontol. 2007;34(7):574-80.

415. Srivastava P. Roles of heat-shock proteins in innate and adaptive immunity. Nat Rev Immunol. 2002;2(3):185.

416. Lamb DJ, El-Sankary W, Ferns GA. Molecular mimicry in atherosclerosis: a role for heat shock proteins in immunisation. Atherosclerosis. 2003;167(2):177-85.

417. Maeda $H$, Miyamoto $M$, Hongyo $H$, Nagai A, Kurihara $\mathrm{H}$, Murayama Y. Heat shock protein 60 (GroEL) from Porphyromonas gingivalis: molecular cloning and sequence analysis of its gene and purification of the recombinant protein. FEMS Microbiol Lett. 1994;119(1-2):129-35.

418. Vayssier C, Mayrand D, Grenier D. Detection of stress proteins in Porphyromonas gingivalis and other oral bacteria by Western immunoblotting analysis. FEMS Microbiol Lett. 1994;121(3):303-7.

419. Lu B, McBride B. Stress response of Porphyromonas gingivalis. Oral Microbiol Immunol. 1994;9(3):166-73.

420. Rizzo M, Cappello F, Marfil R, Nibali L, Gammazza AM, Rappa F, et al. Heat-shock protein $60 \mathrm{kDa}$ and atherogenic dyslipidemia in patients with untreated mild periodontitis: a pilot study. Cell Stress Chaperones. 2012;17(3):399-407.

421. Ueki K, Tabeta K, Yoshie H, Yamazaki K. Self-heat shock protein 60 induces tumour necrosis factor- $\alpha$ in monocyte-derived macrophage: possible role in chronic inflammatory periodontal disease. Clin Exp Immunol. 2002;127(1):72-7.

422. Choi J-I, Chung S-W, Kang H-S, Rhim B, Park Y-M, Kim U-S, et al. Epitope mapping of Porphyromonas gingivalis heatshock protein and human heat-shock protein in human atherosclerosis. J Dent Res. 2004;83(12):936-40.

423. Hinode D, Nakamura R, Grenier D, Mayrand D. Cross-reactivity of specific antibodies directed to heat shock proteins from periodontopathogenic bacteria of human origin. Oral Microbiol Immunol. 1998;13(1):55-8.

424. Yamazaki K, Ohsawa Y, Itoh H, Ueki K, Tabeta K, Oda T, et al. T-cell clonality to Porphyromonas gingivalis and human heat shock protein $60 \mathrm{~s}$ in patients with atherosclerosis and periodontitis. Oral Microbiol Immunol. 2004;19(3):160-7.

425. Ford P, Gemmell E, Walker P, West M, Cullinan M, Seymour $G$. Characterization of heat shock protein-specific T cells in atherosclerosis. Clin Diagn Lab Immunol. 2005;12(2):259-67.

426. Vaarala O, Mänttäri M, Manninen V, Tenkanen L, Puurunen M, Aho K, et al. Anti-cardiolipin antibodies and risk of myocardial infarction in a prospective cohort of middle-aged men. Circulation. 1995;91(1):23-7.

427. Wu R, Nityanand S, Berglund L, Lithell H, Holm Gr, Lefvert AK. Antibodies against cardiolipin and oxidatively modified LDL in 50-year-old men predict myocardial infarction. Arterioscler Thromb Vasc Biol. 1997;17(11):3159-63.

428. Toshima S-i, Hasegawa A, Kurabayashi M, Itabe H, Takano T, Sugano J, et al. Circulating oxidized low density lipoprotein levels: a biochemical risk marker for coronary heart disease. Arterioscler Thromb Vasc Biol. 2000;20(10):2243-7.

429. Schenkein HA, Berry CR, Burmeister JA, Brooks CN, Best $A M$, Tew JG. Locally produced anti-phosphorylcholine and 
anti-oxidized low-density lipoprotein antibodies in gingival crevicular fluid from aggressive periodontitis patients. J Periodontol. 2004;75(1):146-53.

430. Wang D, Nagasawa T, Chen Y, Ushida Y, Kobayashi H, Takeuchi Y, et al. Molecular mimicry of Aggregatibacter actinomycetemcomitans with $\beta 2$ glycoprotein I. Oral Microbiol Immunol. 2008;23(5):401-5.

431. Turunen SP, Kummu O, Harila K, Veneskoski M, Soliymani R, Baumann M, et al. Recognition of Porphyromonas gingivalis gingipain epitopes by natural IgM binding to malondialdehyde modified low-density lipoprotein. PLoS One. 2012;7(4):e34910.

432. Schenkein H, Berry C, Burmeister J, Brooks C, Barbour S, Best $A$, et al. Anti-cardiolipin antibodies in sera from patients with periodontitis. J Dent Res. 2003;82(11):919-22.

433. Türkoğlu O, Barış N, Kütükçüler N, Şenarslan Ö, Güneri S, Atilla G. Evaluation of serum anti-cardiolipin and oxidized lowdensity lipoprotein levels in chronic periodontitis patients with essential hypertension. J Periodontol. 2008;79(2):332-40.

434. Monteiro AM, Jardini MA, Alves S, Giampaoli V, Aubin EC, Figueiredo Neto AM, et al. Cardiovascular disease parameters in periodontitis. J Periodontol. 2009;80(3):378-88.

435. Pussinen PJ, Vilkuna-Rautiainen T, Alfthan G, Palosuo T, Jauhiainen M, Sundvall J, et al. Severe periodontitis enhances macrophage activation via increased serum lipopolysaccharide. Arterioscler Thromb Vasc Biol. 2004;24(11):2174-80.

436. Gunupati S, Chava VK, Krishna BP. Effect of phase I periodontal therapy on anti-cardiolipin antibodies in patients with acute myocardial infarction associated with chronic periodontitis. J Periodontol. 2011;82(12):1657-64.

437. Wilson PW, D’Agostino RB, Levy D, Belanger AM, Silbershatz $\mathrm{H}$, Kannel WB. Prediction of coronary heart disease using risk factor categories. Circulation. 1998;97(18):1837-47.

438. Nibali L, D'aiuto F, Griffiths G, Patel K, Suvan J, Tonetti MS. Severe periodontitis is associated with systemic inflammation and a dysmetabolic status: a case-control study. J Clin Periodontol. 2007;34(11):931-7.

439. Katz J, Chaushu G, Sharabi Y. On the association between hypercholesterolemia, cardiovascular disease and severe periodontal disease. J Clin Periodontol. 2001;28(9):865-8.

440. Losche W, Karapetow F, Pohl A, Pohl C, Kocher T. Plasma lipid and blood glucose levels in patients with destructive periodontal disease. J Clin Periodontol. 2000;27(8):537-41.

441. Rufail M, Schenkein H, Koertge T, Best A, Barbour S, Tew J, et al. Atherogenic lipoprotein parameters in patients with aggressive periodontitis. J Periodontal Res. 2007;42(6):495-502.

442. Koba S, Hirano T. Dyslipidemia and atherosclerosis. Nihon Rinsho. 2011;69(1):138-43.

443. Oz SG, Fentoglu O, Kilicarslan A, Guven GS, Tanrtover MD, Aykac $Y$, et al. Beneficial effects of periodontal treatment on metabolic control of hypercholesterolemia. South Med J. 2007;100(7):686-91.

444. Duan J, Ou-Yang X, Zhou Y. Effect of periodontal initial therapy on the serum level of lipid in the patients with both periodontitis and hyperlipidemia. Beijing Da Xue Xue Bao Yi Xue Ban. 2009;41(1):36-9.

445. Howard BV. Insulin, insulin resistance, and dyslipidemia. Ann N Y Acad Sci. 1993;683:1-8.

446. Salvi GE, Yalda B, Collins JG, Jones BH, Smith FW, Arnold RR, et al. Inflammatory mediator response as a potential risk marker for periodontal diseases in insulin-dependent diabetes mellitus patients. J Periodontol. 1997;68(2):127-35.

447. Miyazawa H, Tabeta K, Miyauchi S, Aoki-Nonaka Y, Domon H, Honda T, et al. Effect of Porphyromonas gingivalis infection on post-transcriptional regulation of the low-density lipoprotein receptor in mice. Lipids Health Dis. 2012;11:121.

448. Ishikawa M, Yoshida K, Okamura H, Ochiai K, Takamura H, Fujiwara N, et al. Oral Porphyromonas gingivalis translocates to the liver and regulates hepatic glycogen synthesis through the Akt/GSK-3beta signaling pathway. Biochim Biophys Acta. 2013;1832(12):2035-43.

449. Hotamisligil GS, Budavari A, Murray D, Spiegelman BM. Reduced tyrosine kinase activity of the insulin receptor in obesity-diabetes. Central role of tumor necrosis factor-alpha. J Clin Invest. 1994;94(4):1543-9.

450. Arimatsu K, Yamada H, Miyazawa H, Minagawa T, Nakajima M, Ryder MI, et al. Oral pathobiont induces systemic inflammation and metabolic changes associated with alteration of gut microbiota. Sci Rep. 2014;4:4828.

451. Palomaki GE, Melillo S, Bradley LA. Association between 9p21 genomic markers and heart disease: a meta-analysis. JAMA. 2010;303(7):648-56.

452. McPherson R, Visel A, Zhu Y, May D, McPherson R, Pertsemlidis A, et al. Chromosome 9p21 and coronary artery disease. $\mathrm{N}$ Engl J Med. 2010;362(18):1736.

453. Schunkert H, Gotz A, Braund P, McGinnis R, Tregouet DA, Mangino $M$, et al. Repeated replication and a prospective metaanalysis of the association between chromosome 9p21.3 and coronary artery disease. Circulation. 2008;117(13):1675-84.

454. Schunkert H, Konig IR, Kathiresan S, Reilly MP, Assimes TL, Holm H, et al. Large-scale association analysis identifies 13 new susceptibility loci for coronary artery disease. Nat Genet. 2011;43(4):333-8.

455. Samani NJ, Erdmann J, Hall AS, Hengstenberg C, Mangino M, Mayer B, et al. Genomewide association analysis of coronary artery disease. N Engl J Med. 2007;357(5):443-53.

456. Consortium WTCC. Genome-wide association study of 14,000 cases of seven common diseases and 3,000 shared controls. Nature. 2007;447(7145):661.

457. Helgadottir A, Thorleifsson G, Manolescu A, Gretarsdottir $\mathrm{S}$, Blondal T, Jonasdottir A, et al. A common variant on chromosome 9p21 affects the risk of myocardial infarction. Science. 2007.

458. Matarin M, Brown WM, Singleton A, Hardy JA, Meschia JF. Whole genome analyses suggest ischemic stroke and heart disease share an association with polymorphisms on chromosome 9p21. Stroke. 2008;39(5):1586-9.

459. Scott LJ, Mohlke KL, Bonnycastle LL, Willer CJ, Li Y, Duren WL, et al. A genome-wide association study of type 2 diabetes in Finns detects multiple susceptibility variants. Science. 2007.

460. Zeggini E, Weedon MN, Lindgren CM, Frayling TM, Elliott KS, Lango $\mathrm{H}$, et al. Replication of genome-wide association signals in UK samples reveals risk loci for type 2 diabetes. Science. 2007;316(5829):1336-41.

461. Saxena R, Voight BF, Lyssenko V, Burtt NP, de Bakker PI, Chen $\mathrm{H}$, et al. Genome-wide association analysis identifies loci for type 2 diabetes and triglyceride levels. Science. 2007;316(5829):1331-6.

462. Schaefer AS, Richter GM, Groessner-Schreiber B, Noack B, Nothnagel M, El Mokhtari N-E, et al. Identification of a shared 
genetic susceptibility locus for coronary heart disease and periodontitis. PLoS genetics. 2009;5(2):e1000378.

463. Ernst FD, Uhr K, Teumer A, Fanghänel J, Schulz S, Noack B, et al. Replication of the association of chromosomal region 9p21. 3 with generalized aggressive periodontitis (gAgP) using an independent case-control cohort. BMC Med Genet. 2010;11(1):119.

464. Schaefer AS, Richter GM, Dommisch H, Reinartz M, Nothnagel $M$, Noack B, et al. CDKN2BAS is associated with periodontitis in different European populations and is activated by bacterial infection. J Med Genet. 2011;Jan;48(1):38-47.

465. Eggesbo JB, Hjermann I, Hostmark AT, Kierulf P. LPS induced release of IL-1 beta, IL-6, IL-8 and TNF-alpha in EDTA or heparin anticoagulated whole blood from persons with high or low levels of serum HDL. Cytokine. 1996;8(2):152-60.

466. Salvi GE, Yalda B, Collins JG, Jones BH, Smith FW, Arnold RR, et al. Inflammatory mediator response as a potential risk marker for periodontal diseases in insulin-dependent diabetes mellitus patients. J Periodontol. 1997;68(2):127-35.

467. Stashenko P, Fujiyoshi P, Obernesser MS, Prostak L, Haffajee $A D$, Socransky SS. Levels of interleukin 1 beta in tissue from sites of active periodontal disease. J Clin Periodontol. 1991;18(7):548-54.

468. Ciampolillo A, Guastamacchia E, Caragiulo L, Lollino G, De Robertis O, Lattanzi V, et al. In vitro secretion of interleukin-1 beta and interferon-gamma by peripheral blood lymphomononuclear cells in diabetic patients. Diabetes Res Clin Pract. 1993;21(2-3):87-93.

469. Zambon JJ, Reynolds H, Fisher JG, Shlossman M, Dunford R, Genco RJ. Microbiological and immunological studies of adult periodontitis in patients with noninsulin-dependent diabetes mellitus. J Periodontol. 1988;59(1):23-31.

470. Iacopino AM. Diabetic periodontitis: possible lipid-induced defect in tissue repair through alteration of macrophage phenotype and function. Oral Dis. 1995;1(4):214-29.

471. Cutler CW, Machen RL, Jotwani R, lacopino AM. Heightened gingival inflammation and attachment loss in type 2 diabetics with hyperlipidemia. J Periodontol. 1999;70(11):1313-21.

472. Lalla E, Papapanou PN. Diabetes mellitus and periodontitis: a tale of two common interrelated diseases. Nat Rev Endocrinol. 2011;7(12):738-48.

473. Pickup JC. Inflammation and activated innate immunity in the pathogenesis of type 2 diabetes. Diabetes Care. 2004;27(3):813-23.

474. Shoelson SE, Lee J, Goldfine AB. Inflammation and insulin resistance. J Clin Invest. 2006;116(7):1793-801.

475. King GL. The role of inflammatory cytokines in diabetes and its complications. J Periodontol. 2008;79(8 Suppl):1527-34.

476. Abbatecola AM, Ferrucci L, Grella R, Bandinelli S, Bonafe M, Barbieri $M$, et al. Diverse effect of inflammatory markers on insulin resistance and insulin-resistance syndrome in the elderly. J Am Geriatr Soc. 2004;52(3):399-404.

477. Gupta A, Ten S, Anhalt H. Serum levels of soluble tumor necrosis factor-alpha receptor 2 are linked to insulin resistance and glucose intolerance in children J Pediatr Endocrinol Metab. 2005;18(1):75-82.

478. Engebretson S, Chertog R, Nichols A, Hey-Hadavi J, Celenti $R$, Grbic J. Plasma levels of tumour necrosis factor-alpha in patients with chronic periodontitis and type 2 diabetes. J Clin Periodontol. 2007;34(1):18-24.
479. Graves DT, Naguib G, Lu H, Leone C, Hsue H, Krall E. Inflammation is more persistent in type 1 diabetic mice. J Dent Res. 2005;84(4):324-8.

480. Nishihara R, Sugano N, Takano M, Shimada T, Tanaka H, Oka $\mathrm{S}$, et al. The effect of Porphyromonas gingivalis infection on cytokine levels in type 2 diabetic mice. J Periodontal Res. 2009;44(3):305-10.

481. Naguib G, Al-Mashat H, Desta T, Graves DT. Diabetes prolongs the inflammatory response to a bacterial stimulus through cytokine dysregulation. J Invest Dermatol. 2004;123(1):87-92.

482. Lu H, Raptis M, Black E, Stan M, Amar S, Graves DT. Influence of diabetes on the exacerbation of an inflammatory response in cardiovascular tissue. Endocrinology. 2004;145(11):4934-9.

483. Salvi GE, Kandylaki M, Troendle A, Persson GR, Lang NP. Experimental gingivitis in type 1 diabetics: a controlled clinical and microbiological study. J Clin Periodontol. 2005;32(3):310-6.

484. Salvi GE, Beck JD, Offenbacher S. PGE2, IL-1 beta, and TNFalpha responses in diabetics as modifiers of periodontal disease expression. Ann Periodontol. 1998;3(1):40-50.

485. Salvi GE, Collins JG, Yalda B, Arnold RR, Lang NP, Offenbacher S. Monocytic TNF alpha secretion patterns in IDDM patients with periodontal diseases. J Clin Periodontol. 1997;24(1):8-16.

486. Karima M, Kantarci A, Ohira T, Hasturk H, Jones VL, Nam BH, et al. Enhanced superoxide release and elevated protein kinase $C$ activity in neutrophils from diabetic patients: association with periodontitis. J Leukoc Biol. 2005;78(4):862-70.

487. Salvi GE, Beck JD, Offenbacher S. PGE2, IL-1 $\beta$, and TNF- $\alpha$ responses in diabetics as modifiers of periodontal disease expression. Ann Periodontol. 1998;3(1):40-50.

488. Takano M, Nishihara R, Sugano N, Matsumoto K, Yamada Y, Takane M, et al. The effect of systemic anti-tumor necrosis factor-alpha treatment on Porphyromonas gingivalis infection in type 2 diabetic mice. Arch Oral Biol. 2010;55(5):379-84.

489. Chang KM, Ryan ME, Golub LM, Ramamurthy NS, McNamara TF. Local and systemic factors in periodontal disease increase matrix-degrading enzyme activities in rat gingiva: effect of micocycline therapy. Res Commun Mol Pathol Pharmacol. 1996;91(3):303-18.

490. Seppala B, Sorsa T, Ainamo J. Morphometric analysis of cellular and vascular changes in gingival connective tissue in long-term insulin-dependent diabetes. J Periodontol. 1997;68(12):123745.

491. Schneir M, Imberman M, Ramamurthy N, Golub L. Streptozotocin-induced diabetes and the rat periodontium: decreased relative collagen production. Coll Relat Res. 1988;8(3):221-32.

492. Claudino M, Ceolin DS, Alberti S, Cestari TM, Spadella CT, Rubira-Bullen IR, et al. Alloxan-induced diabetes triggers the development of periodontal disease in rats. PloS one. 2007;2(12):e1320.

493. Kumar MS, Vamsi G, Sripriya R, Sehgal PK. Expression of matrix metalloproteinases (MMP-8 and -9) in chronic periodontitis patients with and without diabetes mellitus. J Periodontol. 2006;77(11):1803-8.

494. Santos VR, Lima JA, Goncalves TE, Bastos MF, Figueiredo LC, Shibli JA, et al. Receptor activator of nuclear factor-kappa B ligand/osteoprotegerin ratio in sites of chronic periodontitis of subjects with poorly and well-controlled type 2 diabetes. J Periodontol. 2010;81(10):1455-65. 
495. Duarte PM, Neto JB, Casati MZ, Sallum EA, Nociti FH, Jr. Diabetes modulates gene expression in the gingival tissues of patients with chronic periodontitis. Oral Dis. 2007;13(6):594-9.

496. Mahamed DA, Marleau A, Alnaeeli M, Singh B, Zhang X, Penninger JM, et al. G(-) anaerobes-reactive CD4+ T-cells trigger RANKL-mediated enhanced alveolar bone loss in diabetic NOD mice. Diabetes. 2005;54(5):1477-86.

497. He H, Liu R, Desta T, Leone C, Gerstenfeld LC, Graves DT. Diabetes causes decreased osteoclastogenesis, reduced bone formation, and enhanced apoptosis of osteoblastic cells in bacteria stimulated bone loss. Endocrinology. 2004;145(1):44752.

498. Liu R, Bal HS, Desta T, Krothapalli N, Alyassi M, Luan Q, et al. Diabetes enhances periodontal bone loss through enhanced resorption and diminished bone formation. J Dent Res. 2006;85(6):510-4.

499. Liu R, Desta T, He H, Graves DT. Diabetes alters the response to bacteria by enhancing fibroblast apoptosis. Endocrinology. 2004;145(6):2997-3003.

500. Schmidt AM, Weidman E, Lalla E, Yan SD, Hori O, Cao R, et al. Advanced glycation endproducts (AGEs) induce oxidant stress in the gingiva: a potential mechanism underlying accelerated periodontal disease associated with diabetes. J Periodontal Res. 1996;31(7):508-15.

501. Katz J, Bhattacharyya I, Farkhondeh-Kish F, Perez FM, Caudle RM, Heft MW. Expression of the receptor of advanced glycation end products in gingival tissues of type 2 diabetes patients with chronic periodontal disease: a study utilizing immunohistochemistry and RT-PCR. J Clin Periodontol. 2005;32(1):40-4.

502. Takeda M, Ojima M, Yoshioka H, Inaba H, Kogo M, Shizukuishi $S$, et al. Relationship of serum advanced glycation end products with deterioration of periodontitis in type 2 diabetes patients. J Periodontol. 2006;77(1):15-20.

503. Murillo J, Wang Y, Xu X, Klebe RJ, Chen Z, Zardeneta G, et al. Advanced glycation of type I collagen and fibronectin modifies periodontal cell behavior. J Periodontol. 2008;79(11):2190-9.

504. Ren L, Fu Y, Deng Y, Qi L, Jin L. Advanced glycation end products inhibit the expression of collagens type I and III by human gingival fibroblasts. J Periodontol. 2009;80(7):1166-73.

505. Ding KH, Wang ZZ, Hamrick MW, Deng ZB, Zhou L, Kang B, et al. Disordered osteoclast formation in RAGE-deficient mouse establishes an essential role for RAGE in diabetes related bone loss. Biochem Biophys Res Commun. 2006;340(4):1091-7.

506. Yoshida T, Flegler A, Kozlov A, Stern PH. Direct inhibitory and indirect stimulatory effects of RAGE ligand S100 on SRANKLinduced osteoclastogenesis. J Cell Biochem. 2009;107(5):917-25.

507. Lalla E, Lamster IB, Feit M, Huang L, Schmidt AM. A murine model of accelerated periodontal disease in diabetes. J Periodontal Res. 1998;33(7):387-99.

508. Lalla E, Lamster IB, Feit M, Huang L, Spessot A, Qu W, et al. Blockade of RAGE suppresses periodontitis-associated bone loss in diabetic mice. J Clin Invest. 2000;105(8):1117-24.

509. Goova MT, Li J, Kislinger T, Qu W, Lu Y, Bucciarelli LG, et al. Blockade of receptor for advanced glycation end-products restores effective wound healing in diabetic mice. The Am J Pathol. 2001;159(2):513-25.

510. Santana RB, Xu L, Chase HB, Amar S, Graves DT, Trackman PC. A role for advanced glycation end products in diminished bone healing in type 1 diabetes. Diabetes. 2003;52(6):1502-10.
511. Lalla E, Lamster IB, Schmidt AM. Enhanced interaction of advanced glycation end products with their cellular receptor RAGE: implications for the pathogenesis of accelerated periodontal disease in diabetes. Ann Periodontol. 1998;3(1):139.

512. Genco RJ, Grossi SG, Ho A, Nishimura F, Murayama Y. A proposed model linking inflammation to obesity, diabetes, and periodontal infections. J Periodontol. 2005;76:2075-84.

513. Margetic S, Gazzola C, Pegg G, Hill R. Leptin: a review of its peripheral actions and interactions. Int J Obes Relat Metab Disord. 2002;26(11):1407.

514. Johnson R, Serio F. Leptin within healthy and diseased human gingiva. J Periodontol. 2001;72(9):1254-7.

515. Karthikeyan B, Pradeep A. Leptin levels in gingival crevicular fluid in periodontal health and disease. J Periodontal Res. 2007;42(4):300-4.

516. Karthikeyan B, Pradeep A. Gingival crevicular fluid and serum leptin: their relationship to periodontal health and disease. J Clin Periodontol. 2007;34(6):467-72.

517. Matsuzawa Y, Funahashi T, Kihara S, Shimomura I. Adiponectin and metabolic syndrome. Arterioscler Thromb Vasc Biol. 2004;24(1):29-33.

518. Yamaguchi N, Kukita T, Li Y-J, Martinez Argueta JG, Saito T, Hanazawa S, et al. Adiponectin inhibits osteoclast formation stimulated by lipopolysaccharide from Actinobacillus actinomycetemcomitans. FEMS Immunol Med Microbiol. 2007;49(1):28-34.

519. Iwamoto Y, Nishimura F, Soga Y, Takeuchi K, Kurihara M, Takashiba S, et al. Antimicrobial periodontal treatment decreases serum C-reactive protein, tumor necrosis factoralpha, but not adiponectin levels in patients with chronic periodontitis. J Periodontol. 2003;74(8):1231-6.

520. Furugen R, Hayashida H, Yamaguchi N, Yoshihara A, Ogawa $\mathrm{H}$, Miyazaki $\mathrm{H}$, et al. The relationship between periodontal condition and serum levels of resistin and adiponectin in elderly Japanese. J Periodontal Res. 2008;43(5):556-62.

521. Saito T, Yamaguchi N, Shimazaki Y, Hayashida H, Yonemoto K, Doi Y, et al. Serum levels of resistin and adiponectin in women with periodontitis: the Hisayama study. J Dent Res. 2008;87(4):319-22.

522. Bokarewa M, Nagaev I, Dahlberg L, Smith U, Tarkowski A. Resistin, an adipokine with potent proinflammatory properties. J Immunol. 2005;174(9):5789-95.

523. Steppan CM, Bailey ST, Bhat S, Brown EJ, Banerjee RR, Wright $\mathrm{CM}$, et al. The hormone resistin links obesity to diabetes. Nature. 2001;409(6818):307.

524. Camera A, Hopps E, Caimi G. Diabetic microangiopathy: physiopathological, clinical and therapeutic aspects. Minerva Endocrinol. 2007;32(3):209-29.

525. Di Filippo C, Verza M, Coppola L, Rossi F, D’Amico M, Marfella $R$. Insulin resistance and postprandial hyperglycemia the bad companions in natural history of diabetes: effects on health of vascular tree. Curr Diabetes Rev. 2007;3(4):268-73.

526. Castelao JE, Gago-Dominguez M. Risk factors for cardiovascular disease in women: relationship to lipid peroxidation and oxidative stress. Med Hypotheses. 2008;71(1):39-44.

527. Ceriello A, Motz E. Is oxidative stress the pathogenic mechanism underlying insulin resistance, diabetes, and cardiovascular disease? The common soil hypothesis revisited. Arterioscler Thromb Vasc Biol. 2004;24(5):816-23. 
528. Bullon P, Morillo J, Ramirez-Tortosa MC, Quiles J, Newman H, Battino M. Metabolic syndrome and periodontitis: is oxidative stress a common link? J Dent Res. 2009;88(6):503-18.

529. D’Aiuto F, Nibali L, Parkar M, Patel K, Suvan J, Donos N. Oxidative stress, systemic inflammation, and severe periodontitis. J Dent Res. 2010;89(11):1241-6.

530. Chapple IL, Matthews JB. The role of reactive oxygen and antioxidant species in periodontal tissue destruction. Periodontol 2000. 2007;43:160-232.

531. Yamagishi S-i, Matsui T. Advanced glycation end products, oxidative stress and diabetic nephropathy. Oxid Med Cell Longev. 2010;3(2):101-8.

532. McEwen BS. Protection and damage from acute and chronic stress: allostasis and allostatic overload and relevance to the pathophysiology of psychiatric disorders. Ann N Y Acad Sci. 2004;1032(1):1-7.

533. Breivik T, Thrane PS, Murison R, Gjermo P. Emotional stress effects on immunity, gingivitis and periodontitis. Eur J Oral Sci. 1996;104(4):327-34.

534. Warren KR, Postolache TT, Groer ME, Pinjari O, Kelly DL, Reynolds MA. Role of chronic stress and depression in periodontal diseases. Periodontol 2000. 2014;64(1):127-38.

535. Pariante CM, Lightman SL. The HPA axis in major depression: classical theories and new developments. Trends Neurosci. 2008;31(9):464-8.

536. Genco RJ, Ho AW, Kopman J, Grossi SG, Dunford RG, Tedesco LA. Models to evaluate the role of stress in periodontal disease. Ann Periodontol. 1998;3(1):288-302.

537. Williams T, Yarwood H. Effect of glucocorticosteroids on microvascular permeability. Am Rev Respir Dis. 1990;141(2 Pt 2):S39.

538. Cupps TR, Fauci AS. Corticosteroid-mediated immunoregulation in man. Immunol Rev. 1982;65(1):133-55.

539. Schleimer RP, Freeland H, Peters S, Brown K, Derse C. An assessment of the effects of glucocorticoids on degranulation, chemotaxis, binding to vascular endothelium and formation of leukotriene B4 by purified human neutrophils. J Pharmacol Exp Ther. 1989;250(2):598-605.

540. Johannsen A, Rylander G, Söder B, Marie Å. Dental plaque, gingival inflammation, and elevated levels of interleukin- 6 and cortisol in gingival crevicular fluid from women with stress-related depression and exhaustion. J Periodontol. 2006;77(8):1403-9.

541. Johannsen A, Rydmark I, Söder B, Åsberg M. Gingival inflammation, increased periodontal pocket depth and elevated interleukin-6 in gingival crevicular fluid of depressed women on long-term sick leave. J Periodontal Res. 2007;42(6):546-52.

542. Branco-de-Almeida LS, Franco GC, Castro ML, dos Santos JG, Anbinder AL, Cortelli SC, et al. Fluoxetine inhibits inflammatory response and bone loss in a rat model of ligature-induced periodontitis. J Periodontol. 2012;83(5):664-71

543. Fibiger W, Singer G, Miller AJ. Relationships between catecholamines in urine and physical and mental effort. Int I Psychophysiol. 1984;1(4):325-33.

544. Dimsdale JE, Moss J. Plasma catecholamines in stress and exercise. JAMA. 1980;243(4):340-2.

545. Ritchie CS, Kinane DF. Nutrition, inflammation, and periodontal disease. Nutrition. 2003;19(5):475.
546. Kau AL, Ahern PP, Griffin NW, Goodman AL, Gordon JI. Human nutrition, the gut microbiome and the immune system. Nature. 2011;474(7351):327.

547. Kelly JR, Kennedy PJ, Cryan JF, Dinan TG, Clarke G, Hyland NP. Breaking down the barriers: the gut microbiome, intestinal permeability and stress-related psychiatric disorders. Front Cell Neurosci. 2015;9:392.

548. Bercik P, Park A, Sinclair D, Khoshdel A, Lu J, Huang X, et al. The anxiolytic effect of Bifidobacterium longum NCC3001 involves vagal pathways for gut-brain communication. Neurogastroenterol Motil. 2011;23(12):1132-9.

549. Lyte M, Li W, Opitz N, Gaykema RP, Goehler LE. Induction of anxiety-like behavior in mice during the initial stages of infection with the agent of murine colonic hyperplasia Citrobacter rodentium. Physiol Behav. 2006;89(3):350-7.

550. Zheng P, Zeng B, Zhou C, Liu M, Fang Z, Xu X, et al. Gut microbiome remodeling induces depressive-like behaviors through a pathway mediated by the host's metabolism. Mol Psychiatry. 2016;21(6):786.

551. Burokas A, Arboleya S, Moloney RD, Peterson VL, Murphy $\mathrm{K}$, Clarke $\mathrm{G}$, et al. Targeting the microbiota-gut-brain axis: prebiotics have anxiolytic and antidepressant-like effects and reverse the impact of chronic stress in mice. Biol Psychiatry. 2017;82(7):472-87.

552. Desbonnet L, Clarke G, Traplin A, O'Sullivan O, Crispie F, Moloney RD, et al. Gut microbiota depletion from early adolescence in mice: implications for brain and behaviour. Brain Behav Immun. 2015;48:165-73.

553. Diaz Heijtz R, Wang S, Anuar F, Qian Y, Bjorkholm B, Samuelsson A, et al. Normal gut microbiota modulates brain development and behavior. Proc Natl Acad Sci U S A. 2011;108(7):3047-52.

554. Ait-Belgnaoui A, Colom A, Braniste V, Ramalho L, Marrot $A$, Cartier C, et al. Probiotic gut effect prevents the chronic psychological stress-induced brain activity abnormality in mice. Neurogastroenterol Motil. 2014;26(4):510-20.

555. Messaoudi M, Lalonde R, Violle N, Javelot H, Desor D, Nejd A, et al. Assessment of psychotropic-like properties of a probiotic formulation (Lactobacillus helveticus R0052 and Bifidobacterium longum R0175) in rats and human subjects. Br J Nutr. 2011;105(5):755-64

556. Ong IM, Gonzalez JG, Mcllwain SJ, Sawin EA, Schoen AJ, Adluru $\mathrm{N}$, et al. Gut microbiome populations are associated with structure-specific changes in white matter architecture. Transl Psychiatry. 2018;8(1):6.

557. Hemarajata P, Versalovic J. Effects of probiotics on gut microbiota: mechanisms of intestinal immunomodulation and neuromodulation. Therap Adv Gastroenterol. 2013;6(1):39-51.

558. Cryan JF, Dinan TG. Mind-altering microorganisms: the impact of the gut microbiota on brain and behaviour. Nat Rev Neurosci. 2012;13(10):701.

559. Galland L. The gut microbiome and the brain. J Med Food. 2014;17(12):1261-72

560. Darveau RP. Periodontitis: a polymicrobial disruption of host homeostasis. Nat Rev Microbiol. 2010;8(7):481.

561. Hajishengallis G, Lamont RJ. Breaking bad: Manipulation of the host response by P orphyromonas gingivalis. Eur J Immunol. 2014;44(2):328-38 
562. Lee YL, Hu HY, Chou P, Chu D. Dental prophylaxis decreases the risk of acute myocardial infarction: a nationwide populationbased study in Taiwan. Clin Interv Aging. 2015;10:175-82.

563. Peng CH, Yang YS, Chan KC, Kornelius E, Chiou JY, Huang CN. Periodontal Treatment and the Risks of Cardiovascular Disease in Patients with Type 2 Diabetes: A Retrospective Cohort Study. Intern Med. 2017;56(9):1015-21.

564. Holmlund A, Lampa E, Lind L. Poor Response to Periodontal Treatment May Predict Future Cardiovascular Disease. J Dent Res. 2017;96(7):768-73.

565. Freitas CO, Gomes-Filho IS, Naves RC, Nogueira Filho Gda R, Cruz SS, Santos CA, et al. Influence of periodontal therapy on C-reactive protein level: a systematic review and meta-analysis. J Appl Oral Sci. 2012;20(1):1-8.

566. D’Aiuto F, Nibali L, Parkar M, Suvan J, Tonetti MS. Short-term effects of intensive periodontal therapy on serum inflammatory markers and cholesterol. J Dent Res. 2005;84(3):269-73.

567. D’Aiuto F, Parkar M, Nibali L, Suvan J, Lessem J, Tonetti MS. Periodontal infections cause changes in traditional and novel cardiovascular risk factors: results from a randomized controlled clinical trial. Am Heart J. 2006;151(5):977-84.

568. Tonetti MS, D’Aiuto F, Nibali L, Donald A, Storry C, Parkar M, et al. Treatment of periodontitis and endothelial function. $\mathrm{N}$ Engl J Med. 2007;356(9):911-20.

569. Knofler GU, Purschwitz RE, Eick S, Pfister W, Roedel M, Jentsch HF. Microbiologic findings 1 year after partial- and full-mouth scaling in the treatment of moderate chronic periodontitis. Quintessence Int. (Berlin, Germany : 1985). 2011;42(9):e107-17.

570. Orlandi M, Suvan J, Petrie A, Donos N, Masi S, Hingorani A, et al. Association between periodontal disease and its treatment, flow-mediated dilatation and carotid intima-media thickness: a systematic review and meta-analysis. Atherosclerosis. 2014;236(1):39-46.

571. Piconi S, Trabattoni D, Luraghi C, Perilli E, Borelli M, Pacei M, et al. Treatment of periodontal disease results in improvements in endothelial dysfunction and reduction of the carotid intimamedia thickness. FASEB J. 2009;23(4):1196-204.

572. Taylor BA, Tofler GH, Carey HM, Morel-Kopp MC, Philcox S, Carter TR, et al. Full-mouth tooth extraction lowers systemic inflammatory and thrombotic markers of cardiovascular risk. J Dent Res. 2006;85(1):74-8.

573. Vidal F, Figueredo CM, Cordovil I, Fischer RG. Periodontal therapy reduces plasma levels of interleukin-6, C-reactive protein, and fibrinogen in patients with severe periodontitis and refractory arterial hypertension. J Periodontol. 2009;80(5):786-91.

574. Hussain Bokhari SA, Khan AA, Tatakis DN, Azhar M, Hanif $M$, Izhar M. Non-surgical periodontal therapy lowers serum inflammatory markers: a pilot study. J Periodontol. 2009;80(10):1574-80.

575. Corretti MC, Anderson TJ, Benjamin EJ, Celermajer D, Charbonneau F, Creager MA, et al. Guidelines for the ultrasound assessment of endothelial-dependent flow-mediated vasodilation of the brachial artery: a report of the International Brachial Artery Reactivity Task Force. Leducq Transatlantic Network on Atherothrombosis. 2002;39(2):257-65.

576. Seinost G, Wimmer G, Skerget M, Thaller E, Brodmann M, Gasser R, et al. Periodontal treatment improves endothelial dysfunction in patients with severe periodontitis. Am Heart J. 2005;149(6):1050-4.
577. D’Aiuto F, Graziani F, Tete S, Gabriele M, Tonetti MS. Periodontitis: from local infection to systemic diseases. Int J Immunopathol Pharmacol. 2005;18(3 Suppl):1-11.

578. Higashi Y, Goto C, Hidaka T, Soga J, Nakamura S, Fujii Y, et al. Oral infection-inflammatory pathway, periodontitis, is a risk factor for endothelial dysfunction in patients with coronary artery disease. Atherosclerosis. 2009;206(2):604-10.

579. Vidal F, Cordovil I, Figueredo CM, Fischer RG. Non-surgical periodontal treatment reduces cardiovascular risk in refractory hypertensive patients: a pilot study. J Clin Periodontol. 2013;40(7):681-7.

580. Brunner H, Cockcroft JR, Deanfield J, Donald A, Ferrannini E, Halcox J, et al. Endothelial function and dysfunction. Part II: Association with cardiovascular risk factors and diseases. A statement by the Working Group on Endothelins and Endothelial Factors of the European Society of Hypertension. J Hypertens. 2005;23(2):233-46.

581. Blum A, Kryuger K, Mashiach Eizenberg M, Tatour S, Vigder F, Laster Z, et al. Periodontal care may improve endothelial function. Eur J Intern Med. 2007;18(4):295-8.

582. Iwamoto Y, Nishimura F, Soga Y, Takeuchi K, Kurihara M, Takashiba S, et al. Antimicrobial periodontal treatment decreases serum C-reactive protein, tumor necrosis factoralpha, but not adiponectin levels in patients with chronic periodontitis. J Periodontol. 2003;74(8):1231-6.

583. D'Aiuto F, Ready D, Tonetti MS. Periodontal disease and C-reactive protein-associated cardiovascular risk. J Periodontal Res. 2004;39(4):236-41.

584. Nakajima T, Honda T, Domon H, Okui T, Kajita K, Ito H, et al. Periodontitis-associated up-regulation of systemic inflammatory mediator level may increase the risk of coronary heart disease. J Periodontal Res. 2010;45(1):116-22.

585. Yamazaki K, Honda T, Oda T, Ueki-Maruyama K, Nakajima T, Yoshie $\mathrm{H}$, et al. Effect of periodontal treatment on the $\mathrm{C}$-reactive protein and proinflammatory cytokine levels in Japanese periodontitis patients. J Periodontal Res. 2005;40(1):53-8.

586. Ide M, McPartlin D, Coward PY, Crook M, Lumb P, Wilson RF. Effect of treatment of chronic periodontitis on levels of serum markers of acute-phase inflammatory and vascular responses. J Clin Periodontol. 2003;30(4):334-40.

587. Ioannidou E, Malekzadeh T, Dongari-Bagtzoglou A. Effect of periodontal treatment on serum C-reactive protein levels: a systematic review and meta-analysis. J Periodontol. 2006;77(10):1635-42.

588. D’Aiuto F, Parkar M, Tonetti MS. Periodontal therapy: a novel acute inflammatory model. Inflamm Res. 2005;54(10):412-4.

589. Minassian C, D’Aiuto F, Hingorani AD, Smeeth L. Invasive dental treatment and risk for vascular events: a self-controlled case series. Ann Intern Med. 2010;153(8):499-506.

590. Merchant AT, Georgantopoulos P, Howe CJ, Virani SS, Morales DA, Haddock KS. Effect of Long-Term Periodontal Care on Hemoglobin A1c in Type 2 Diabetes. J Dent Res. 2016;95(4):408-15.

591. Lalla E, Kaplan S, Yang J, Roth GA, Papapanou PN, Greenberg S. Effects of periodontal therapy on serum C-reactive protein, sE-selectin, and tumor necrosis factor-alpha secretion by peripheral blood-derived macrophages in diabetes. A pilot study. J Periodontal Res. 2007;42(3):274-82.

592. Sun WL, Chen LL, Zhang SZ, Ren YZ, Qin GM. Changes of adiponectin and inflammatory cytokines after periodontal 
intervention in type 2 diabetes patients with periodontitis. Arch Oral Biol. 2010;55(12):970-4.

593. Correa FO, Goncalves D, Figueredo CM, Bastos AS, Gustafsson A, Orrico SR. Effect of periodontal treatment on metabolic control, systemic inflammation and cytokines in patients with type 2 diabetes. J Clin Periodontol. 2010;37(1):53-8.

594. Artese HP, Foz AM, Rabelo Mde S, Gomes GH, Orlandi M, Suvan J, et al. Periodontal therapy and systemic inflammation in type 2 diabetes mellitus: a meta-analysis. PLoS One. 2015;10(5):e0128344.

595. Katagiri S, Nitta H, Nagasawa T, Uchimura I, Izumiyama $\mathrm{H}$, Inagaki $\mathrm{K}$, et al. Multi-center intervention study on glycohemoglobin (HbA1c) and serum, high-sensitivity CRP (hs(RP) after local anti-infectious periodontal treatment in type 2 diabetic patients with periodontal disease. Diabetes Res Clin Pract. 2009;83(3):308-15.

596. O’Connell PA, Taba M, Nomizo A, Foss Freitas MC, Suaid $F A$, Uyemura $S A$, et al. Effects of periodontal therapy on glycemic control and inflammatory markers. J Periodontol. 2008;79(5):774-83.

597. Matsumoto S, Ogawa H, Soda S, Hirayama S, Amarasena N, Aizawa $\mathrm{Y}$, et al. Effect of antimicrobial periodontal treatment and maintenance on serum adiponectin in type 2 diabetes mellitus. J Clin Periodontol. 2009;36(2):142-8.

598. Teeuw WJ, Gerdes VE, Loos BG. Effect of periodontal treatment on glycemic control of diabetic patients: a systematic review and meta-analysis. Diabetes Care. 2010;33(2):421-7.

599. Offenbacher S, Beck JD, Moss K, Mendoza L, Paquette DW, Barrow DA, et al. Results from the Periodontitis and Vascular Events (PAVE) Study: a pilot multicentered, randomized, controlled trial to study effects of periodontal therapy in a secondary prevention model of cardiovascular disease. J Periodontol. 2009;80(2):190-201.

600. Badersten A, Nilveus R, Egelberg J. Effect of nonsurgical periodontal therapy. I. Moderately advanced periodontitis. J Clin Periodontol. 1981;8(1):57-72.

601. Lowenguth RA, Greenstein G. Clinical and microbiological response to nonsurgical mechanical periodontal therapy. Periodontol 2000. 1995;9:14-22.

602. Al-Mubarak S, Ciancio S, Aljada A, Mohanty P, Ross C, Dandona $P$. Comparative evaluation of adjunctive oral irrigation in diabetics. J Clin Periodontol. 2002;29(4):295-300.

603. Campus G, Salem A, Sacco G, Maida C, Cagetti MG, Tonolo G. Clinical effects of mechanical periodontal therapy in type 2 diabetic patients. Diabetes Res Clin Pract. 2007;75(3):368-9.

604. Stewart JE, Wager KA, Friedlander AH, Zadeh HH. The effect of periodontal treatment on glycemic control in patients with type 2 diabetes mellitus. J Clin Periodontol. 2001;28(4):306-10.

605. Ozcelik O, Haytac MC, Seydaoglu G. Immediate post-operative effects of different periodontal treatment modalities on oral health-related quality of life: a randomized clinical trial. J Clin Periodontol. 2007;34(9):788-96.

606. Tonetti MS, Lang NP, Cortellini P, Suvan JE, Adriaens P, Dubravec $D$, et al. Enamel matrix proteins in the regenerative therapy of deep intrabony defects: A multicentre randomized controlled clinical trial. J Clin Periodontol. 2002;29(4):317-25.

607. Mahendra L, Mahendra J, Borra SK, Nagarajan A. Estimation of salivary neopterin in chronic periodontitis. Indian J Dent Res. 2014;25(6):794.
608. Arjunkumar R, Sudhakar U, Jayakumar P, Arunachalam L, Suresh S, Virupapuram P. Comparative analysis of gingival crevicular fluid neopterin levels in health and periodontal disease: a biochemical study. Indian J Dent Res. 2013;24(5):582.

609. Fenol A, Swetha V, Krishnan S, Perayil J, Vyloppillil R, Bhaskar $A$, et al. Correlation of salivary neopterin and plasma fibrinogen levels in patients with chronic periodontitis and/or type 2 diabetes mellitus. Pteridines. 2017;28(3-4):177-83.

610. Bodur A, Baydar T, Ozmeric N, Engin AB, Uraz A, Eren K, et al. Neopterin profile to evaluate the effectiveness of treatment in aggressive periodontitis. Pteridines. 2003;14(3):77-81.

611. Atchison KA, Dolan TA. Development of the geriatric oral health assessment index. J Dent Educ. 1990;54(11):680-7.

612. Gooch B, Dolan T, Bourque L. Correlates of self-reported dental health status upon enrollment in the Rand Health Insurance Experiment. J Dent Educ. 1989;53(11):629-37.

613. Rosenberg D, Kaplan S, Senie R, Badner V. Relationships among dental functional status, clinical dental measures, and generic health measures. J Dent Educ. 1988;52(11):653-7.

614. Slade GD, Spencer AJ. Development and evaluation of the oral health impact profile. Community Dent Health. 1994;11(1):3-11.

615. Nagarajan S, Chandra R. Perception of oral health related quality of life (OHQOL-UK) among periodontal risk patients before and after periodontal. Community Dent Health. 2012;29:90-4

616. Vergnes JN. Hemoglobin A1c levels among patients with diabetes receiving nonsurgical periodontal treatment. JAMA. 2014;311(18):1920-1.

617. Mizuno H, Ekuni D, Maruyama T, Kataoka K, Yoneda T, Fukuhara $D$, et al. The effects of non-surgical periodontal treatment on glycemic control, oxidative stress balance and quality of life in patients with type 2 diabetes: A randomized clinical trial. PLoS One. 2017;12(11):e0188171.

618. Marcus SE, Drury TF, Brown LJ, Zion GR. Tooth retention and tooth loss in the permanent dentition of adults: United States, 1988-1991. J Dent Res. 1996;75 Spec No:684-95.

619. Lockhart PB, Brennan MT, Sasser HC, Fox PC, Paster BJ, Bahrani-Mougeot FK. Bacteremia associated with toothbrushing and dental extraction. Circulation. 2008;117(24):3118-25.

620. Forner L, Larsen T, Kilian M, Holmstrup P. Incidence of bacteremia after chewing, tooth brushing and scaling in individuals with periodontal inflammation. J Clin Periodontol. 2006;33(6):401-7.

621. Kinane DF, Riggio MP, Walker KF, MacKenzie D, Shearer B. Bacteraemia following periodontal procedures. J Clin Periodontol. 2005;32(7):708-13.

622. Geerts SO, Nys M, De MP, Charpentier J, Albert A, Legrand $\mathrm{V}$, et al. Systemic release of endotoxins induced by gentle mastication: association with periodontitis severity. J Periodontol. 2002;73(1):73-8

623. Merchant A, Pitiphat W, Douglass CW, Crohin C, Joshipura $\mathrm{K}$. Oral hygiene practices and periodontitis in health care professionals. J Periodontol. 2002;73(5):531-5.

624. Baelum V, Luan WM, Chen X, Fejerskov O. A 10-year study of the progression of destructive periodontal disease in adult and elderly Chinese. J Periodontol. 1997;68(11):1033-42. 
625. Anerud A, Loe H, Boysen $\mathrm{H}$. The natural history and clinical course of calculus formation in man. J Clin Periodontol. 1991;18(3):160-70.

626. American Academy of Periodontology-Research, Science, and Therapy Committee; American Academy of Pediatric Dentistry. Treatment of plaque-induced gingivitis, chronic periodontitis, and other clinical conditions. Pediatr Dent. 2005;27(7 Suppl):202-11.

627. Califano JV. Position paper: periodontal diseases of children and adolescents. J Periodontol. 2003;74(11):1696-704.

628. Lal S, Cheng B, Kaplan S, Softness B, Greenberg E, Goland RS, et al. Gingival bleeding in 6- to 13-year-old children with diabetes mellitus. Pediatr Dent. 2007;29(5):426-30.

629. Chalmers JM, King PL, Spencer AJ, Wright FA, Carter KD. The oral health assessment tool--validity and reliability. Aust Dent J. 2005;50(3):191-9.

630. Griffiths J, Jones V, Leeman I, Lewis D, Patel K, Wilson K, et al. Oral Health Care for People with Mental Health Problems Guidelines and Recommendations: Report of BSDH Working Group. 2000 [updated January, 2000]. Available from: https://www.academia.edu/7695445/Oral_Health_Care_ for_People_with_Mental_Health_Problems_Guidelines_and_ Recommendation.

631. Chalmers J, Spencer A, Carter K, King P, Wright C. Caring for oral health in Australian residential care. 2009 [updated 2009]. Available from: https://www.adelaide.edu.au/arcpoh/ downloads/publications/reports/dental-statistics-researchseries/2009-2010-residential-care.pdf.

632. Machtei EE, Hausmann E, Dunford R, Grossi S, Ho A, Davis G, et al. Longitudinal study of predictive factors for periodontal disease and tooth loss. J Clin Periodontol. 1999;26(6):374-80.

633. Merchant AT. Will periodontal treatment prevent heart disease and stroke? J Evid Based Dent Pract. 2012;12(4):212-5.

634. Rubin DB. Estimating causal effects of treatments in randomized and nonrandomized studies. J Educ Psychol. 1974;66(5):688.

635. Hernán MA, Hernández-Díaz S, Robins JM. Randomized trials analyzed as observational studies. Ann Intern Med. 2013;159(8):560-2.

636. Robins JM, Hernan MA, Brumback B. Marginal structural models and causal inference in epidemiology. Epidemiology. 2000;11(5):550-60.

637. Robins JM. Marginal structural models versus structural nested models as tools for causal inference. In: Statistical Models in Epidemiology, the Environment, and Clinical Trials. The IMA Volumes in Mathematics and its Applications, vol 116: Springer. New York, NY; 2000.

638. Suarez D, Borràs R, Basagaña X. Differences between marginal structural models and conventional models in their exposure effect estimates: a systematic review. Epidemiology. 2011;22(4):586-8. 